Portland State University

PDXScholar

\title{
Early Identification of At-Risk Children in a Rural School District Using Multiple Predictor Variables
}

Richard Wayne Wilde

Portland State University

Follow this and additional works at: https://pdxscholar.library.pdx.edu/open_access_etds Let us know how access to this document benefits you.

\section{Recommended Citation}

Wilde, Richard Wayne, "Early Identification of At-Risk Children in a Rural School District Using Multiple Predictor Variables" (1991). Dissertations and Theses. Paper 1401.

https://doi.org/10.15760/etd.1400

This Dissertation is brought to you for free and open access. It has been accepted for inclusion in Dissertations and Theses by an authorized administrator of PDXScholar. Please contact us if we can make this document more accessible: pdxscholar@pdx.edu. 


\section{INFORMATION TO USERS}

This manuscript has been reproduced from the microfilm master. UMI films the text directly from the original or copy submitted. Thus, some thesis and dissertation copies are in typewriter face, while others may be from any type of computer printer.

The quality of this reproduction is dependent upon the quality of the copy submitted. Broken or indistinct print, colored or poor quality illustrations and photographs, print bleedthrough, substandard margins, and improper alignment can adversely affect reproduction.

In the unlikeiy event that the author did not send UMI a complete manuscript and there are missing pages, these will be noted. Also, if unauthorized copyright material had to be removed, a note will indicate the deletion.

Oversize materials (e.g., maps, drawings, charts) are reproduced by sectioning the original, beginning at the upper left-hand corner and continuing from left to right in equal sections with small overlaps. Each original is also photographed in one exposure and is included in reduced form at the back of the book.

Photographs included in the original manuscript have been reproduced xerographically in this copy. Higher quality $6^{\prime \prime} \times 9^{\prime \prime}$ black and white photographic prints are available for any photographs or illustrations appearing in this copy for an additional charge. Contact UMI directly to order.

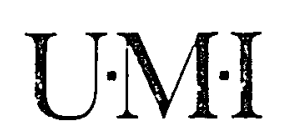

University Microfilms internatıonal

A Bell \& Howell Information Company 300 North Zeeb Road. Ann Arbor. MI 48106-1346 USA

313/761-4700 800:521-0600 
Order Number 9208443

Early identification of at-risk children in a rural school district using multiple predictor variables

Wilde, Richard Wayne, Ed.D.

Portland State University, 1991

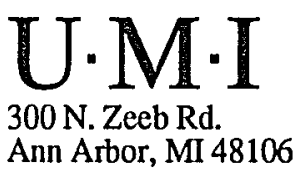




\title{
EARLY IDENTIFICATION OF AT-RISK CHILDREN \\ IN A RURAL SCHOOL DISTRICT USING \\ MULTIPLE PREDICTOR VARIABLES
}

\author{
by \\ RICHARD WAYNE WILDE
}

A dissertation submitted in partial fulfillment of the requirements for the degree of

\author{
DOCTOR OF EDUCATION \\ in \\ EDUCATIONAL LEADERSHIP: ADMINISTRATION \\ AND SUPERVISION
}

Portland State University

1991 
TO THE OFFICE OF GRADUATE STUDIES:

The members of the Committee approve the dissertation Richard Wayne Wilde presented July 12, 1991.

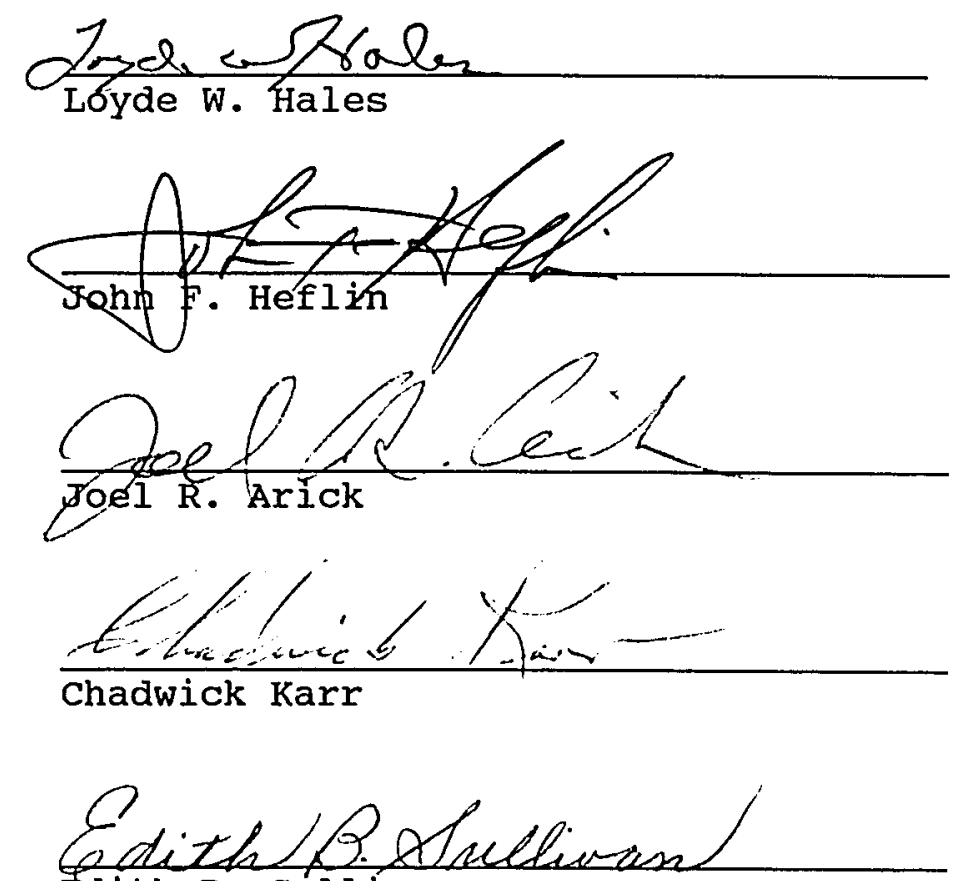

Edith B. Sullivan

\section{APPROVED :}

$$
\text { tis Evestirn }
$$

Robert B. Everhart, Dean, School of Education

$$
\text { C. Willin soveng }
$$

C. William Savery, Vice Provost for Graduate Studies and Research 
AN ABSTRACT OF THE DISSERTATION OF Richard Wayne wilde for the Doctor of Education in Educational Leadership: Administration and Supervision presented July 12, 1991.

Title: Early Identification of At-Risk

Children in a Rural School District

Using the Multiple Predictor Variables.

APPROVED BY MEMBERS OF THE DISSERTATION COMMITTEE:

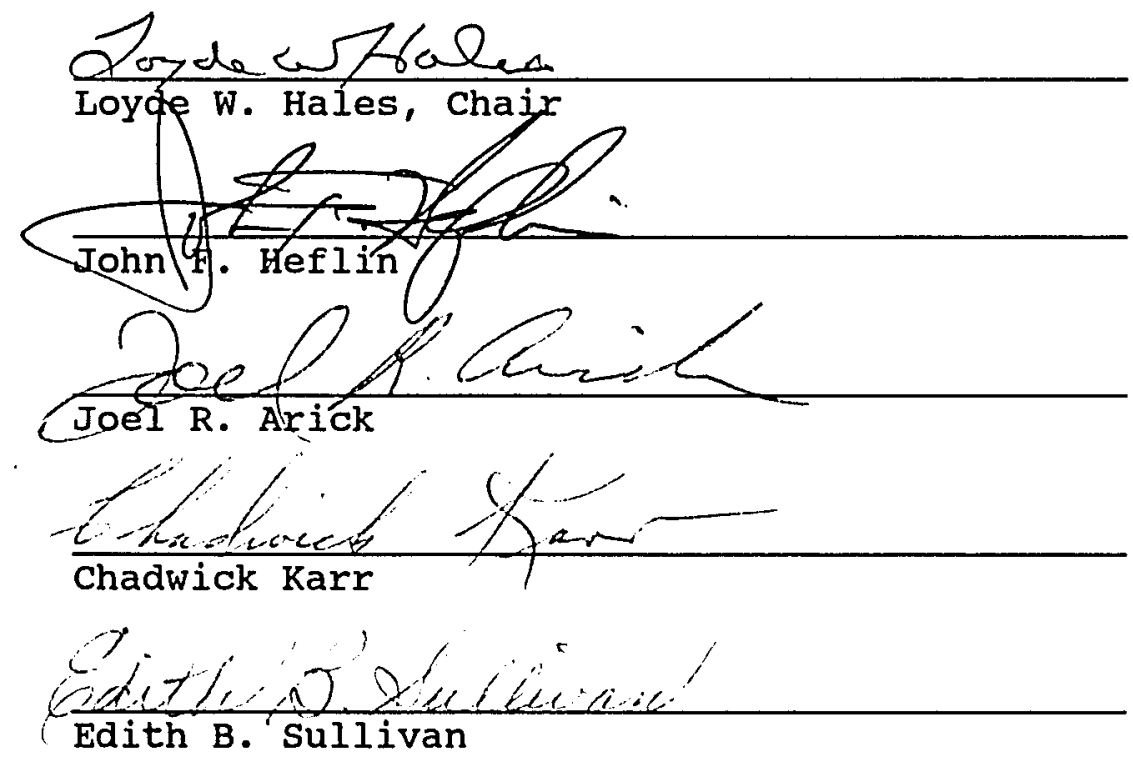

The purpose of this study was to determine if data routinely collected during the kindergarten year and at entry into first grade could be used to predict whether a child would be perceived as successful or not successfül by the end of first grade. The need for immediate continued 
research on this topic was established through the review of literature, which highlighted the extent of the at-risk problem both locally and nationally. The growing number of at-risk students combined with the minimal impact of the educational programs mandates the need to identify these students in time to prevent school failure. However, clear identification procedures are not currently available and previous studies have raised substantial questions regarding the accuracy of early identification procedures.

The presenting problem of this study was to determine the sensitivity and specificity of a set of predictor variables, and then to analyze these findings as to whether or not they were accurate enough for use as an initial identification process for subsequent classes.

The primary research approach of this study was a longitudinal data collection and correlational analysis, with discriminant analysis techniques used to determine predictive accuracy. The study was limited to data on the class of 2001 from two elementary schools within the Washougal School District. The data collected and the subsequent analysis were used to answer six exploratory research questions. No hypothesis was proposed.

This study used ratings and scores obtained from the administration of the Preschool screening system, kindergarten teacher ratings, the school success Rating Scale, and the Gates-MacGinitie Reading Readiness Tests as 
predictor variables. Criterion measures of school success/failure were: placement into special programs or grade retention, and end-of-first-grade evaluations of individual student success (report cards, teacher ratings, Gates-MacGinitie Reading Achievement, and the School success Ratings Scale).

The demographic variables of gender, age, parent marital status, and eligibility for free or reduced lunch were analyzed for their potential to exceed or enhance the accuracy of the predictor variables.

Three types of measurement were defined and required in order for a predictor or predictor combination to be considered adequate for use in an identification process. These were, overall accuracy, criterion sensitivity and specificity accuracy, and prediction sensitivity and specificity accuracy. An 80 percent accuracy level was desired on all three types of measurement.

Findings of this study indicated that no single or combination of predictor, and/or demographic variables produced all three desired levels of accuracy. Various combinations of the predictor and demographic variables produced overall accuracy rates exceeding 80 percent for each of the criterion variables. Criterion measured sensitivity and specificity were found to be adequate for use in the prediction of at-risk students. Prediction measured specificity was also found to be highly accurate. 
Prediction sensitivity, however, was below the desired 80 percent level, indicating that the predictor variables over identify at-risk students.

It was concluded that the predictor variables could be used in an identification process if mild over-identification of at-risk students was acceptable to the district. Any use of these identification procedures is assumed to be in connection with ethical intervention practices. Recommendations from this study included crossvalidation of the results and continuation of the study regarding the predictive accuracy of the identified variables as the students move through higher grade levels. The study also encouraged the Washougal School District to develop a formal collection and processing procedure for their routinely collected data. 


\section{DEDICATION}

This study is dedicated to my entire family, who have encouraged me all of my life. It is especially dedicated in loving memory of my mother, Rosa Lee Wilde. 


\section{ACKNOWLEDGEMENTS}

I wish to express my appreciation to the Washougal School District Board of Directors and Superintendent, Brent C. Garrett, for the support and cooperation provided me in conducting this study.

To the members of my dissertation committee, I thank you. Thank you|John Heflin for setting the professional standard against which I measure myself. Joel Arick for assisting me with the statistics, and encouraging me at that point when I was ready to quit the study. I also thank chad Karr for the detailed readings and the guidance in writing this report, and Edith Sullivan for being the "positive voice" through my many rough drafts. I especially thank Loyde Hales for $/$ spending the long hours discussing this study and helping me integrate my training into a dissertation, and then helping me transfer my dissertation into skills I can use within the profession.

I would like to express my thanks and appreciation to Wendy Johnston-Dally for her technical support and encouragement in the development of this document. This paper is as much hers as it is mine.

I want to thank Chris Wilde for providing our children, Brian and Gina, the extra love and support while I spent hours on this task. 
TABLE OF CONTENTS

PAGE

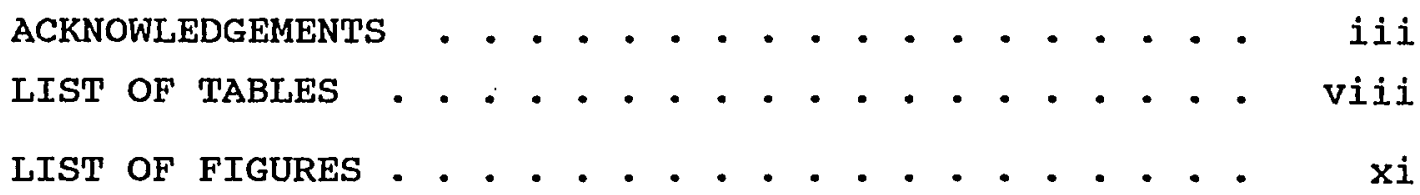

CHAPTER

I

INTRODUCTION TO THE STUDY • • • • • • • • • 1

Purpose of the study . . . . . . . . 5

Statement of the Problem . . . . . . 6

Research Questions . . . . . . . . 9

The Significance of the Proposed Study . 13

Definitions of Terms . . . . . . . . 13

Iimitations of the study . . . . . . 18

Overview of the study . . . . . . . . 18

II REVIEW OF THE LITERATURE . . . . . . . . 20

The At-Risk Problem . . . . . . . . 20

The Cost of the Dropout Problem

The Washington state At-Risk Problem

The Washougal School District At-Risk Problem

Dropout Characteristics/Indicators 
Current Thought for Addressing At Risk Youth . . . . . . . . . . 40

Preschool

Elementary School

Secondary School

Effectiveness of Current Efforts:

A Conclusion

Early Identification Procedures . . . . 53

Testing and Early Identification

Procedures

Early Identification and Prediction

studies

Summary . • • • . . • . . . . . 70

III METHODOLOGY AND PROCEDURES . . . . . . . . 72

Design . . . . . . . . . . . . 72

Variables

Subjects . . . . . . . . . . . . 79

Instrumentation . . . . . . . . . 80

The Preschool Screening system

The School Success Rating Scale

The Gates-MacGinitie Reading Tests (Third Edition)

Teacher Ratings

Report Card

Program Placement

Data Analysis . . . . . . . . . . . 91

IV REPORT AND ANALYSTS OF THE DATA . . . . . . . 93

Introduction . . . . . . . . . . . 93

Descriptive Data Overview . . . . . . 98 
Secondary Study Questions . . . . . 105

Correlations Among Variables

Student Differences by Demographic Variables

Discriminant Analysis, Sensitivity, and Specificity: Model Explanation Prediction Accuracy of Demographic Variables

Primary Study Questions . . . . . . . 128

PSS Sensitivity and Specificity

Predictive Accuracy of the

Secondary Predictors

Most Accurate Predictions

Summary of Chapter IV . . . . . . . . 155

V SUMMARY, CONCLUSIONS AND RECOMMENDATIONS •. • 157

Summary . . . . . . . . . . . . 157

Question 1

Question 2

Question 3

Question 4

Question 5

Question 6

Conclusions and Recommendations . . . . 165

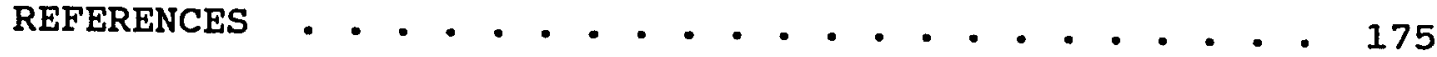

APPENDIX . . . . . . . . . . . . . . . . . 188

A MOILANEN'S DESCRIPTORS OF DROPOUT

CHARACTERISTICS 1986 . . . . . . . . . 188

B THE SCHOOL SUCCESS RATING SCALE INSTRUMENT

DEVELOPMENTAL REPORT BY QUEST STAFF • . . 190

C FIRST GRADE REPORT CARD . . . . . . . . . 220 
vii

APPENDIX

PAGE

D DISCRIMINANT ANALYSIS OF VARIANCE

BY PREDICTOR/DEMOGRAPHIC VARIANCE

FOR THE CRITERION VARIABLES • . . . 223 


\section{LIST OF TABLES}

TABLE

PAGE

I Linear Progression of Data Collection ...

II Predictor, Criterion, and Demographic

Variables Included in this Study . . .

III Reported Dropout Descriptors and Self-

Reported Reasons for Dropping

Out of School . . . . . . . . 36

IV Summary of the NASSP Dropout Prevention Strategy . . . . . . . . . . . . . 49

V Research Variables of the study . . . . . 75

VI Delineation of Demographic Variables . . . 77

VII School Success Rating Scale Sample • • . . 84

VIII Demographic and Predictor Variables . . . 95

IX Criterion Variables . . . . . . . . 96

X Class Size by Grade-Level and Teacher . . . 99

XI Demographic Variables by subcategory

Counts and Percentages . . . . . . 101

XII Means and Standard Deviations

for Interval Data . . . . . . . . 102

XIII Criterion Variable Distribution in Two-

Category Ordinal Scale . . . . . . 103 
XIV Phi Correlations Among Demographic Variables . . . . . . . . . . . 106 XV Subcategory Sub-Group Comparisons for

Demographic Variables with Significant Correlations . . . 106 XVI Correlational Matrix for Predictor Variables . . . . . . . . . 107

XVII Correlational Matrix for Criterion Variables . . . . . . . . . 109 Correlations Between Predictor and Criterion Variables . . . . . . . 111

XIX Phi Correlations for Demographic to Criterion Variables . . . . . . . . 112

XX Test of Significance for Demographic Variables Using Analysis of Variance . • 114 XXI Means, Standard Deviations, and Ranges for Demographic Subgroups having Significant Differences on the School Success Rating scale and the Gates-MacGinitie Reading Test .

XXII Significant Chi Square Results Between

Demographic Variables and Criterion Variables . . . . . 
XXIII Direction of Significant Chi Square Relations Between Demographic and Criterion

Variables . . . . . . . . .

XXIV Overall Accuracy of the Demographic

Variables: Discriminant Analysis

Predictions by Percent of Total $\underline{\mathrm{N}}$. .

XXV Overall Accuracy of the PSS: By Percent

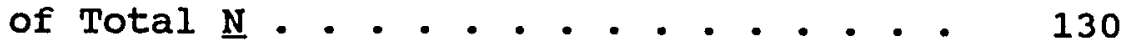

XXVI Accuracy of the PSS Predictions: Criterion

Variable Sensitivity and Specificity . .

XXVII Accuracy of the PSS: Predictor

Sensitivity and Specificity . . . . 133

XXVIII Overall Accuracy of Secondary Predictors:

Predictions by Percent of Total N . . . 136

XXIX Criterion Sensitivity and Specificity for

Secondary Predictor Variables . . . . 138

XXX Prediction Sensitivity and specificity for

Secondary Predictor Variables . . . . 142

XXXI Significant Predictor/Demographic Variables

for Predicting the Criterion Variables . 145

XXXII Predictions with overall Accuracy

Above 80 Percent . . . . . . . . . . 148

XXXIII Predictions with the Highest Accuracy

Sensitivity and Specificity . . . . . 154 


\section{LIST OF FIGURES}

FIGURE

PAGE

1. Fourth grade median percentile scores 1986-89 . . . . . . . . . . . . 33

2. Crosstab concept for Discriminant Analysis - 121

3. An example of a 2 by 2 crosstab . . . . . 123

4. An example of a 3 by 2 crosstab

with overall prediction accuracy and error computed . . . . . . . 124

5. An example of a 2 by 2 crosstab with criterion sensitivity computed . . . . 125

6. An example of a 2 by 2 crosstab with prediction sensitivity computed . . . . . . . . . . 
CHAPTER I

\section{INTRODUCTION TO THE STUDY}

A cursory review of current newspapers, television reports, and national news magazines will confirm that education continues to be at the forefront of the nation's concerns. At the top of the compelling issues dominating today's general media and educational literature is the "atrisk" problem.

The 1983 study, A Nation at Risk: The Imperative for Educational Reform, (National Commission on Excellence in Education) coined the term "at-risk." Historically, when referring to children at-risk, writers have used terms such as culturally deprived, minority children, low income, dropouts, disadvantaged, learning handicapped, and underachievers. Statistically, these children have a greater likelihood of school failure.

Slavin and Madden (1989) defined the at-risk student as "one who is in danger of failing to complete their education without the skills to function adequately in our society" (p.4). They reported the factors associated with at-risk as: 1) low achievement, 2) behavior problems, 3) poor attendance, 4) retention and, 5) low socioeconomic status. 
Natriello, McDill, and Pallas (1990) discussed the

extent of the educationally disadvantaged (at-risk)

population. They wrote:

Despite the imprecise nature of the available indicators of the educationally disadvantaged population, it is clear that substantial numbers and troubling proportions of U.S. children may be classified as educationally disadvantaged. (p.30)

They elaborated on the extent of the problem and summarized:

Thus while most of the background indicators show that about $20 \%$ to $25 \%$ of children can be classified as disadvantaged on a single indicator, NAEP reading tests show that about $35 \%$ to $40 \%$ of students can be classified as educationally disadvantaged. This figure is quite close to our rough guess of the total proportion of children who bear at least one of the five indicators of disadvantaged we have considered. (p.32)

Speaking to the challenge that the at-risk student

presents for educators, Capuzzi and Gross (1989) wrote:

For those working with at-risk youth, the challenges are many, the frustrations are great, and the population increases daily. There are no easy answers or solutions to reduce the challenges or eliminate the frustrations. As the information in Chapter 1 indicates, the population identified as being at risk is not new to those who have worked in the area of education. What is new is the economic, social, and cultural impact this population has had and will continue to have on the continued growth of this country. Steps have to be taken to stem this growing dilemma. (p. 17)

Gastright (1989) studied the dropout problem in the Cincinnati Public Schools and compared his findings with national statistics to conclude that:

dropout characteristics differ from community to community and that the results drawn from national sample studies don't necessarily apply in local settings. (p.4) 
Gastright wrote that he believed the information most useful in identifying potential dropouts is not available in the majority of school districts. He concluded that the dropout problem is complex and district specific, therefore requiring district-specific study and intervention.

Concurrently, there is mounting evidence linking the experiences of the primary years directly to the dropout problems at the secondary level (Bachman, Green \& Wirtamen, 1971; Grissom \& Shepard 1988). Shepard and Smith (1986, 1988) suggested that all factors being equal, an extra year in school (retention) increased the risk (probability) of dropping out by :20-30 percent. They credited kindergarten programs moving |away from being the bridge between home and school as a major part of increased retention policies. As kindergarten programs expanded their academic demands, the number of chilidren unable to meet these expectations has also increased. | Shepard and Smith (1988) proposed that these performance demands result from a curriculum pushed down to lower grades by uninformed, but well-meaning, educational leaders.

This trend / created a situation where educators mistakenly assumed that children should possess equivalent skill levels when they arrive at kindergarten. The expectation of "readiness" resulted in an increase in the use of standardized tests with young children. Fromberg (1989) linked the increase in testing with an increase in 
inappropriate uses of standardized tests (denial of school entry, and retention). It is an assumption of my study that any inappropriate use of tests by educators is simply a lack of knowledge by those educators about the standardized tests administered. This assumption implies that educators need explicit training in the administration and use of standardized measurement instruments.

The National Association for the Education of Young Children (NAEYC, 1988) published a position paper on the testing of young children that concurs with Gastright's conclusion on the district-specific nature of educational problems. This position paper expressed concern regarding the use of testing with young children. The NAEYC asserted that children and demographics are unique to each school district, and therefore, local educators must substantiate claims made by the test developers. Prior to extensive test utilization, NAEYC emphasized that this substantiation is essential as districts begin to implement at-risk identification procedures with young children.

As indicated, there is currently a national dropout problem, and this problem is growing. Additionally many other students complete their formal public education and enter society at risk of life long failure because they lack skills needed for employment and survival in the adult world. Research has identified a linkage between the atrisk problem and experiences in the primary years. Thus, 
there is a need to identity, as early as possible, potential at-risk students so that intervention can occur. However, there is evidence that standardized tests have been misused, often due to the lack of local study and validation with district-specific populations. In response to this need for early identification, and in keeping with the testing philosophy of NAFYC, I have undertaken this attempt to develop a means of early identification in the Washougal School District.

\section{PURPOSE OF THE STUDY}

I followed the Washougal School Districts' class of 2001 from entry day of kindergarten to the closing day of first grade. The purpose was to gather normally collected data and through discriminant analysis determine if those data could be used to predict accurately whether a child would be perceived as successful or not successful at the end of first grade. This information could then be used to develop an identification procedure for the subsequent classes (acknowledging that further study of the procedure would be required) .

My review of literature defined the extent of the atrisk problem, nationally, within the state of washingtor., and specifically within the Washougal school District. The review has highlighted current thought on how to address the at-risk (or dropout) problem and concludes with a summary of 
studies that sought to develop procedures for identifying at-risk children early in their school career.

By attempting to define the extent of the problem, analyzing the state of the art in addressing the at-risk problem, and then through reviewing the conclusions of similar studies, I have established the urgency and need for extensive study on this educational topic.

STATEMENT OF THE PROBLEM

The primary presenting problem was to determine the sensitivity and specificity of a set of predictor variables in identifying at-risk children. My study attempted to develop a procedure to identify at-risk children in their first year of formal public school.

Meisels (1987) defined sensitivity of a screening instrument (or procedure) to be the proportion of children at-risk who are correctly identified. Conversely, specificity of a screening procedure or instrument is the proportion of children not-at-risk, correctly excluded from further assessment. Meisels (1987) and Langhorst (1989) suggested that an 80 percent sensitivity and 80 percent specificity accuracy rate be used as the minimum criteria for evaluating screening instruments (and/or screening procedures). The 80 percent dual prediction rate was the standard for evaluating adequacy of my study's research predictor variables. 
Specifically, my study attempted to determine the relationship between the Preschool screening system (Hainsworth \& Hainsworth, 1980) and early student success as measured by a set of criterion variables. The Preschool Screening system (PSS) is a developmental screening instrument. I evaluated the PSS in terms of its predictive ability in identifying at-risk students when administered to children entering kindergarten within the Washougal School District.

Table I presents the linear progression of this longitudinal study. This table includes the general time frame of the study, as well as data collection or instrument administration points for specific variables identified in the research questions.

My study analyzed the increase in the discriminant function of the identification procedure when I added the following variables to the PSS: a) kindergarten teacher ratings of success, b) kindergarten teacher observations of student routines using the School success Rating Scale (Quest Staff, 1989), and/or c) individual test results from the Gates-MacGinitie Reading Readiness Test (MacGinitie \& MacGinitie, 1989). I attempted to establish the degree to which these measures forecast student "success." Criterion variables measuring success were: student placement in special programs, first-grade report card grades, standardized test reading scores (Gates-MacGinitie Reading 
TABLE I

LINEAR PROGRESSION OF DATA COLLECTION

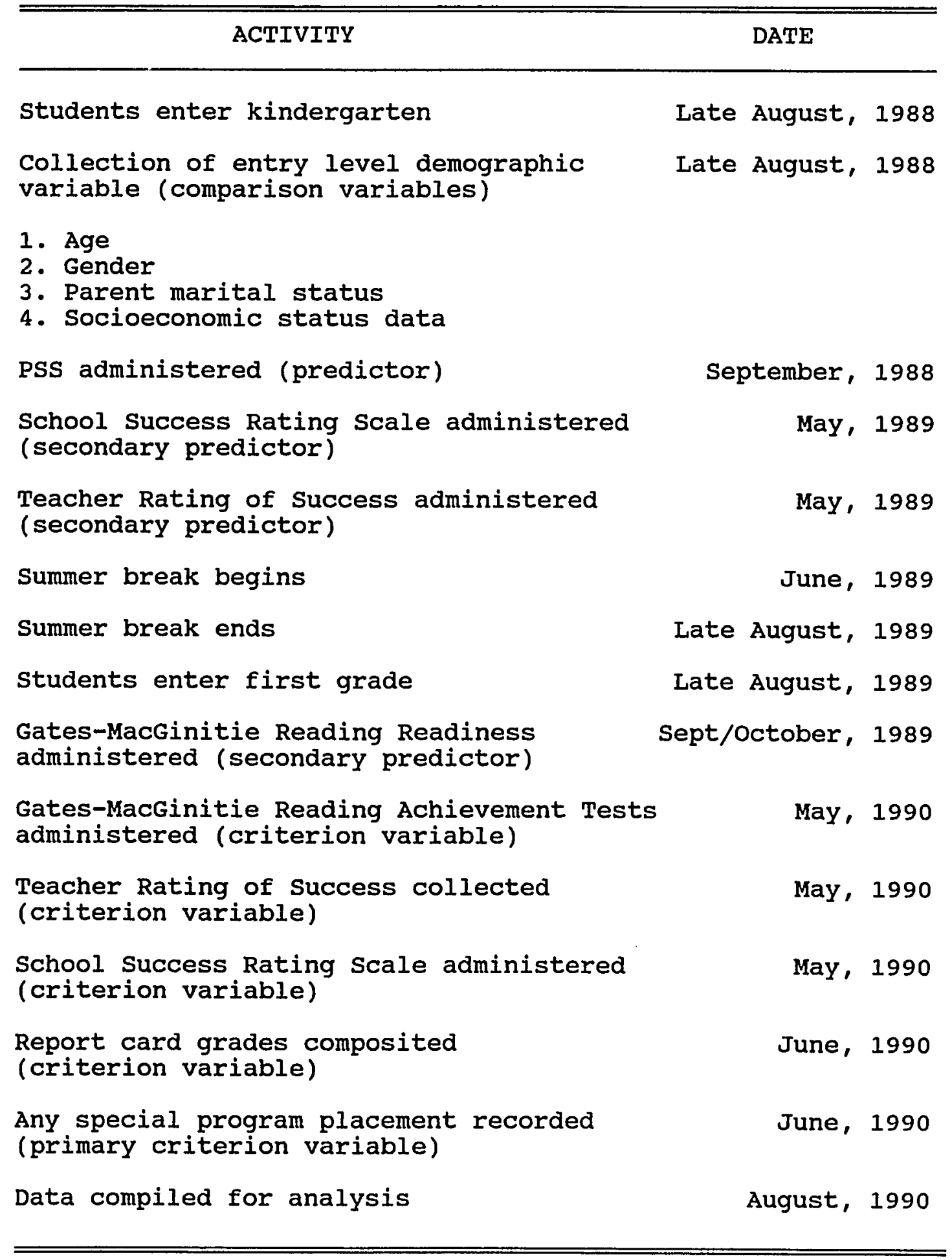


Tests), Teacher Rating, and scores on the student Success Rating scale. Criterion measures were collected at the end of first grade. I compared the predictive strength of gender, age, parent marital status, and socioeconomic background with the predictive accuracy of the PSS. These demographic variables served as comparison variables against which I could evaluate the utility (usefulness of test results to improve services and educational outcomes for children) of the PSS. Additionally, I combined demographic variables with the predictor variables to achieve the highest sensitivity and specificity rates possible.

I used the terms, predictor, criterion, and demographic when referring to variables, rather than independent, dependent, and or control. I adopted this nomenclature to emphasize the passive nature of correlational research.

\section{RESEARCH QUESTIONS}

As an initial study in developing an early identification process for at-risk children with the Washougal School District, I proposed no hypothesis.

Six research questions were proposed. I considered the first three study questions to be secondary questions, addressing relationships of and between the sets of variables (predictors, demographic, and criterion). Questions 4, 5, and 6 are primary questions and address the sensitivity and specificity of the predictor variables (and combinations of the predictor variables). 
My research questions were:

1. What are the correlations among the variables (predictor, criterion, demographic)?

2. Are student differences on measures of student success related to student differences in demographic variables?

3. What is the predictive accuracy of the demographic variables?

4. What is the predictive accuracy of the Preschool Screening system (administered during the fall of the kindergarten year) in identifying "student success" as measured by the criterion variables?

5. What is the predictive accuracy of the kindergarten teacher ratings, the School success Rating scale (kindergarten administration), and the Gates-MacGinitie (administered during the fall of the first-grade year) in identifying "student success" as measured by the criterion variables?

6. Which combination of predictor variables determines the most accurate identification rate of sensitivity and specificity for at-risk children?

Question 1 simply asked the degree of relationship among sets of variables (predictor, criterion, demographic). Question 2 investigated whether there was a significant 
difference in Istudent measures of success attributable to the demographic variables. I selected gender, age, teacher, socioeconomicistatus, and parent marital status as the demographic variables for study. I arranged to have these measures collected at entry into kindergarten.

Question 3, a secondary study question, investigated the predictive usefulness of any demographic variable found to be significant in relation to differences in student "success."

Question 4, a primary question of this study, investigated the predictive accuracy with which the PSS can discriminate between students that will come to be considered "successful" or "not successful" during their first two years of public school experience.

Question 5, another primary study question investigated the predictive accuracy of initial administrations of 1 ) Teacher Ratings, 2) Student Success Rating Scale, and 3) the Gates-MacGinitie Reading Tests.

Questions 6 identified the combination of predictor variables that provided the most accurate prediction of "atrisk" children possible with the variables in question. Table II lists the variables of this study by their function. Chapter III will address the variables of study in greater detail. 
TABLE II

PREDICTOR, CRITERION, AND DEMOGRAPHIC VARIABLES INCLUDED IN THIS STUDY

Primary Predictor

1. Preschool Screening System

\section{Secondary Predictors}

1. School Success Rating Scale (kindergarten administration)

2. Teacher Ratings (kindergarten administration)

3. Gates-MacGinitie Reading (fall/first grade administration)

\section{Criterion}

1. School Success Rating Scale (first grade administration)

2. Teacher Ratings of Success (first grade administration)

3. Gates-MacGinitie Reading (spring of first grade administration)

4. Report Card Grades (first grade year)

5. Student placement (kindergarten/first grade years)

6. Student performance (an aggregate of all criterion variables except placement) 
THE SIGNIFICANCE OF THE PROPOSED STUDY

The potential of this study to improve educational practice is threefold. First, it is an application of the literature regarding local validation of tests used with early childhood populations. Second, it adds to the literature regarding the use of educational test results, specifically by the early identification of at-risk youth through developmental screening instruments. Third, this study contributes to the literature regarding the use of assessment in the decision making process. With testing again on the increase in education, it is imperative that educators understand test use and misuse. Because rural districts seldom have access to research and evaluation departments to assist them in appropriate uses of testing, it is essential for administrators serving in rural districts to acquire a broader knowledge of testing than urban administrators who may have more specialized tasks.

\section{DEFINITIONS OF TERMS}

Academic Achievement. Academic achievement is knowledge obtained or skills developed in school subjects, usually assessed by test scores or rated by teachers, or both.

At-Risk students. At-risk students are those students in danger of failing to complete their education with an adequate level of skills to be employable in our society or to go on to higher education. Risk factors include low 
achievement, retention in grade, behavior problems, poor attendance, low socioeconomic status, and attendance at schools with large numbers of poor students.

Content Validity. Content validity in a school setting refers to the evidence that shows the extent to which the content of a test is appropriately related to the subject matter being taught.

Criterion-Referenced. Criterion-referenced refers to a test for which interpretation of scores is made in relation to a specified performance level rather than to the performance of other people.

Criterion-Related Validity. Criterion-related validity is evidence that demonstrates that test scores or other variables are systematically related to one or more of the outcome criteria.

Criterion Variable. In predictive research, the behavior or event which is to be predicted or forecast.

Decision Making. Decision making is a process wherein an awareness of a problematic state of a system, influenced by information and values, is reduced to competing alternatives among which a choice is made based on expected outcome states of the system.

Developmental screening. Developmental screening is a brief assessment procedure designed to identify children who, 
because of the risk of a possible learning problem or handicapping condition, should proceed to a more intensive level of diagnostic assessment. Screening serves as the first step in an evaluation and intervention process that is intended to help children achieve their maximum potential.

Developmental Test. A developmental test is an age-related norm-referenced assessment of skills and behaviors that children have acquired in comparison to children of the same chronological age.

Dropout. A dropout is a public-school-age student that has withdrawn from the formal education process prior to completion of an expected course of study or receipt of a diploma.

Early Childhood. Early childhood is the developmental period between birth and age eight.

Early Leaver. An early leaver is a public-school-age student that has left the formal education process prior to completion of an expected course of study. A dropout.

Early Identification. Early identification refers to the identifying of children that are at risk of academic difficulty and failure in their primary school years.

Evaluation. Evaluation is the process of delineating, obtaining, and providing useful information for judging instructional outcomes. 
Intervention. Intervention refers to the implementation of an educational strategy that is designed to remedy an educational problem for a single student or a group of students.

Predictor Variable. A measurelused to forecast or predict some future behavior or event. In this study, the PSS is the main predictor variable, and student success or failure in school is the behavior to be predicted.

Predictive Validity. Predictive validity refers to the evidence of criterion-related validity; for example, the score on an educational test with predictive validity will predict future school performance.

\section{Preschool screening system. A|developmertal screening} instrument that purports to identify students in need of further evaluation because of potential learning difficulty.

Readiness Test. A readiness test purports to assess a child's level of preparedness for a specific academic or pre-academic program.

Reliability. Reliability refers to the degrees to which test scores are consistent, dependable, or repeatable; that is, the degree to which test scores can be attributed to actual differences in test-takers' performance rather than to errors of measuremert. 
Risk Factors. Examples are characteristics of demographics or events that increase the probability of failure in school or the work setting.

Sensitivity. Sensitivity refers to the proportion of children at-risk correctly identified by a standardized instrument.

Specificity. Specificity refers to the proportion of children not-at-risk, correctly excluded from further assessment or a standardized remedial procedure.

Standardized Test. A standardized test is an instrument, composed of empirically selected items, that has definite instructions for use, adequately determined norms, and data on its reliability and validity.

Test Utility. Test utility refers to the usefulness of test results to improve services and educational outcomes for children; implied is that expended resources are commensurate with outcomes obtained.

Validity. Validity refers to the degree to which a test measures what it purports to measure. It is the degree to which a certain inference from a test is appropriate or meaningful. 


\section{LIMITATIONS OF THE STUDY}

This study collected data on students from the Washougal School District's class of 2001 during this cohort's first two years of public education. The results of the study are therefore directly applicable to only the Washougal School District. Because the subject pool was not representative of the nation's ethnic distribution, and because it was a somewhat small sample impacted by mobility, generalizations from the obtained results are limited.

The reliability and validity of the predictor and criterion variables used in this research further limited the application of the results to other settings.

The limitations noted above are in addition to the inherent weaknesses found in correlational studies (i.e., correlations do not identify cause and effect relationships, correlational research is often less rigorous than the experimental approach, and the identified relationships are often ambiguous).

\section{OVERVIEW OF THE STUDY}

Chapter I provides an introduction to the study that includss: background, questions to be investigated, significance of this research, assumptions, limitations, and definitions applicable to the study.

Chapter II provides a review of the related literature to clarify the at-risk problem within American education and 
to identify some current practices aimed at remedying this problem. Additionally, I explored literature related to the use of testing in the early identification of at-risk children.

Chapter III outlines the research instruments and methodology I employed in gathering data for analysis. The topics include the design, subjects, instrumentation, data collection procedures, and data analysis.

Chapter IV is a report of the data collected and an analysis of the data.

Chapter $\mathrm{V}$ includes my conclusions from the findings, discussion of the findings and implications for administrative decision making regarding at-risk students, and recommendations for further study. 
CHAPTER II

REVIEW OF THE LITERATURE

Fotheringham (1987) presented demographic data with subsequent projections compiled from several sources for the Washington Association of School Administrators. He concluded that educators will in the future deal with greater numbers of handicapped children, more underprivileged children, more children with life trauma, more non-English speaking children, and therefore, inevitably, more school failure and more dropouts.

THE AT-RISK PROBLEM

The National School Boards' Association Task Force on At-Risk Youth (McCormick, i989) estimated that 21 million children were at-risk of school failure. They reported that these children were at-risk because of factors that included poverty, abuse, homelessness, drug involvement, pregnancy, handicaps, and limited proficiency with the English language.

Mann (1987) supported the conclusion that there is a major American problem with students leaving school without adequate preparation for the world of work. He projected that 25 percent of the fifth grade class of 1986 will fail 
to graduate from high school. Mann cited data from a longitudinal study as the basis of his prediction. He reported that $5,880,000$ students dropped out of American schools between 1979 and 1982, over 1.5 million youth per year.

Fine (1986) reported that over 50 percent of the innercity children never graduate from high school. Austin and Meister (1990) abstracted 12 major reports published between 1985-1989 on at-risk children. One of their conclusions was that children at-risk form a growing proportion of all children.

Hodgkinson (1985) estimated that over 50 percent of the nation's poor are children. He further concluded from census data that 59 percent of the children born in the early 1980's will live with only one parent before reaching the age of eighteen. Hodgkinson additionally identified that teenagers give birth to about 700,000 children a year (about 25 percent of the nation's births). Teen births and births to low-socioeconomic groups had a higher probability of being premature (Robinson \& Robinson, 1976). Premature births are historically linked to low birth weight. Lowbirth weight has a high correlation with learning difficulties (Drillien, 1970; Niswander \& Gordon, 1972; Robinson \& Robinson, 1965). Schorr (1988) described lowbirth weight babies as more susceptible to environmental insufficiencies than full-term babies, implying a strong 
negative effect on disadvantaged children. Looking at the percentage of children born in poverty, or to ceen parents, one can draw the conclusion that there is the potential that nearly 25 percent of the children entering school in the 1990's will need special assistance. Walsh (1989), citing information from the National center for Children in Poverty, reported that 23 percent of the children under the age of six live below the poverty line. Further, more than 53 percent of these children came from families with at least one parent working full-time. This disturbing demographic fact confirms expansion of the working poor in America.

The potential growth of at-risk children is substantiated when the drug-exposed children are included. An article in Education Week (Viadero, 1989) reported an estimated 375,000 babies are born each year to mothers using drugs during pregnancy. Leeson (1989) reported that national studies indicate one in 11 babies is born affected by illegal drugs. While little is known about the long-term impact on these children, it is known that they have difficulty learning and are especially at risk of school failure (Robinson \& Robinson, 1976).

Drugs also play a role in the adolescent at-risk problem. The National Institute on Drug Abuse (1988) estimated from national surveys that 25 percent of high school age students were frequent users of illegal drugs. 
Frequent use of drugs is correlated with the at-risk behaviors of memory reduction, thought processing difficulty, and lack of motivation (United states Department of Education, 1986).

Sub-populations traditionally associated with "at-risk" are also growing. Fotheringham (1987) concluded from his data sources that from 1975-85 the United States experienced the largest immigration of any ten-year period in American history. These immigrants were reportedly non-white, non-English speaking, and poor.

Newberger, Melnicoe, and Newberger (1986) reported that 47 percent of the Black children, 40 percent of the Hispanic children and 10 percent of the Caucasian children live part, or most, of their childhood in poverty. Hodgkinson (1989) projected that, by the year 2010, nearly 40 percent of all of the nation's students will be from minority families. This demographic trend confirms the potential for a significant increase in the numbers of children living in poverty. Many of the children will have limited English language proficiency.

Levine (1989), in his review of the at-risk problem, concluded that "the at-risk student population is growing at a more rapid rate than the rest of the population" (p.48). He cited increases in non-English speaking minority populations and families in poverty as major contributing factors. In discussing the at-risk potential of minorities, 
Levine notea the high numbers of child bearing age, disproportionate numbers of teen and single mothers, and limited fluency with the language, as issues that must be addressed.

A 1987 publication by the office of Educational Research and Improvement, Dealing with Dropouts: The Urban Superintendents' Call to Action, reported that an estimated 682,000 teenagers dropped out of school in 1985-86. The publication further identified that individuals that have not completed high school compose a large portion of the long-term unemployed. This conclusion supports the position that at-risk students are not only at risk of school failure, but also of life-long failure. The potential for growth of at-risk students is extremely clear when child abuse is considered. An extended 1987 report by the National Council of Juvenile and Family Court Judges speculated that nearly four million children are abused or neglected each year. The report estimated that an additional million run away from home annually. Generally speaking, children that are neglected, abused, or on the streets have considerable difficulty in attaining success within the traditional school setting.

From this brief review of figures and demographics, one can predict that by the time the class of 2001 graduates, there will be least 12 million additional dropouts. Many of these youth will continue the failure cycle by becoming 
chronically unemployed, teen-parents, drug addicted, homeless, or all of the above.

\section{The cost of the Dropout Pyooblem}

The statistics regarding the percents and/or numbers of students dropping out of school are inconsistent, but they do consistently identify a major national problem and a continuing dilemma for education and America.

Smey-Richman (1989) wrote of low-achievers that "these students put our country at risk of becoming a place inhabited by citizens who are dependent, uncompetitive, and unreactive to market forces"l (p.2). A report by the U.S. Department of Commerce (1986) identified that lifetime earnings of high school dicopouts was about 35 percent less than high school graduates and only approximately 50 percent of college graduate incomes. Berlin and Sum (1988) and sum (1983) compared basic skills scores of graduates and nongraduates with income. They reported that dropouts scoring in the lowest quartile earned only about one-half of a dropout scoring in the highest quartile. Interestingly, graduates seem to follow a similar pattern.

In their 1980 study of the dropout problem, Beck and Muia concluded that, "without a diploma or marketable skills, the dropout faces unemployment or a low-paying blue collar job, together with feelings of inferiority and alienation" (p.65). Timberlake's (1983) findings indicated that unemployment for dropouts was twice that of high school 
graduates. She concluded that we are, as a nation, moving toward a time when the high school diploma will be a minimum requirement for entry into the work world. Expanding on this problem, Hodgkinson (1989) reported that 4.5 million Americans working full-time were eligible for poverty benefits. This single statistic emphasizes that entry into the work force is no longer enough (in the 1990s) to break the poverty cycle.

Disregarding causes, the National Association of Secondary School Principals (NASSP) (1988) report estimated that the dropout problem costs the nation 228 billion dollars a year in unemployment, welfare, lost tax revenue, and related additional law enforcement costs. The NASSP concluded that these figures continue to grow annually. Harold Howe, a former U. S. Commissioner of Education, stated that "children at-risk are growing in number and proportion in schools; for economic reasons, we need to make them successful" (Howe, 1982 cited in Cardenas, 1985, p.7). This concern for the economy was also voiced by Owen Butler. Butler (1989) is a retired chairperson of the Procter and Gamble Company and past chairperson of the Committee for Economic Development. He concluded that the dropout problem is a "matter of survival" (p.53). He implied that the economic costs of the dropout problem, combined with the loss to human dignity, are burdens that the nation cannot permit to continue if it is to survive. Pellicano (1987) 
supported Butler's conclusion of a national concern. He wrote "at-risk youngsters place society at risk of becoming a third world" (p. 48).

The Committee for Economic Development (1987) and the Carnegie Council on Adolescent Development (1989) confirmed the estimates from the National Association of School Principals (1988). All three agencies report that a single year of dropouts (approximately 973,000 students) will lose in excess of 228 billion dollars in personal income during their lifetime. Additionally, they will not pay the 68.4 billion dollars in taxes that their personal income would have generated. When the actual costs to the nation in terms of crime-related expenditures, public assistance, public medical expenses, and social services are added in, the cost of the students that did not graduate in a single year become staggering.

on a national scope, the dropout problem is massive, and while there are some indications that the situation improved in the 1970s (Hahn, 1987), significant demographic shifts and projections for the 1990s suggest a reversal to any previous improvement (Hodgkinson, 1985). Even if the dropout rate remains stable, there is cause for extreme concern, given current trends in the labor market. Specifically, a shortage of entry-level workers during the 1990 s and an increase in the percentage of American jobs requiring advanced skill training, combined with the dropout 
rate to significantly threaten the American economy (Johnson, 1986).

The Washington state At-Risk Problem

Cheryl Chow, former Washington State Assistant Superintendent of Public Instruction, released a memo to all public school officials on March 21, 1988 regarding the issue of disproportionality in the dropout statistics. She wrote that the dropout rate was the single most dramatic indicator of the degree to which the Washington educational programs were failing children. This conclusion by Chow was supported by statements in Goodlad's (1983) book, A Place Called school. Goodlad suggested that the quality of an educational institution should be measured as much by its holding power as by its graduates.

Chow expanded her conclusions, citing that statecollected data revealed that one of four students entering as a freshman fails to complete or obtain a diploma on schedule. The memo further indicated the dropout rate for Blacks was twice that for Caucasian students, and that Hispanic students dropped out at a rate four times that of Caucasians. The document went on to state that statistically, dropouts experience higher unemployment and have a lower standard of living than high school graduates. The implications of these statistics are further magnified when coupled with statistics cited in another document from the Washington state Superintendent of Public Instruction's 
Office. "Achieving Excellence for All" (Brouillet, 1983) reported that the state of Washington's population grew by 21 percent between 1970 and 1980. However, the Hispanic population grew by 37 percent, the Black population by 30 percent, the Native American population by 67 percent, and the Asian population by 93 percent. Projecting current dropout trends into the future population identifies significant increases in the actual numbers of at-risk chilaren.

Brouillet's document additionally estimated that 17 percent of the state's population moves annually, with 70-80 percent of those moving being between 20 and 35 years of age (the average age of most parents of school-age children). Mobility during the school years has been suspected of having an impact on achievement. While the impact of mobility is still unresolved, it has been found by some researchers to be negatively correlated with school success (Benson \& Weigal, 1981; Blyth, Simmons \& Bush, 1978; and Schaller, 1975). These statistics have led me to conclude that the dropout rate in Washington will climb during the 1990s.

This supposition of a growing "at-risk" problem was further validated by the December 1989 "Superintendent's Message" from Washington state Superintendent of Public Instruction, Judith Billings. Her message addressed the rising numbers of at-risk children in Washington. She 
indicated that the numbers of students in the at-risk category would rise, given current demographic trends, from an approximate 227,000 in 1980 to an estimated 344,000 by the year 2000 .

Reporting similar dropout trends for oregon, the Oregon State System of Higher Education completed a study in June of 1987 that reported approximately 75.3 percent of the students entering as freshman in 1981-82 completed high school on schedule. The study confirmed that only 8.9 percent of the class were early leavers; however, 15.8 percent of the students were unable to be accounted for by normal and reasonable means. An interesting note of this study was in the analysis of siblings of the student identified as an early leaver. Of those students confirmed as dropouts and having older siblings, 58 percent reported that at least one of their older siblings had previously dropped out of school. Data further indicated that, of those with younger siblings, 23.1 percent had a younger sibling who also dropped out during the life of this oregon study. This study implies a strong family dynamic related to the dropout issue.

Hodgkinson (1990) summed up the dropout situation for Washington quite nicely in a 1990 report for the state legislature.

While ranking 17th in school dropouts is good compared to the (miserable) national average of 30 percent, the state has such a highly educated adult population, relatively low levels of youth 
in poverty and a rather homogenous population compared to the nation, you would expect a rate comparable to Minnesota's, which leads the nation in the percentage of students who graduate from high school. (p. 7)

Hodgkinson said that 22.2 percent of the state's students fail to complete high school on schedule (compared to Minnesota's nine percent). He concluded that, "For some reason, Washington's well-educated adults seem not to motivate their children toward high school graduation" (p. 7)

The Washougal School District At-Risk Problem

The town of Washougal, Washington is 25 miles east and slightly north of Portland, Oregon. The Washougal School District is in Clark and Skamania Counties and serves the suburban/rural community of Washougal, the Washougal River Valley, and the Columbia Gorge regions of Mt. Norway, Mt. Pleasant, and Cape Horn-Skye. The district includes east clark County, west Skamania County, and extends from the Columbia River to the foot of Mount st. Helens. At the present time the school district has three elementary schools, one middle school, and one high school. The district serves a total student population of just over 2000 and maintains a 25-to-1 student-to-classroom-teacher ratio. Approximately 98 percent of the students are of Caucasian origin.

The Washington State office of Superintendent of Public Instruction publishes annual reports describing graduation 
and dropout statistics. Review of the 1988 document, revealed that of the state's 39 counties, Skamania county had the highest dropout percentage per capita. The report listed clark County as having the fourth highest per capita dropout rate. Washougal's dropout rate was second highest in Clark County. The Office of Financial Management (1989) ranked clark county as sixth in teen pregnancies, a demographic highly correlated to dropout behavior.

The local district's ECIA Chapter 1 Needs Assessment data (Washougal School District, 1989) reported that approximately 40 percent of the elementary children were eligible for free or reduced lunch. This contrasted with a 1980 district average of approximately 18 percent and a current state average of 14 percent (Hodgkinson, 1990). The high school dropout rate varies from 9 to 30 percent, depending upon the statistical measure applied. State statistical measures place the percent of dropouts to be among the upper quartile of high school dropout rates within the state. Review of the high school grading summaries reveals that approximately 25 percent of the students fail each semester in the core subjects of English, math, and science.

In 1985, the State of Washington updated, through bid process, the statewide fourth-grade testing program, abandoning the California Achievement Test for the more recently normed Metropolitan Achievement Test (6th edition). 
Using the updated instrument, district test results aropped from a median in the 70 percentile range to the low 60 percentile range. This 10 percent drop in scores was anticipated and was consistent across the state. However, the district scores continued to decline from 1986 through 1989. Our district's median test battery score in 1986 was at the 63rd percentile, with 16 percent of the students in the bottom quartile. In 1989 our median score was at the 45th percentile, with 27 percent of the students in the lowest quartile. Figure 1 presents a visual display of the fourth-grade test score decline from 1986 through 1989. Considering these regional and district demographic data in terms of at-risk definitions purposed by slavin and Madden (1989), or Hodgkinson (1985), a local "at-risk" problem and the need for intervention was clearly visible.

\begin{tabular}{ccccc}
\hline PERCENTILE & 1986 & 1987 & 1988 & 1989 \\
\hline 70 & 63 & & & \\
60 & & & & \\
50 & & & & \\
40 & & & \\
30 & & & \\
20 & & & \\
10 & & & \\
\hline
\end{tabular}

Figure 1. Fourth grade median percentile score 1986-89. 
Research by Carnine, Carnine, Karp, and Weisberg (1988), clarified the validity for concern regarding the downward trend of the Washougal testing results. They concluded that 80 percent of the fourth-grade students scoring in the bottom quartile of standardized tests fail to complete high school. If this finding of a correlation between fourth-grade test results and high school droppingout behavior is accurate, then the doubling of Washougal students in the lower quartile could be a predictor of a significant increase in the district's future dropout rate.

Further, presuming a relationship (though not a cause and effect relationship) between fourth-grade test scores and eventual early leaving, it seems reasonable to conclude that intervention in the dropout problem must begin prior to fourth grade. In order to provide early intervention, educators must develop means to identify accurately the students that have, or will have, a high probability of scoring low on the fourth-grade tests.

\section{Dropout Characteristics/Indicators}

Effective intervention in the dropout problem requires accurate identification of who will be a dropout. Much of the current research has examined the "dropout's" characteristics. Several sources have compiled and condensed histories of the dropout student into group descriptors. Moilanen (1986) reviewed the literature describing the youth that have dropped out of school. She 
categorized these descriptors into three generic headings: personal/social characteristics, self-reported reasons for dropping out, and school-related characteristics (Appendix A). While any list of dropout characteristics could vary depending on the point of origin, they will undoubtedly include: academic (retention, special program placement, poor grades, low test scores); school/social (attendance and discipline problems; court involvement); home/family (low-socioeconomic status, minority, single parent or unstable home factor, limited value placed on education); and personal (low self-esteem, teen parent, drug/alcohol abuse).

My Table III is a modification of Moilanen's table; it adds drug use, homelessness, and lack of vocational skills and deletes some of the characteristics reported by her. Review of Table III highlights that personal/social characteristics and self-reported reasons greatly outnumber school-related characteristics. In reviewing the characteristics Iisted, one can note that the majority of characteristics are not under the influence of school personnel, and little or no data are commonly maintained on many of the personal/social characteristics.

A study conducted by Eggert, Herting, and Nicholas (1988) for the National Institute on Drug Abuse found several significant differences between high-risk youth and typical high school students. 
TABLE III

REPORTED DROPOUT DESCRIPTORS AND SELF-REPORTED REASONS FOR DROPPING OUT OF SCHOOL

\begin{tabular}{|c|c|c|}
\hline $\begin{array}{l}\text { PERSONAL/SOCIAL } \\
\text { CHARACTERISTICS }\end{array}$ & $\begin{array}{c}\text { SELF-REPORTED } \\
\text { REASONS FOR DROPOUT }\end{array}$ & $\begin{array}{l}\text { SCHOOL-RELATED } \\
\text { CHARACTERISTICS }\end{array}$ \\
\hline $\begin{array}{l}\text { 1. Frequent student } \\
\text { mobility }\end{array}$ & $\begin{array}{l}\text { 1. Perception } \\
\text { too far behind } \\
\text { to catch up }\end{array}$ & $\begin{array}{l}\text { 1. Low- } \\
\text { achievement } \\
\text { in general }\end{array}$ \\
\hline $\begin{array}{l}\text { 2. Minimal parent } \\
\text { support for } \\
\text { education }\end{array}$ & $\begin{array}{l}\text { 2. Feelings of not } \\
\text { belonging: No } \\
\text { adult support }\end{array}$ & $\begin{array}{l}\text { 2. Poor atten- } \\
\text { dance }\end{array}$ \\
\hline $\begin{array}{l}\text { 3. Broken or weak } \\
\text { home }\end{array}$ & 3. Lack of interest & $\begin{array}{l}\text { 3. } \begin{array}{l}\text { Retained in } \\
\text { grade }\end{array}\end{array}$ \\
\hline $\begin{array}{l}\text { 4. Feelings of not } \\
\text { belonging in } \\
\text { school }\end{array}$ & 4. Dislike peers & $\begin{array}{l}\text { 4on-partici- } \\
\text { pation in } \\
\text { extra- } \\
\text { curricular } \\
\text { activities }\end{array}$ \\
\hline 5. Usually male & 5. Dislike teachers & $\begin{array}{l}\text { 5. Poor be- } \\
\text { havior/dis- } \\
\text { cipline at }\end{array}$ \\
\hline $\begin{array}{l}\text { 6. Low socio- } \\
\text { economic status }\end{array}$ & 6. Dislike schools & $\begin{array}{l}\text { 6. Suspension/ } \\
\text { Expulsion }\end{array}$ \\
\hline $\begin{array}{l}\text { 7. Often non-Asian } \\
\text { minority }\end{array}$ & $\begin{array}{l}\text { 7. Expelled; asked } \\
\text { to leave }\end{array}$ & $\begin{array}{l}\text { 7. Lack of } \\
\text { vocational } \\
\text { skills }\end{array}$ \\
\hline $\begin{array}{l}\text { 8. Older siblings } \\
\text { dropped out }\end{array}$ & 8. Marriage/pregnancy & \\
\hline $\begin{array}{l}\text { 9. Involvement with } \\
\text { juvenile court }\end{array}$ & 9. Desire for work & \\
\hline $\begin{array}{l}\text { 10. Drug use/Family } \\
\text { drug use }\end{array}$ & 10. Family problems & \\
\hline 11. Homelessness & & \\
\hline
\end{tabular}


In studying 210 students from four high schools, significant differences were found in six major areas.

These areas were: feelings about their school experiences, drug use, personal problems, family factors, social support, and characteristics of close friends. Of these six areas, it is noted that schools do not routinely collect data on five of them. And of the sixth, school experiences and attitudes, schools maintain little data on school experiences in an easily accessible manner, and seldom collect data on student's attitudes toward school (Frymeir, 1990).

Webster (1987) contributed a preliminary paper on youth at-risk in Washington State for the Department of Social and Health Services. She summarized her position as follows:

There is a growing awareness by the schools, and social and health service agencies, and by businesses that four problem areas are contributing to the population of youth at-risk:

$$
\begin{aligned}
& \text {.. dropping qut of school } \\
& \ldots \text { substance abuse } \\
& \text {.. juvenile delinquency } \\
& \text {.. adolescent pregnancy (p. 1) }
\end{aligned}
$$

Webster's review of current literature on these topics concluded with:

The common factors of these four problem areas are:

1. Poverty

2. Minority status (although not Asian)

3. A child of teen-aged parents, who did not graduate from high school (p. 3)

She added that child abuse, early anti-social behavior, lack 
of parent support for success, family drug or alcohol use, family history of criminality, and low achievement were also contributing factors. The factors associated with at-risk vary, but of those noted, only low achievement is traditionally addressed by education. The schools have no control over the background that a child brings with him or her; however, schools can choose to influence whether a child will become a teen-parent, use drugs, or live his or her adult life in poverty. Webster concluded from her review of the literature that an interagency approach was necessary for any effective strategy in serving at-risk children. She based her conclusion on the acknowledgement that many of the at-risk problems of youth extend beyond the school and across the responsibility domains of other public agencies.

Frymier and Gansneder (1989), in conjunction with Phi Delta Kappa, conducted an extended study of at-risk students. Their project involved 22,018 students in 276 schools from 100 Phi Delta Kappa chapters. Forty-five factors of "at-risk" were identified from relevant literature for the study. Students exhibiting six or more of the factors were considered to be at-risk of school or life failure. Frymier and Gansneder are attempting to develop a predictive scale to identify at-risk youth. Initial conclusions were that between 25 and 35 percent of the students studied were at-risk. Predictors used in the 
study included non-traditional families, retention in grade, absenteeism, suspension from school, English as a second language, non-participation in extra-curricular activities, negative sense of self-esteem, drug use, family member drug use, suicide attempts, drug-vending, physical or sexual abuse, and pregnancy.

Frymier and Gansneder found that the majority of educators thought that most of the predictive factors of dropping out were beyond the school's ability to assist the student. These researchers also reported that 90 .percent of the educators within their study believed that parents, not teachers, should help students cope with these problems. They further concluded that much of the information analyzed by schools was by convenience. That is, typically schools used only readily available information in analyzing the at-risk problem. Specifically, Fuymeir and Gansneder wrote:

Finally, faced with this dearth of information, some professionals have adopted the position that such information is not only unimportant, but is detrimental. Teachers who have and use such information, some critics have argued, label children and stereotype them. (p. 146)

Frymier (1990), speaking in Vancoldver, Washington, on the topic of at-risk students, concluded that educators are reluctant to acquire or maintain data on key predictors of at-risk potential. He further stated that without this information educators would be unable to predict or intervene significantly in the at-risk problem facing education today. 
Phlegar (1987) asserted that many of the at-risk characteristics are observable at entry into school, and therefore early identification was highly possible.

The need to do this is made clear by stevens' and Pihl's (1982) discussion of children in remediation programs. One of their initial conclusions about these children was that their failure histories left them with "defective problem-solving strategies and more vulnerable to the stress of failure" (p. 541). The defect in problem solving strategies place them at risk of future failure.

CURRENT THOUGHT FOR ADDRESSING AT-RISK YOUTH

Hodgkinson (1985) reported that the dropout rate has declined from a 90 percent rate for males in 1900 to a historical low of approximately 18 percent in the mid-tolate 1970s. However, this century-old trend of a declining dropout rate reversed itself in the 1980 s and would appear to be worsening as we move into the 1990s, despite several educational restructuring movements in the past two decades. Yet, some practices do appear to hold promise for addressing the problem at hand.

\section{Preschool}

There are two nationally recognized reports on the effects of preschool education with disadvantaged children. These reports, the High/Scope Perry Preschool Project (Berrueta-Clement, Schweinhart, Barnett, Epstein, \& Weikart, 
1984) and the federal government's final report on Project Head Start (U.S. Department of Health and Human Services, 1985), claimed similar findings and conclusions. The Head start study found that participating students had significant positive gains in cognitive and social skills that were maintained through the primary grades. These children were also reported to be healthier, and less likely to be retained or referred to special education during the early grades.

The High/Scope Educational Research Foundation conducted a longevity study on 123 poor, Black children with reportedly low IQ'S. These children were monitored from age 3 to 19 (Berrueta-Clement, et/al., 1984). Approximately half of the group attended preschool, with the other half receiving no early intervention. Comparisons between the two groups revealed that those attending preschool significantly attained higher/grades in school, spent less time in special education, graduated a higher percentage, had fewer teen births, enrolled higher numbers in post high school education, and had an overall higher level of youth employment.

Acknowledging some limitations of these studies (e.g., possible parental differencesl these two studies still encourage the belief that a first step toward dropout prevention is the expansion of participants in quality preschool programs. 


\section{Elementary School}

Slavin, Karweit, and Madden (1989) have published what is probably the most extensive and current synthesis and analysis of the research pertaining to elementary programs for academically at-risk youth. Much of their work was an analysis of the ECIA Chapter I program effectiveness and, therefore, directly evaluated what educators have considered to be the nation's greatest effort toward academic assistance for the disadvantaged child. In their book, Effective Programs For Students At-Risk, they defined effective impact as improvement on standardized test scores. Slavin and Madden (1989) concluded in the second chapter of their book that programs falling into the "continuous progress" category appear to be the most effective. Continuous progress programs are structured so that students "proceed through a well-specified hierarchy of skills" (p. 29). Thus, the program regroups students not mastering a skill to provide them with additional learning opportunities. These findings were consistent for both "in-class" and "pullout" models of instruction. They summarized that cooperative learning approaches were the next most effective, but noted that research on this modality was limited.

Sla jin and Madden (1989) discussed growing dissatisfaction with what has been traditionaliy labeled the "pullcut" model. Coulson, Hanes, Ozenne, Bradford, Doherty, 
Duck, and Hemenway (1977), as well as Glass and Smith (1977), concluded that pullout programs are correlated with reduced learning. This conclusion is of interest in light of a 1987 study by Washington's Office of Superintendent of Public Instruction conducted for the state's legislature. The study was a major attempt to provide the legislature with information on the services provided to special needs students. Most applicable to this literature review were the set of findings from page four of the report. The report concluded that not much specialized service is provided to students with special needs in the regular classroom. The pull-out model was by far the most commonly used procedure with most teachers surveyed indicating that they probably had difficulty in working with special needs students in the regular classroom. Three-fourths of the teachers surveyed indicated that they were "satisfied" or "highly satisfied" with pullout services. The report further indicated that, the state testing results at grades 4, 8, and 10 show that many more students are in need of assistance than receive it with the gap between need and service being especially large in the higher grades. Citing demographic forecasts, the report concluded that not only will the number of children in the 5-17 age range grow substantially by the year 2000 , but the percentage of children in need of learning assistance will increase. Thus, if pullout models are indeed limited in their 
effectiveness, if they are the preferred educational strategy at the elementary level in Washington, if the numbers of "in need" children increase as students move through the system, and if the percentage of "in need" children entering the system is expected to increase during the 1990s, then the hope for lowering the dropout rate is severely limited.

Challenging current thought on effective practices with disadvantage youth, a U.S. Department of Education (1990) publication, Better Schooling for the Children of Poverty: Alternatives to Conventional wisdom, cast doubt on the success and impact of elementary programs serving students from impoverished homes. In discussing elementary schools in the introduction, the report stated:

Until recently, a "conventional wisdom" about effective practice in such settings has emphasized the remediation of learners' deficits, a curriculum broken down into discrete skills, teacher-directed instruction, a uniform approach to classroom management, and the grouping of students by ability. In the hands of skilled teachers, the conventional wisdom can work well, especially when the goal is improving student performance on relatively simple academic tasks. It has important limits though, which are the subject of this report. (p. 1)

The report went on to summarize "conventional wisdom" and "alternatives." The comparison highlighted that the alternative view emphasizes addressing "higher order" skills with student application of learned processes in cooperative teams, as opposed to fixed, sequential, teacher-directed learning. This distinction implies that Slavin and Madden's 
finding on continuous progress programs may indeed assist disadvantaged youth gain low-level skills, but this approach has not been successful in facilitating disadvantaged youth to a competitive level with advantaged youth. The U. S. Department of Education report was, however, consistent with Slavin and Madden (1989) in encouraging cooperative learning techniques with disadvantaged youth.

This brief look at elementary efforts serving at-risk youth is best summed up by Slavin and Madden (1989) when they wrote:

We are still at a primitive state in understanding effective instruction for students at-risk. What is needed is a renewed focus on the development, evaluation, and component analysis of programs based on many models of teaching and learning. (pp. 46-47)

Secondary School

As students move into the secondary schools, concerns for at-risk youth quickly expand to include drug use, classroom disruption, teen pregnancy, criminal involvement, dropping out, and the ultimate dropout, suicide. Based on the literature, education's predominant approach to addressing these issues appears to have been remedial or "after the fact" rather than preventive. The bases for this approach appear to be clear; these are the students most easily iảentified as being in trouble.

Druian and Butler (1987) synthesized the effective schools research and identified implications of that 
literature for the at-risk youth. They concluded that, for the most part, the descriptors of effective schools address the needs of at-risk youth. To illustrate this, they identified "at-risk" research which concluded that teachers had; 1) low expectations of at-risk children, 2) that atrisk children were disciplined a disproportionate number of times, and 3) that teachers generally felt inadequate in assisting at-risk students. Druian and Butler noted that at-risk youth report having feelings of isolation and limited feelings of success, and they appear to be passive rather than interactive learners. Druian and Butler then contrasted their synthesis of "effective schools" characteristics with the at-risk youth characteristics, implying that the effective schools literature could be a major key in drop-out intervention. Specifically they noted the effective schools characteristics of high expectations for all, clear achievable goals, clear rules for behavior that were fairly enforced, and careful monitoring of student progress were counter measures to the at-risk symptoms noted above.

In discussing characteristics of successful programs for at-risk youth, Druian and Butler (1987) concluded that, for the most part, these programs were self-contained or alternative type approaches. Second, they noted that participating staff exhibited intense levels of commitment to their students. Third, they discussed finding 
non-traditional relationships between program administrators and staff, as well as between staff and students. Druian and Butler noted that staff in these programs maintained a strong belief that their students could and would perform well in school. They highlighted that the programs were typically small in size, with a great deal of autonomy from the general educational system.

Conrath (1987) supported the finding of alternative programs as a successful method for addressing at-risk youth. Further, in discussing programs for at-risk youth, he concluded, "Schools within schools appear to be making a comeback" (p. 35). This suggests that smaller more autonomous programs are developing within the traditional secondary school structure.

Moilanen's (1986) review of alternative program studies caused her to have similar conclusions regarding effective strategies for secondary at-risk youth. She wrote:

While traditional organizational responses may not appropriately meet the needs of potential dropout/high risk groups, alternative schools suggest an institutional response which may have been more successful. Much of the literature describing institutional role and responsibility for dropouts is closely associated with alternative schools studies; in addition to its emphasis on more personalized curricular design and instructional delivery, the alternative school's literature considers effects of non-traditional organizational structures, policy, and regulations. (p. 34 )

Raywid (1984) studied schools of choice and found that they could be distinguished from traditional schools by 
their autonomy, their emphasis on feeling tone or school climate, and a receptiveness by staff to address both the life needs and academic needs of the students. This description of alternative programs is similar in nature to Frymier's (1989) assumption that, in order for schools to address effectively the at risk problem, they must address the social needs of the child and with the prevention strategies endorsed by the National Association of Secondary School Principals (1988). In the publication, The Practioner, Peck and Eberhard (1988) summarized prevailing thought and research on dropout prevention. They advocated a prevention plan emphasizing seven dimensions (see Table IV).

These dimensions include educators understanding their own local problem so they can coordinate an interagency strategy for attacking the at-risk problem. Major keys to success of the NASSP recommendations are parent involvement, and a more "inviting" educational setting.

Raywid (1981) used the term "system serving" in describing different types of alternative schools, implying that developing programs for the difficult-to-serve student permits the traditional system to remain intact, regardless of its effectiveness. Given current dropout statistics, there does not appear to be an accepted, transferable, effective solution to addressing the dropout problem. 
TABLE IV

SUMMARY OF THE NASSP DROPOUT

PREVENTION STRATEGY

1. Understand the local at-risk problem, the

population at-risk, the contributing factors, and

develop a plan of action that addresses the needs

of the "whole" child.

2. Formulate a "new mentality" focusing linkages

between schools, parents, and community agencies

because the scope of the problem is beyond the

resources and mission of the public schools.

3. Encourage and promote greater parent involvement.

4. Make schools a more caring, supportive, and nurturing

place to be. overcome the feelings of alienation

reported by many dropouts.

5. Develop a positive belief system within staff that the at-risk child can learn, and provide staff with

clear classroom strategies for instructing at-risk youth.

6. Use counseling departments in key roles. Have them identify at-risk youth, counsel with students and parents, link parents with community resources, and act as the link between school and home.

7. Encourage school attendance. Develop activities to positively influence students to attend. Be alert to attendance patterns. 
In summation of the secondary schools efforts for atrisk youth, it would appear that there has been an awareness that the life needs of the child must be considered in addition to the academic needs. Currently, schools within schools or separate alternative programs appear to be the preferred educational strategy at the secondary level. This type of approach may be popular because it is also a "system-serving" approach.

\section{Effectiveness of Current Efforts: A Conclusion}

A study conducted for the federal government by the Rand Corporation (Hill, 1978) on the effectiveness of ECIA Chapter I programs found that participating students made significant annual gains. However, the academic distance between the 50th percentile child and the disadvantaged child continued to expand as they moved through the educational system. In an elaborate discussion on the effect of thie summer hiatus, Hill concluded that, regardless of whether one subscribed to "a learning loss theory" or a simpler "lack of learning theory," the disadvantaged child lost ground in comparison to their advantaged peer over the summer. Summer schools were reported as ineffective in breaking this cycle. Hill continued his discussion to address whether chapter I should or should not be continued. He wrote in answer to the question, "If there are more promising alternative ways of improving the achievement of disadvantaged children, they are not widely known" (p. 14). 
In the same era as the Rand study, Ron Edmonds (1979), noted effective schools researcher, concluded that we have enough knowledge to teach all children, but summarized, "Whether or not we do it must finally depend on how we feel about the fact that we haven't so far" (p. 23). These two findings, the Rand study and Edmonds' conclusion, still stand in conflict a decade later.

Hodgkinson's 1990 report on Washington's educational system gave no indication that the local dropout statistics were improving, or that the at-risk population was decreasing. Kolb and LeTendre wrote, in the Foreword of the 1990 publication Better Schooling for the Chilaren of Poverty, that "High dropout rates in our centxal cities and rural areas attest to our limited success" (p. v).

In the concluding chapter of Slavin, Karweit, and Madden's (1989) book, they wrote, "First, the remedial and special education programs now in widespread use are not doing enough to overcome the problems of students at-risk for school failure" (p. 356). They continued:

we believe that to make a marked differerice in the chance that at-risk students will succeed in school and in life, fundamental changes are needed in the basic organization of the elementary school. (p. 356)

Frymeir (1990), speaking on the Phi Delta Kappa at-risk study, commented that we spend a great deal of money on the at-risk problem in this country, and it has had very little impact. He then said that there would be little success 
until schools and other public agencies addressed non-academic factors related to dropping out. Even a combined effort may not be enough to make a difference, given the research findings being reported for the mildly handicapped populations served by special education. Liechtenstein (1988), commenting on special education dropouts, wrote: "despite improvement and expansion in services for students with disabilities in the decade since the passage of Public Law 94-142, the provision of appropriate educational services remains problematic for a substantial number of students with handicaps" (p. 13). Special education programs, both philosophically and by legal mandate, assume that the handicapped child must be provided an appropriate education regardless of the accommodations required. Given additional resources, clear legal mandates, parent involvement incentives, and a staff receptive to meeting the broad needs of children, one would expect to find the lowest dropout rates among this school sub-population. However, studies have found that the dropout rate for learning disabled and behaviorally disabled students (mildly handicapped) has exceeded 40 percent (Edgar, 1987; Zigmond \& Thornton, 1985). This figure becomes alarming when noted that 80 percent of the students served with special education are only mildly handicapped (Edgar \& Hayden, 1985). It does not appear that special educators or basic educators have been, to date, 
effective in ameliorating the factors precipitating the dropout of the 1980s, let alone the dropout of the 1990s.

\section{EARLY IDENTIFICATION PROCEDURES}

Shepard and Smith (1986) linked early school failure with increased probability of "early leaving" from the educational system. Levine (1989) studied the relationship of attendance and school success. She reported that retention in grade was associated with excessive absenteeism. Her findings indicated that children were more likely to be retained in kindergarten, first grade, and second grade respectively than at other grade levels. Given the relationship between retention and early leaving, it appears consistent that dropout prevention procedures must include prevention of conditions leading to early retention. This requirement implies procedures for early identification and early intervention are a necessity. If retention is related to dropping out, and if the demographic data regarding more needy students at entry age level are accurate, it seems reasonable to conclude that the resultant interaction between these two events will be a significant increase in the number of teenage dropouts over the next decade.

In order to determine the child's readiness for kindergarten and/or first grade, educators have turned to standardized testing (Meisels, 1987), instruments and 
procedures that staff know little about and that often lead them to faulty conclusions about children (Smedley, 1987). The National Association for the Education of Young Children has published a position statement (1988) regarding the use of standardized testing with kindergartners. This document charges educational leaders at the local levels with the responsibility of insuring "test utility." Gastright (1989) endorsed the concept that the at-risk problem must be addressed at local levels so that local demographics and problems can be specifically addressed. He wrote:

Faced with inadequate data for understanding the local dropout problem, it has been tempting for some districts to fall back on stereotypical views of at-risk students, lower-achieving, mostly male students with poor attendance, bad discipline problems, and a record of previous school failure. Educators who attempted to reduce dropout rates on the basis of such stereotypes may have failed because they neglected local characteristics. (p. 1)

Olsen (1987) insisted that immediate attention must be given to untangling the problems that are plaguing nearly half of America's students. The National Association of Secondary school Principals (1988) declared that it is in the elementary school that dropout prevention must begin. They proposed that it is there, in the elementary school, that the prevention process begins through early identification of children with potential learning problems. Albuquerque Superintendent|Lilian Barna was referenced in Dealing with Dropouts (Office of Educational Research \& 
Improvement, 1987) as supporting intervention programs during the formative years as the possible key to controlling the dropout problem.

In discussing identification procedures of at-risk children, Carnine, Carnine, Karp, and Weisberg (1988) stated that documentation of the reliability and validity of such procedures is limited; however, they do note that some instruments show promise in determining which kindergarten students may need additional assistance. Successful intervention, however, requires accurate identification. The literature regarding early identification currently raises as many questions as it answers.

\section{Testing and Early Identification Procedures}

In 1986,25 states had developmental screening requirements for children, ages 3 through 5 years (Meisels, 1987). The expansion of Public Law 94-142: The Education for All Handicapped Children Act of 1975, has extended educational entitlement to 3 through 5-year-old handicapped children. This has resulted in an expansion of screening procedures for this age group in all states. Meisels, Wiske, and Tivnan (1984) cited Joiner's technical analysis of screening instruments as establishing the need for predictive studies with screening inventories. Joiner's 1977 survey of 170 school districts reported that 150 different early identification screening procedures were used, of which he considered only 16 to be minimally 
appropriate for that use, and that few of those had undergone local validation studies.

The NAEYC (1988) position on the testing of young children charged local districts with the responsibility of ensuring appropriate testing procedures and with appropriate use of the results. They further advocated that test utility requires thorough knowledge of the instruments used, as well as local study of the predictive value of tests, and an analysis of whether the usefulness of the instrument is commensurate with the resources required to administer and evaluate the results. Test utility also implies that the use of the results should be to assist in the development of appropriate programs for children, and should not be used for the purpose of exclusion or tracking.

The California State Department of Education Task Force (1988), consisting of representatives from that state's School Board Association and the Association of California School Administrators, supported the NAEYC position. The Task Force report concluded with reconmendations for school districts which are beginning to formulate programs to cope with the problem of school dropouts. Their first and foremost recommendation for school districts was to "provide greater staff development opportunities in assessment, diagnosis and prescription to help teachers better individualize instruction" (p. 10). The report emphasized that educators must start where the child is educationally, 
and that this place will probably not be the same for all children assigned to a classroom.

Schweinhart (1988), writing to school administrators said: "In the assessment of young children's performance two aspects of validity have special importance--developmental validity and predictive validity" (p. 34). He defined developmental validity as test items developmentally appropriate for the child being assessed. He interpreted predictive validity as a measure that can predict a child's future school success or failure (reiention, special. education, remediation, low achievement). Schweinhart cited Meisels' 1985 review of screening instruments and concluded that only four instruments were adequate in validity and reliability. These instruments were: the Denver Developmental Screening Test, the Early Screening Inventory, the McCarthy Screening Test, and the Minneapolis Preschool Screening Instrument. This scarcity of suitable instruments further supports the need for local school districts to substantiate the predictive ability of instruments adopted for use in the early identification of at-risk students. Langhorst (1989) stated that it is legitimate to use large scale assessment of children when the results are used to benefit the children. She further suggested that the two main legitimizing reasons for testing are "screening to identify children at-risk for potential learning problems and in need of further, more intensive evaluation" and for 
the "assessment of readiness for specific academic programs" (p. 4).

Meisels (1985) indicated that developmental screening procedures should be used as a brief assessment process to identify children with potential learning problems. These children should subsequently receive further intensive diagnostic evaluation. Therefore, screening should focus on identifying if factors exist that would interfere with the child's ability to acquire skills, unlike readiness tests that are designed to measure skill acquisition. Meisels emphasized the importance of validity in screening instruments. He stated that concurrent and predictive validity are essential in a screening instrument to justify the resources used in administration of the instrument. Meisels, Wiske, and Tivnan (1984) reporiced that most developmental screening instruments have extremely limited validity information and, therefore, most require additional validation prior to placing confidence in the inferences drawn from the instrument.

\section{Early Identification and Prediction studies}

There has been considerable research directed toward prediction (identification) of students at-risk of school failure. Adelman and Feshbach (1971), Barrett (1965), Becker (1976), Haring and Ridgeway (1967), Henig (1949), Hinton and Knight (1971), Keogh and Smith (1970), Keogh and Becker (1973), and Monroe (1932) are but a few that have 
struggled with this problem. While some of these studies report significant correlations between predictors and criterion variables, the relationships, for the most part, have been weak and inconsistent.

In a general discussion paper on prediction of reading failure, Adelman and Feshbach (1971) noted that reading readiness measures did not provide high levels of predictive accuracy. They suggested that a majority of the identification procedures do not reveal variables that are key in predicting future school success. They encouraged the adoption of identification procedures that are similar to performance conditions found in the classroom. Thurlow, O'Sullivan, and Ysseldyke (1986), in studying and questioning the accuracy of early screening processes for special education, collected data from nearly 400 Minnesota school districts. Their analysis suggested that districts varied widely in the percentage of students referred for special programs, despite similar instruments and similar demographic factors. They further concluded that few systematic differences in screening practices existed among screening programs. This was confirmed through interviews with personnel from districts with high referral rates and those that had low rates. Their surveys of model programs for early education programs indicated that, while greater numbers of tests are used for screening purposes, only about one-sixth of these tests adequately 
measure what they claim to measure (validity), or produce stable measures (reliability), or are based on an appropriate sample (norming). Decisions based on data elicited by screening instruments were questioned.

To improve the situation, they suggested that a higher priority be placed on keeping accurate local records of decision-outcomes or on monitoring decision-making procedures over time. Their research also indicated that dramatic changes in screening-assessment outcomes occur from year to year, but they were unable to identify the factors causing the changes. Thurlow et al. (1986) contended that failure to pay closer attention to how and why we identify handicapped preschoolers will result in more repair work being required after our well-designed and well-intentioned prevention programs are implemented. This implies that screening programs are inconsistent despite consistent practices and, therefore, should be suspect until answers to this paradox are found.

Hinton and Knight (1971) conducted a three-year followt up of 67 children referred for learning problems during the primary grades. They selected these children on the basis of referrals from family physicians to pediatric neurologists. These children displayed average range intellectual ability, but with a learning difficulty not attributed to a gross neurological abnormality. They found that the IQ score of the Peabody Picture Vocabulary Test and 
the IQ score of the Wechsler Intelligence Scale for Children were "a very important variable in predicting academic success" (p. 516). They reported that 50 percent of the subjects were retained in a grade during the primary years and that the IQ score correlated positively with retention and special class placement. To connect retention to dropping out behavior, Hinton and Knight (1971) cited Fitzsimmons', Cheever, Leonard, and Macunovich's (1969) study on high school àropouts. Fitzsimmons et al. (1969) reported that 94 percent of the youth from their study that left school early had failed a grade in the elementary school. In an extended discussion, Hinton and Knight combined their findings with Fiztsimmon's et al. findings. They concluded from the relationships between retention and $I Q$, and retention and dropping out, that IQ scores could be used to identify at-risk children. They further assumed from their data that IQ scores could be used in the identification of early school failure, and thus result in a substantial impact on the nation's dropout rate.

Colarusso, Gill, Plankenhorn and Brooks (1980) researched prediction of first-grade success based on the testing of kindergarten age children. They discussed the use of the IQ variable and the works of Egeland, DiNello, and Carr (1970) and Panther (1967) in this area. They concluded that, "although all of these correlations were significant, the low magnitude suggests that IQ's cannot be 
relied upon as a single variable to accurately predict potential learning problems in kindergarten" (p. 357). Colarusso et al. (1980) also reviewed studies involving single-variable predictors of school success. In summation of this approach, they concluded that "there are significant relationships between certain predictor variables and certain achievement variables. However, the differences in magnitude of correlation coefficients, particularly when sex is considered, have demonstrated the danger in attempting to identify a single variable that will predict school failure" $(p .357)$.

Colarusso, Gill, Plankenhorn, and Brooks (1980) used multiple test sub-tests and demographic variables in their study. They selected 40 inner city black children, all age five, and followed the children through kindergarten and first grade. Of the thirteen variables they selected for study, only two were significant at the .05 level. These were the Motor-Free Visual Perception Test and the math component of the Illinois Test of Psycholinguistic Abilities. However, given the minimal relationship strengths, these researchers summarized "they primarily supported earlier findings questioning the value of formal tests for early identification of children with potential learning problems" (p.361). Dykstra (1967) summarized the previous 30 years of research on the predictive validity of readiness tests. He 
reported predictive coefficients consistently ranging between .40 and .60 , regardless of the instrumentation or the methodology used. He questioned whether that level of relationship was accurate enough for selecting children for special placements.

Lindquist (1982) studied the Weber School District's screening program for predictive accuracy of reading scores of primary grade students. The Weber district administered the Denver Developmental Screening Test (DDST) to all children as they registered for kindergarten. The GatesMacGinitie Reading Tests were administered to all elementary children (grades 1-3) during the spring. Lindquist sought to determine if the DDST scores predicted the GatesMacGinitie Reading Test scores. Findings in this study indicated that a significant correlation between the GatesMacGinitie Reading Test score and the Denver Developmental Screening Test existed. However, he concluded that the relationship lacked adequate strength to permit practical or general prediction of individual students.

Lindeman, Goodstein, Sachs, and Young (1984) evaluated the predictive validity of the Yellow Brick Road Test (YBRT), administered at kindergarten entry, with the Metropolitan Achievement (MAT). This study reviewed three prediction-performance cut-off scores in attempting to identify "best fit" selection of at-risk children. The YBRT was administered to 214 children, and they were tracked 
through the end of second-grade. The YBRT correlated .67 with the MAT. The overall best hit rate of the true positives and the true negatives produced by the instrument was 72 percent. The authors general conclusion was that the YBRT was moderately valid in predicting reading achievement. These researchers further encouraged that districts employ similar prediction-performance studies as they implement screening programs.

Ferineden and Jacobsen (1970) screened kindergarten children with the Evanston Early Identification Scale and the Wide Range Achievement Test (WRAT). They then followed the students through first grade and reported a 99 percent accuracy rate for the Evanston Scale and a 93 percent accuracy rate for the WRAT in identifying children that experienced poor success in reading at the first-grade level.

Book (1980) studied group test performance of 472 children who were identified in kindergarten as educationally high, moderate, or low. He followed students from grades one through four. End of kindergarten predictive measures were the Kindergarten Evaluation of Learning Potential (KELP), Bender-Gestalt Test (B-GT), and the Slosson Intelligence Test (SIT). Follow-up measures were group achievement tests administered in April of each school year. The high and low risk groups showed substantial differences in achievement performance. During the 
first four grades, significant correlations were found between the risk group designation and achievement performance. Students of high risk (Group I) consistently performed below the 25th percentile on group achievement tests, and less than 11 percent of this group ever performed above the 50th percentile. About 43 percent of Group II performed below the 25th percentile, and about 27 percent performed above the 50th percentile. This indicated that Group II students were at a moderate risk of low achievement. Less than 4 percent of the children from Group III performed below the 25th percentile, and 79 percent performed above the 50th percentile, indicating them to be at low risk for average achievement. The results of this study supported possible predictive validity of the three instruments used as the screening battery. The combined results of the tests during the kindergarten year reportedly predicted group achievement performance in grades one through four. These results are similar to findings by Keogh and Smith (1970), and Pope (1978) who have reported high predictive utility from standardized tests through second grade.

Book's (1980) extended analysis indicated that individual student's group test performance change little during the first four years of school. Thus, his study presented the conclusion that at-risk students do not necessarily improve, but persistently lag behind low-risk 
students. Book suggested that not only can students be identified, but that intervention programs should be designed to provide continuous support over several years, and that intervention programs must be designed so that students learn at an accelerated rate in order that they "catch-up."

Swanson, Payne, and Jackson (1981) studied the predictive validity of the individually administered Meeting Street School Screening Test (MSSST), by Hainsworth and Siqueland (1969), and the group administered Metropolitan Readiness Test (MRT). They administered these instruments to two samples of approximately 65 children each. Subjects were of entering first-grade age, and the Metropolitan Achievement Test (MAT) was the criterion measure. Evaluation of the predictors revealed a total score correlation of .73 between the MSSST and the MAT and a correlation above .82 between the MRT and the MAT. Multiple-regression analysis, combining the two predictors, resulted in a correlation above .84 between the instruments and the MAT. The authors concluded that both instruments, individually, could be used for the identification of children that would have difficulty learning to read during first grade.

Kapelis (1975) also studied the Meeting Street School Screening Test as a predictor of first-grade reading ability (Metropolitan Achievement Test, Primary 1 Battery). For a 
sample of 200 students, she reported moderate correlation of .60 , and cautioned potential test users against the use of screening procedures for permanent school placements. Ireton, Shing-Lun, and Kampen (1981) reported that the Minnesota Preschool Inventory provides a systematic, standardized method for screening pre-kindergarten children. They reported that the inventory format, based on the parent's report of the child's current development, adjustment, and symptoms, provides a convenient means for obtaining developmental information. They reported that when used in combination with the Minnesota Preschool Inventory profile norms, the parent reports identified a high percentage of those children who were at risk for kindergarten failure.

In the Ireton et al. (1981) study, validity of data was discussed in terms of correlation and congruence between the mother's report at the beginning of kindergarten and teacher's ratings at the end of kindergarten. Teacher's ratings were based on overall kindergarten performance. Normative data were based upon a sample of 360 prekindergarten children. These researchers found that the developmental scales were related to kindergarten performance. Combination of the developmental scales of Comprehension, Memory, Letter Recognition, and Number Comprehension identified 12 of the 20 students (60 percent) who were rated in the bottom 5 percent by teachers. The 
subtests misidentified (at-risk) only 3 percent of students rated successful by teachers. The sub-test items of the inventory identified an additional three of the eight poorly performing students who were not identified by the developmental scales. The Minnesota Preschool Inventory presents a picture of the parents' concerns regarding the child's development, adjustment, and symptoms. Low scores on certain developmental scales raise serious question about the child's ability to meet kindergarten expectations. Parents' concerns, the developmental scales, the adjustment scales, and the symptom items were all reported to point to a need for further assessment of identified children and, possibly, for special education or psychological services. Glazzard (1977) sought to predict children with potential learning disabilities. She studied teacher ratings, reading readiness, and reading achievement test scores as predictor variables. Reading achievement at the completion of first-grade was the criterion. Specifically, she used the Gates-MacGinitie Readiness Skills Test, the Gates-MacGinitie Reading Test, and the Kindergarten Teacher Estimate of Kindergarten Pupil's Abilities as predictors. She used the Gates-MacGinitie Reading Test as the criterion variable and administered at the end of the first-grade. She reported significant multiple correlation coefficients of the three predictor variables: .77 for the Gates Readiness Test, .77 for the Teacher Estimate, and .57 for 
the initial Gates-MacGinitie Reading Test. She found the Teacher Estimate to be uniquely predictive of reading comprehension. She did not report discriminate prediction percentages.

one inevitable question regarding prediction is whether ethnic or economic class is a better indicator than the assessment instruments.| A study by Sandler, Jamison, Delisher, Cohen, Emkey, and Keith (1972) sought to determine whether or not the Denver Developmental Screening test identified at-risk or disadvantaged children. They administered the DDST to 373 disadvantaged Black children attending preschool nursery classes in a large urban area. Findings reported that these children "performed similarly to the normative expectancies of the screening test" (p. 205). These researchers found that 77 percent of the children scored in the normal rating area, 25 percent scored as questionable and in need of further evaluation, and one percent as abnormal. They concluded that disadvantaged children perform "similarly to the normative expectancies of the screening test" (p.|205). This conclusion was similar to the findings from Thurlow, O'Sullivan, and Ysseldyke's (1986) extensive study of Minnesota children that reported "we found no relationship between screening referral rates and any of the general social, economic, or educational factirs" (p. 94).

Federici, Simms, and Bashian (1976) studied the Meeting 
Street School Screening Test and the Myklebust Pupil Rating Scale with first-grade Black children. The MSSST identified about fifteen percent of the subject population (580 urban children). This result was approximately the same proportion of children that would be expected in the population at large. The Myklybust results were not as conclusive.

The prediction studies reviewed have not yielded conclusive findings regarding the utility of screening tests in identifying at-risk children at entry level to school. The studies do indicate that the potential for effective use of screening instruments is high. Local study and validation can clarify the utility of specific instruments for school district populations.

\section{SUMMARY}

This chapter reviewed literature related to the at-risk problem. The chapter addressed three areas within the atrisk topic, 1) the extent of the problem, 2) current thought for addressing the at-risk problem, and 3) early identification procedures.

I believe that the literature presented adequately supports the basic following conclusions:

1. The student at-risk problem is growing significantly and rapidly.

2. The student at-risk problem becomes the 
adult at-risk problem.

3. The at-risk problem is rapidly endangering the nations economy and social structure.

4. Current efforts to ameliorate the student at-risk situation have had minimal effect, possibly due to the lack of local study of the problem prior to implementing solutions.

5. Increasing emphasis is being placed on early intervention.

6. Given limited resources, early|intervention requires early accurate identification.

7. The literature regarding the use of standardized tests in early identification is inconclusive. Although there is some encouragement to be found in the literature for the use of testing instruments, accuracy of the process is solidly questioned.

8. In the absence of other, more effective solutions to the early identification of the student atrisk, further research regarding testing for identification is warranted. The next chapter discusses the procedures used to collect and analyze the data within my study. Data collected is orientated toward the development of a process that will accurately identify at-risk children within their first-grade year of formal schooling. 


\section{METHODOLOGY AND PROCEDURES}

This chapter is a discussion of the study's overall design, variables, subjects, instrumentation, and statistical analysis of the data to answer the research questions. The methods and procedures used in this study generated data specific to the Washougal School District's student "at-risk" identification procedure. Within the limitations of the sample and the design (correlational research), this study contributes to the literature germane to the use of normed referenced testing in the identification of children in danger of school failure. This study also contributes to the use of testing in the school administrator's decision-making process. The statistical analysis of data collected is the basis for answering the six questions put forth in chapter I of this study.

\section{DESIGN}

The primary research approach of this study was a longitudinal data collection and correlational analysis, with discriminant analysis used to determine predictive accuracy. 
Kindergarten teachers and support staff, trained in the administration and scoring of the Preschool screening system (PSS), administered the instrument to all kindergarten students entering the Washougal School District in the fall of 1988. I monitored this class through the completion of their first-grade year. I considered those students to be at risk who were referred during this two-year period for retention, remediation, special education, or other special interventions. Additionally, I classified students to be at-risk who scored below the 25th percentile on the GatesMacGinitie Reading Tests or who were perceived by their teachers as likely to fail.

Near the end of the kindergarten year, teachers completed a School Success Rating Scale (SSRS) on each of their students. Additionally, I asked the teachers to predict the success level of their students in first grade. Levels of "success" were simply "not successful," "successful," or "highly successful."

Early in their first-grade year, teachers administered the Gates-MacGinitie Reading Tests, Level R, Form $\mathrm{K}$ to these same students. In the spring of first-grade, they again administered the Gates-MacGinitie to these students. I also summated report card grades from the first-grade year in the areas of reading, language, math, cooperation, and effort. In June of 1990 , the first-grade teachers completed the SSRS on each of their students and rated their students' 
"success" level. I collected demographic data on the students' eligibility for free or reduced lunch, age at kindergarten entry, parent marital status, gender, and teacher grouping during kindergarten. I used the four demographic factors as comparison variables to evaluate the utility of the predictor variables. I analyzed variables in terms of their correlational relationships and discriminant/predictive ability, both individually and cumulative. The predictor or predictor combinations that produced the most usable sensitivity and specificity results were iclentified and discussed.

\section{Variables}

This research project sought to establish an "at-risk" early identification procedure with a strong predictive base determined by an analysis of interrcorrelattional patterns of three sets of variables. All totaled, foulfteen variables in this study functioned as either predictor, criterion, or demographic measures. The design permitted some measures to be both predictor and criterion variables, depending on the point in time the measure was taken. I have used the terms predictor, criterion, and demographic, wheln referring to variables, rather than independent, dependent, and, or control. This nomenclature was to emphasize the passive nature of correlational research.

Table $V$ presents the research variables, as well as the type of measure they represent (with the exception of 
student performance which is a composite criterion variable developed during data analysis). Table $\mathrm{V}$ also identifies the point at which each variable was measured/collected in this study. Again it is noted that the PSS was the primary predictor variable of the study. As such, the PSS was analyzed for its ability to predict performance on all

TABLE V

RESEARCH VARIABLES OF THE STUDY

\begin{tabular}{|c|c|c|c|}
\hline KINDERGARTEN ENTRY & KINDERGARTEN EXIT & PIRST GRADR ENTRY & PIRST GRADE EXIT \\
\hline $\begin{array}{l}\text { Gender } \\
\text { (demographic) }\end{array}$ & & $\begin{array}{l}\text { Gates-NacGinitie Level-R } \\
\text { (secondary predictor }\end{array}$ & $\begin{array}{l}\text { Teacher rating } \\
\text { (criterion) }\end{array}$ \\
\hline $\begin{array}{l}\text { Age } \\
\text { (demographic) }\end{array}$ & $\begin{array}{l}\text { Teacher rating } \\
\text { (secondary predictor) }\end{array}$ & & $\begin{array}{l}\text { SSRS } \\
\text { (criterion) }\end{array}$ \\
\hline $\begin{array}{l}\text { Socioeconomic status } \\
\text { (demographic) } \\
\text { Parent marital status } \\
\text { (denographic) } \\
\text { PSS } \\
\text { (predictor) }\end{array}$ & $\begin{array}{l}\text { SSRS } \\
\text { (secondary predictor) }\end{array}$ & & $\begin{array}{l}\text { Gates-HacGinitie } \\
\text { Level-1 } \\
\text { (criterion) } \\
\text { (spring) } \\
\text { Program placenent } \\
\text { (criterion) } \\
\text { Report cards } \\
\text { (criterion) }\end{array}$ \\
\hline
\end{tabular}

subsequent measures, both secondary predictors and criterion measures. I also analyzed the results of the PSS in relationship to, in combination with, and in contrast to demographic measures collected at kindergarten entry. Variables identified in Table $\mathrm{V}$ as secondary predictors are the School Success Rating Scale, the Gates-MacGinitie Reading Readiness Tests; Level-R, and kindergarten teacher 
ratings. I evaluated these measures as predictors of the criterion variabiles listed, and analyzed them as possible early criterion variables for school success in studying the PSS.

Demographic variables included gender, age, socioeconomic status, and parent marital status. Predictive accuracy of these variables were of interest since, obviously, if any comparison variable (or combination of demographic variables) could predict at-risk children with equal or greater accuracy than-the designated predictor variables, there would be little, if any, benefit in administering the test instruments. Additionally, I analyzed combinations of the predictor and demographic variables to establish the identification process that results in the highest identification accuracy rate, as well as the process identifying the most useable sensitivity and specificity ratés.

Table VI isi a delineation of demographic variables, defining the levels of age at school entry, socioeconomic status, gender, and parent marital status.

For the purpose of analysis, I divided age into the three categories of young, average, and old. Washington state requires that a child be 60 months of age by the first day of september in order to enter kindergarten. Young was therefore defined as a child having their fifth birthday in the four months prior ta the september cutoff date for 
school entry. Average age was defined as any student having turned age five during the eight months after the previous years cutoff date of september first.

Socioeconomic status was defined as either low income or adequate income. Low income reflected families eligibility to access subsidized lunch assistance for the school age children. The adequate income classification reflected a family income above the cutoff level for free and reduced lunch eligibility.

Parent marital status was divided into two categories, natural and other. Natural implies two adults in the home, both of whom are natural parents. Other implies all other types of family arrangements.

TABLE VI

DELINEATION OF DEMOGRAPHIC VARIABLES

\begin{tabular}{lccc}
\hline \hline VARIABLE & DELINEATION & \\
\hline Age & Young & Average & Old \\
& $60-63$ mons. & $64-71$ mons. & Over 71 mons. \\
\hline $\begin{array}{l}\text { Socioecononic } \\
\text { status }\end{array}$ & Low income & Average income \\
\hline $\begin{array}{l}\text { Gender (sex) } \\
\text { Free/reduced lunch }\end{array}$ & Full price lunch \\
\hline $\begin{array}{l}\text { Parent } \\
\text { marital } \\
\text { status }\end{array}$ & Male & Female \\
\hline \hline
\end{tabular}


School success is, in actuality, the essential criterion variable of this study. However, because school success is an abstract or relative term, I defined it in this research in terms of performance (i.e., scores on the stated criterion variables).

The criterion variables were as follows: first grade teacher ratings of success, School Success Rating Scale scores (SSRS), Gates-MacGinitie Reading Tests Scores (Level 1), special program placements, and report card grades. I classified students rated one standard deviation below the mean on the SSRS as not successful. I classified students scoring below the 25 th percentile on the Gates-MacGinitie as not successful. I classified students averaging an aggregate report card score of "2" or below as not successful (from a report card scale of 1 to 5 , with 2 and below indicating needs improvement or not successful).

For the purpose of discriminant analysis functions, I converted each criterion measure score to a two- or threechoice ordinal scale of "not successful," "successful," or "highly successful." "Successful" and "highly successful" categories were then combined into one category of "successful" for the purpose of predicting at-risk or notat-risk.

We can consider special placement as adult action on the part of the school district. Scores on the Gates- 
MacGinitie, SSRS, reading placement, report card grades, and teacher ratings are measures of student performance. I collapsed these variables into a single variable called "student performance" for the purpose of analyzing the predictors in terms of predicting district behavior and in predicting student behavior.

I created the student performance variable by combining the ordinal level criterion variables of the SSRS, GatesMacGinitie, teacher prediction, and the report card. Scores were converted to a two-level "at-risk" and "not at-risk" scales. I defined scale scores one standard deviation below the mean for student performance as at-risk; scores above this level, I considered as representing students not-atrisk. Dichotomous scores from each of the scales were added together to produce combined student performance score.

\section{SUBJECTS}

Students enrolled in kindergarten in two different elementary schools of the Washougal School District during the 1988-89 school year served as subjects for this study. Nearly all the subjects were Caucasian (less than 3 percent were Black, Asian, and/or Hispanic) and all were English speaking. Initially, 175 students, with relatively equal numbers of boys and girls, participated in the study. Family mobility (a limitation within the study) reduced that number to 133 students with complete sets of data from 
kindergarten entry to first-grade exit. Approximately 38 percent were eligible for free or reduced lunches, with the majority of the district's children coming from nonprofessional working families.

\section{INSTRUMENTATION}

The Preschool screening system, the student Success Rating Scale, the Gates-MacGinitie Reading Tests, and Kindergarten teacher rating were the predictive measures used in this study. Kindergarten teacher ratings were teacher perceptions collected as classifications of success level.

The Preschool Screening system

The Preschool screening System (PSS) by Hainsworth and Hainsworth (1980) is a descendent instrument of the Meeting Street School screening System Test (Hainsworth \& Siqueland, 1969), originally published in 1969. The PSS is an individually administered screening test, designed to survey the learning skills of large numbers of children entering kindergarten or preschool for the purposes of identifying students with potential special learning needs and identifying group needs for annual curriculum adaptation.

Either a certificated or non-certificated teacher can administer the PSS. Screening usually requires between 10 to 20 minutes per child. The theoretical base of the instrument was information processing theory (Hainsworth \& 
Siqueland, 1969). Information processing theory, as used in this context, is the set of assumptions that individuals process information through three modalities: gross motor, fine motor, and language. Thus, the authors of the PSS concluded that evaluation of these three areas can reveal a student's ability to acquire and process information, a basic fundamental of learning. Therefore, one would expect students having difficulty with one or|more of the processing modalities to have difficulty in the educational system.

To develop the instrument, the authors started with over 100 field trial sub-tests that they reduced to 15 subtests divided into four information processing modalities: a) Body Awareness and Control, b) Visual Perceptual Motor, c) Language Understanding and Expression, and d) other subtests.

Approximately 3,000 children participated in the norming process, and developmental tables are available for ages 2 years 6 months to 5 years 9 months. The authors manual reports test-retest reliability for the total PSS score to be .94 , with an inter-rater reliability of .99 . The manual reports spearman correlation coefficients between the PSS and the McCarthy Scales of Children's Abilities (McCarthy, 1972) at .88 and with the Metropolitan Readiness Tests (Hildreth, Griffiths, \& McGauvran, 1969) at .82. The manual discusses content validity. It reports content 
validity as having been previously established through the extensive instrument development procedures and through a panel review by several dozen preschool professionals. The manual states that long-term predictive validity studies support upwards of 77 percent accuracy in the prediction of at-risk students.

A 1990 Fducational Resources Information Center (ERIC) search produced no current field validation studies on the PSS. However, Federici, Sims, and Bashian (1976) studied The Meeting street School Screening Test (MSSST) and concluded that the instrument did not identify larger numbers of minority at-risk children than would be expected from the population at large. Kapelis (1975) studied the predictive validity of both the Meeting School screening Test, and Slingerlands' Prereading screening Procedures. Kapilis reported a significant correlation between the MSSST (predictor) and the Metropolitan Achievement Tests readingsubtests (criterion).

When compared with the accuracy criterion established for the evaluation of test utility ( 80 percent accuracy) used in this study, the prediction rate reported in the manual and in field studies of the parent instrument would eliminate the PSS from acceptability. However, the authors noted in the PSS administration manual that the cut-off point for "refer/not refer," is a "thorny issue" (p. 104). The authors suggested that the cut-off point is really an 
issue of local. purpose, analysis, and study. The PSS manual states: "ANY SCHOOL SYSTEM CAN IMPROVE ITS PREDICTIONS BY DEVELOPING ITS OWN NORM TABLE" (p. 105).

\section{The School Success Rating scale}

Portland State University, School of Education "Project Quest" staff members and graduate students are developing The School Success Rating Scale (SSRS) (Quest Staff, 1989). It is an instrument under design to predict and measure first-grade success based on functional routines rather than academic measures. In conjunction with my study, we modified the instrument. Based on initial reliability and validity data analysis, it was reduced from a 27-item instrument to a 12-item, five category, 1-to-4 teacherrating matrix. Teachers used the instrument to rate a student's ability to act or behave in an appropriate manner during instruction, play, transition, and eating times and when given responsibility. The scale is presented, in part, in Table VII.

Instrument development began with a review of related literature that identified potential items for inclusion. Then, a panel of first-grade teachers rated the importance of each item. Items having less than an 80 percent teacher agreement on "importance" for inclusion were discarded. Teachers then used the instrument to rate a sample of 35 first-grade students. Teachers had previously reported success levels for these students as either not successful, 


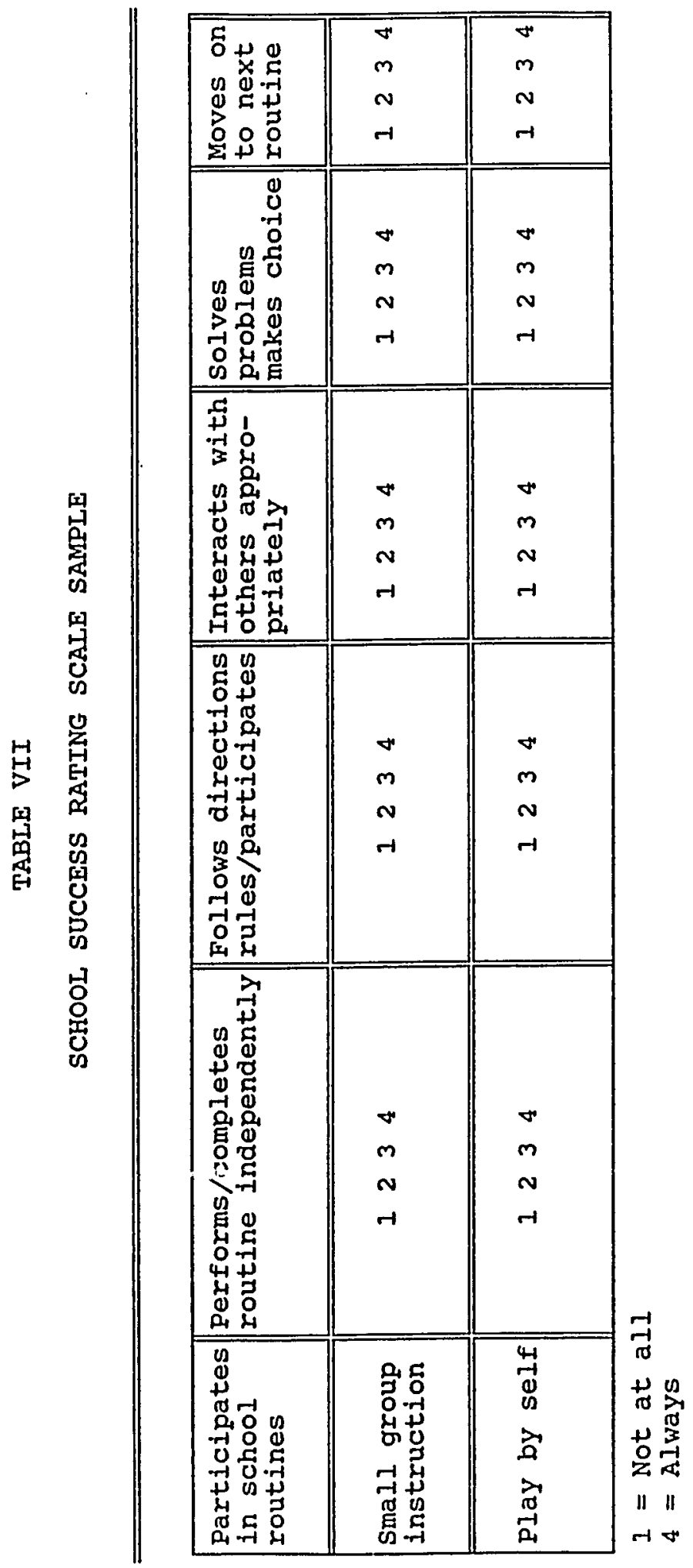


successful, or highly successful. Discriminant analysis of each item permitted the exclusion of all individual items that were not consistent with the "teacher ratings of success" in at least 70 percent of the sample. Project Quest staff calculated the internal consistency of SSRS by split-half technique. Split-half reliability was reported as .74 using the Pearson Product Moment correlation. The authors of the SSRS concluded that this process in constructing the instrument provided evidence of content and predictive validity, but that more extensive development was required for the instrument. Appendix B includes a more extended discussion of the development of the instrument, and provides a detailed report on the development of the SSRS at various stages of development.

Feshbach, Adelman, and Fuller (1974) lent support to the concept of kindergarten teacher ratings of student behaviors effectively predicting first-grade success. They studied kindergarten teacher ratings of students cognitive, affective, and social attributes in comparison with first-grade academic success. They labeled their instrument the student Rating Scale (SRS). Impulse control, following rules, working independently, listening attentively, and preparation were scale items in the social attribute realm.

These items are similar in nature to those found in the SSRS. Feshback et al. (1974) found that the SRS had 
comparable predictive accuracy with the extensively studied, de Hirsch Predictive Index Scale of Reading Failure (de Hirsch, Jansky, \& Langford, 1966), when using bottom quartile performance on the Gates-MacGinitie as the criterion measure.

Cowgill, Friedland and Shapiro (1973) also examined behavioral and trait ratings for early diagnosis of learning difficu2cy. They reviewed anecdotal records of kindergarten teachers, evaluating the occurrence of fifty-three specific traits. They concluded that kindergarten teacher ratings of behavioral traits could be used to determine, with relative accuracy, those children that would be referred to special education by the end of first grade.

While there are no predictive validation studies on the SSRS, the literature does support the development and use of instruments similar to the SSRS.

The Gates-MacGinitie Reading Tests (Third Edition)

Two levels of the Gates-MacGinitie Reading Tests were used in conjunction with this study. Level-R was administered at the beginning of first grade. Level-R reportedly measures beginning reading achievement and allows for the evaluation of growth of reading skill between the beginning and the end of first grade. This instrument assesses the skill areas of initial consonants, final consonants, vowels, and the use of context.

Authors designed Level-1 to sample reading skill at the 
end of first grade and reported a student's normal curve attainment. Generally speaking, the Gates-MacGinitie Reading Tests, Third Edition (MacGinitie and MacGinitie, 1989 ) is a descendent of the 1926 Gates silent Reading Test and the Gates Primary Reading Tests. The reported uses of the Gates-MacGinitie Reading Tests are: (1) to select students in need of individual diagnosis, (2) to plan instructional emphasis, (3) to identify students capable of advanced schoolwork, and (4) to evaluate the effectiveness of instructional programs.

The publisher standardized the 3rd edition of GatesMacGinitie Reading Test in October 1987, January 1988, and April 1988. Sampling was based on 1980 census data and stratified according to region, district enrollment size, and socioeconomic status. The sample size was 42,000 students, kindergarten through grade twelve, from 67 school systems. Extensive norming procedures are available in the technical summary. The manual reports specific reliability and validity information regarding each of the sub-tests for each of the nine levels and two forms of the instrument. The Gates-MacGinitie Reading Tests consist of Vocabulary Tests and Comprehension Tests; two forms designed for use at nine levels, with each level and form designed with multiple grade level items. Norms tables provide for the conversion of raw scores to stanines, national percentile rankings, grade equivalents, standard scores, and 
normal curve equivalents for the three norming periods: fall, winter, and spring. I used percentile ranks in this study.

\section{Teacher Ratings}

Teachers used a simple, three-choice classification of student success. Teachers classified students as: "not successful," "successful," and, "highly successful."

While not an instrument per se, I used teacher perception of school success as both a predictor and a criterion variable, and therefore warrants some discussion.

While I did not conduct a formal validation of teacher ratings of student performance, the literature has given teacher perceptions of student achievement considerable attention. Several studies have used teacher ratings to predict learning problems. Keogh and Smith (1970) found significant correlations between teacher ratings at kindergarten and achievement in the elementary grades. Keogh, Hall, and Becker (1974) reported 82 percent accuracy of kindergarten teacher predictions through the end of the first-grade year. Cowgill, Friedland, and Shapiro (1973) have also reported significant identification rates of atrisk children by kindergarten teachers.

Teacher expectations (perceptions) have also been studied in relation to student achievement. Teacher expectations received notoriety with the publication of :osental's and Jacobsen's 1968 study, "Pygmalion in the 
classroom." Several other researchers have cited "teacher expectation" as an observable effect (Brophy, 1982; Brophy \& Good, 1970; Rosenthal \& Rubin, 1978; and Washington, 1980). Cooper (1979) reviewed the literature on teacher expectation and wrote:

For now, then, it seems best to conclude that expectations influence performance, but they likely sustain it at a pre-existing level or allow innate differences in student performance to emerge rather than radically alter its course (p.392).

This conclusion, that teacher expectation is a sustaining phenomena, rather than a casual relationship, gives strong support to the concept that teachers not only discriminate between the functional levels of children in their classrooms, but that they also act in a manner that maintains those differences.

Given current literature, it seems logical to assume that one can use teacher perceptions of success to predict future student success, or the lack of success.

\section{Report Card}

The First Grade Report Card used in this study was developed by eleinentary teachers and administrators for use in the Washougal School District. The district's Learning Objectives and Scope and Sequence Chart served as the basis for the student progress reporting system. Teachers use the report card to report student progress toward the attainment of specified learning objectives in the subject matter areas 
of Reading, Math, Social Studies, Language, Penmanship, Science/Health, Art, Work Habits, Physical Education, Music, and Social Behavior.

Teachers report student progress at one of three levels of attainment; Need Improvement, Satisfactory, or outstanding. (Appendix $c$ includes a copy of the first grade report card.)

I converted all third-trimester letter grades given within each of the broad topic areas of math, reading, language, work habits, and social behavior to scores of 1 , 2 , or 3 ( 1 = needs improvement, 2 = satisfactory, $3=$ outstanding). I used the total and average sub-scores within each broad area, thus presenting a success level score between 1.0 and 3.0 for each broad topic area. Each rating of subject area success served as a criterion measure.

Program Placement

If a student was retained in a grade or served by either a remediation program or a special education program, then I defined that action as program placement. Students required to repeat kindergarten or first grade are retained students. Students participating in ECIA Chapter 1 funded programs are remediation students. Special education students are those students eligible for services as defined by Public Law 94-142 (1975).

Retention or placement in a special program for any 
length of time during the two-year period of this study constituted "Special Program|Placement."

DATA ANALYSIS

I have identified for study a total of thirteen (fourteen including the composite variable student performance) variables in six research questions. Interval variables are reported in means and standard deviations. Ordinal and nominal data are reported in frequency distributions and percents as appropriate. The descriptive data reports include an intercorrelational matrix of predictor, demographic, and criterion variables. I used phi and Kendall's tau b with ordinal level variables. I used Pearson's product-moment correlation coefficients to determine the relationships among interval and ratio data.

I conducted analysis of variance or chi square (as appropriate) to determine the significance of relationship between demographic variable subgroups and student scores on the criterion variables. I included demographic variables with significant subgroup differences in the analysis to determine the predictor or predictors that produced the highest sensitivity and specificity for each criterion variable.

Discriminant analysis was the primary statistical treatment used to answer the research questions. The questions proposed for study consider whether at-risk 
students can be discerned from not-at-risk students based on analysis of a set of characteristics (predictor variables). In other words, could the predictor variables discriminate between at-risk and not-at-risk children? My primary criterion for at-risk determination was special placement or retention in a grade. I further analyzed the predictiveness of at-risk children as defined by a bottom quartile score on the Gates-MacGinitie, or score one standard deviation below the mean on the School success Rating Scale, or low report card average, or a teacher prediction of high potential for future failure, or a low score on the composite variable of student performance. Thus, discriminate analysis was used to predict at-risk and not-at-risk group memberships for six different methods of classifying students as at-risk.

I used the statistical computer package SYSTAT (Wilkinson, 1988) to conduct the statistical analysis. 

possible predictor variables with the hope that they could enhance the sensitivity and specificity of an early identification formula.

Table VIII lists the demographic and predictor variables by the abbreviated names that I have used in the tables of this chapter. I have also included a brief description of each variable and the number of students for which data were collected on each specific variable.

I have converted data obtained on age, the GatesMacGinitie Reading Test, and the School Success Rating Scale from interval or multi-level ordinal scales to two- or three-level ordinal scales. In subsequent tables, when this conversion is required, I have added a "2" or " 3 " to the end of the variable name (e.g., SSRS(1st)(2) is School Success Rating Scale for first grade, reduced to two categories: successful and unsuccessful). A primary reason for this conversion was a need to define students measured by the criterion variables as either at-risk or not-at-risk. For use in discriminant analysis it was advantageous to scale all variables in a similar manner. Statistical analysis procedures primarily used this ordinal data rather than raw scores. Table IX presents information on criterion variables in a format similar to that found in Table VIII, listing abbreviated names, descriptions, and the number of student for whom data were collected. 
TABLE VIII

DEMOGRAPHIC AND PREDICTOR VARIABLES

\begin{tabular}{|c|c|c|c|}
\hline Variable & Variable Description & Type & $\underline{\underline{N}}$ \\
\hline Sex & Gender of student: male, female & Demographic & 241 \\
\hline Age & Age of student at kindergarten entry & Demographic & 241 \\
\hline Age (3) & Age reduced to three categories & Denographic & 241 \\
\hline Lunch & $\begin{array}{l}\text { Two category family income } \\
\text { free, reduced or regular lunch }\end{array}$ & Demographic & 241 \\
\hline Parents & Parent marital status at kindergarten entry & Demographic & 241 \\
\hline Screening test & Preschool Screening Test & Predictor & 181 \\
\hline Teacher ratings(K) & $\begin{array}{l}\text { Kindergarten Teacher Rating of Success: } \\
\text { Interval scores }\end{array}$ & Predictor & 184 \\
\hline $\operatorname{SSRS}(\mathrm{K})$ & School Success Rating Scale & Predictor & 169 \\
\hline Reading readiness & $\begin{array}{l}\text { Gates-MacGinitie Reading Readiness Test } \\
\text { normal curve equivalents fron fall of 1st } \\
\text { grade administration. }\end{array}$ & Predictor & 188 \\
\hline Reading readiness $(2)$ & $\begin{array}{l}\text { Gates-HacGinitie Reading Readiness } \\
\text { normal curve equivalents from fall of } \\
\text { 1st grade adninistration. } \\
\text { Two category: above } 25 \text { percentile, and } \\
\text { below } 25 \text { percentile }\end{array}$ & Predictor & 178 \\
\hline
\end{tabular}


TABLE IX

CRITERION VARIABLES

\begin{tabular}{|c|c|c|c|}
\hline Variable & Variable Description & Type & $\underline{\mathbb{N}}$ \\
\hline Placement & $\begin{array}{l}\text { Placenent in a special education, remedial, } \\
\text { grade retention or no placement }\end{array}$ & criterion & 231 \\
\hline Teacher ratings(1st) & $\begin{array}{l}\text { First grade teacher rating of success: } \\
\text { successful, not successful }\end{array}$ & criterion & 184 \\
\hline Reading score & $\begin{array}{l}\text { Gates-HacGinitie Reading Test score } \\
\text { normal curve equivalents: end of 1st } \\
\text { grade adrainistration }\end{array}$ & Criterion & 185 \\
\hline Reading score(2) & $\begin{array}{l}\text { Gates-HacGinitie Reading Test Score, } \\
\text { nornal curve equivalents: end of 1st grade } \\
\text { two category: above } 25 \text { percentile and } \\
\text { below } 25 \text { percentile }\end{array}$ & Criterion & 187 \\
\hline SSRS(1st) & $\begin{array}{l}\text { School Success Rating Scale } \\
\text { for first grade }\end{array}$ & criterion & 185 \\
\hline $\operatorname{SSRS}(1 \mathrm{st})(2)$ & $\begin{array}{l}\text { School Success Rating Scale } \\
\text { for first grade: two category }\end{array}$ & Criterion & 185 \\
\hline Report card & $\begin{array}{l}\text { Pirst grade report card scores composited } \\
\text { to two category: successful, not successful }\end{array}$ & criterion & 181 \\
\hline Performance & $\begin{array}{l}\text { Sunmated student performance score nade up } \\
\text { of lst grade teacher rating, SSRS: 1st grade, } \\
\text { reading NCE and repcrt card. Two category: } \\
\text { successful, not successful }\end{array}$ & Criterion & 165 \\
\hline
\end{tabular}


This chapter is a presentation of the data collected and an analysis of that data as they relate to the study questions presented in Chapter I. It also provides a general overview of the descriptive data, and then addresses the six study questions in order. The questions for study presented in Chapter I, and addressed in this chapter, are:

1. What are the correlations among the variables? (predictor, criterion, demographic)(Secondary study question)

2. Are student dirfrerences on measures of student success related to student differences in demographic variables? (Secondary study question)

3. What is the predictive accuracy of the demographic variables? (Secondary study question)

4. What is the predictive accuracy of the Preschool Screening System (administered during the fall of the kindergarten year) in identifying "student success" as measured by the criterion variables?

5. What is the predictive accuracy of the kindergarten teacher ratings, of the School Success Rating Scale (klndergarten administration), and the Gates-MacGinitie Reading Tests (administered during the fall of the firstgrade year) in identifying "student success" as measured by the criterion variables? 
6. Which combination of predictor variables

determines the most accurate identification rate of sensitivity and specificity for at-risk children?

DESCRIPTIVE DATA OVERVIEW

The Preschool Screening System was administered to 181 kindergarten students within the first month of their formal schooling career. The students ranged in age from 60 to 79 months. Due to family mobility, only 128 students completed the two-year study, from entry into kindergarten to the close of first grade in the Washougal School District (indicating an exit mobility rate just under 30 percent during the two-year period). An additional 60 students entered the district during the time frame of my study, thus a total of 113 students had partial sets of information that are included in the analysis of the data.

Table $\mathrm{X}$ presents the number of students served by each of the kindergarten and first-grade teachers. The numbers served ranged from a low of 18 to a high of 31 . No classroom exceeded 26 students at any given time during the two years. Those teachers with higher numbers served reflected higher mobility of children within their classrooms. Teachers with numbers averaging below 20 reflect average class sizes within one of the elementary schools included in this study. 
TABLE X

CLASS SIZE BY GRADE-LEVEL AND TEACHER

\begin{tabular}{|c|c|c|c|}
\hline Grade Level & Teacher & $\underline{\mathbf{N}}$ & Percent \\
\hline \multirow[t]{7}{*}{ Kindergarten } & 1 & 28 & 14.21 \\
\hline & 2 & 28 & 14.21 \\
\hline & 3 & 26 & 13.20 \\
\hline & 4 & 31 & 15.75 \\
\hline & 5 & 31 & 15.74 \\
\hline & 6 & 27 & 13.71 \\
\hline & $\underline{7}$ & 26 & 13.20 \\
\hline Total & 7 & 197 & 100.00 \\
\hline \multirow[t]{8}{*}{ First grade } & 1 & 29 & 13.68 \\
\hline & 2 & 29 & 13.84 \\
\hline & 3 & 19 & 8.96 \\
\hline & 4 & 18 & 8.49 \\
\hline & 5 & 31 & 14.62 \\
\hline & 6 & 28 & 13.21 \\
\hline & 7 & 29 & 13.68 \\
\hline & $\underline{8}$ & 29 & 13.68 \\
\hline Total & 8 & 212 & 100.00 \\
\hline
\end{tabular}

Note: Actual percentages total slightly more than 100 percent due to rounding of decimals. 
Approximately 55 percent of the total student population studied was male and 45 percent was female. Fifty-seven percent lived with their two natural parents, while 43 percent lived in other types of family arrangements, including blended families, one-parent homes, foster care placements, and/or with other relatives. Nearly 40 percent qualified for free or reduced lunch. The mean age at kindergarten entry was 67.4 months with approximately equal numbers of students found in the older and younger categories (50 and 48, respectively). However, 76 percent of the students (38) in the 72-month or older category were boys. This imbalance suggests that any effect by age could actually be an effect by sex, or vice versa, i.e., the effects of age and sex are confounded.

Table XI highlights the demographic variables by the number of students within a sub-category count (e.g., male and female), sub-category percentage of the total category, and total category "N" count. I further reported in this table a breakdown of the number of males and females falling into each of the age categories of younger, average, and older. This breakdown further highlights the finding of higher numbers of boys as compared to girls in the "older" category. 
TABLE XI

DEMOGRAPHIC VARIABLES BY SUBCATEGORY COUNTS AND PERCENTAGES

\begin{tabular}{|c|c|c|c|c|}
\hline Variable & \multicolumn{2}{|l|}{ Category } & $\underline{\mathrm{N}}$ & Percent \\
\hline Sex & \multicolumn{2}{|l|}{$\begin{array}{l}\text { Male } \\
\text { Female }\end{array}$} & $\begin{array}{l}133 \\
108\end{array}$ & $\begin{array}{l}55.18 \\
44.81\end{array}$ \\
\hline Parents & \multicolumn{2}{|c|}{$\begin{array}{l}\text { Not natural parents } \\
\text { Natural parents }\end{array}$} & $\begin{array}{l}104 \\
137\end{array}$ & $\begin{array}{l}43.15 \\
56.85\end{array}$ \\
\hline Lunch & \multicolumn{2}{|c|}{$\begin{array}{l}\text { Free/reduced lunch } \\
\text { Regular lunch }\end{array}$} & $\begin{array}{r}94 \\
143\end{array}$ & $\begin{array}{l}39.66 \\
60.34\end{array}$ \\
\hline Age (3) & $\begin{array}{l}72 \text { plus } \\
64-71 \\
60-63\end{array}$ & $\begin{array}{l}\text { Months } \\
\text { Months } \\
\text { Months }\end{array}$ & $\begin{array}{r}50 \\
143 \\
48\end{array}$ & $\begin{array}{l}20.75 \\
59.34 \\
19.92\end{array}$ \\
\hline Male age(3) & $\begin{array}{l}72 \text { Plus } \\
64-71 \\
60-63\end{array}$ & $\begin{array}{l}\text { Months } \\
\text { Months } \\
\text { Months }\end{array}$ & $\begin{array}{l}38 \\
73 \\
22\end{array}$ & $\begin{array}{l}28.57 \\
54.89 \\
16.54\end{array}$ \\
\hline Female age( 3 ) & $\begin{array}{l}72 \text { Plus } \\
64-71 \\
60-63\end{array}$ & $\begin{array}{l}\text { Months } \\
\text { Months } \\
\text { Months }\end{array}$ & $\begin{array}{l}12 \\
70 \\
26\end{array}$ & $\begin{array}{l}11.11 \\
64.81 \\
24.07\end{array}$ \\
\hline
\end{tabular}

Note: As indicated in Table XII the mean age in months was 67.4 .

Means and standard deviations for data collected in interval and ratio scales are listed in Table XII. The Preschool Screening Test had a raw score mean of 55.1 and a standard deviation of 12.4. The School Success Rating scale (kindergarten) had a mean of 179.0 and a standard deviation of 46.9. The School Success Rating Scale (first grade) scores had a mean of 194.0 and a standard deviation of 44.6 . 
TABLE XII

MEANS AND STANDARD DEVIATIONS FOR INTERVAL DATA

\begin{tabular}{llcccc}
\hline \hline Variable & Type of Variable & $\underline{N}$ & Range & Hean & SD \\
\hline Screening test & Predictor & 181 & $22-80$ & 55.14 & 12.41 \\
SSRS(K) & Predictor & 169 & $14-240$ & 179.00 & 46.86 \\
Reading readiness & Predictor & 188 & $2-99$ & 42.46 & 19.37 \\
SSRS(1st) & Criterion & 185 & $18-240$ & 194.00 & 44.61 \\
Reading score & Criterion & 187 & $1-99$ & 38.51 & 22.13 \\
Age & Denographic & 241 & $60-79$ & 67.44 & 2.31 \\
\hline \hline
\end{tabular}

Normal curve equivalents (NCE) from the fall

administration of the Gates-MacGinitie Reading Readiness Tests had a mean of 42.5 and a standard deviation of 19.4 . Normal curve equivalents from the spring administration of the Gates-MacGinitie had a mean of 38.5 and a standard deviation of 22.1. When compared to the norming population, the fall to spring drop in the NCE mean scores indicate a loss in relative position of reading achievement for the Washougal students. Interestingly, while the mean NCE score dropped, the variation (SD) within the students increased and the range remained the same (1-99). This would suggest increasingly wider skill differences between students within the heterogenous classrooms at the second grade level.

Review of Table XIII showed that the potential number of at-risk children varied widely, 
TABLE XIII

CRITERION VARIABLE DISTRIBUTION

IN TWO-CATEGORY ORDINAL SCALE

\begin{tabular}{llrrr}
\hline \hline Variable & Category & Count & Percent & $\underline{\underline{N}}$ \\
\hline & & 40 & 17.32 & 231 \\
Placement & Special placement & 191 & 82.68 & \\
& No placement & 39 & 21.20 & 184 \\
Placement by students & Special placement & 145 & 78.80 & \\
enrolled at end of 1st grade & No placement & 51 & 27.72 & 184 \\
& Not successful & 133 & 72.28 & \\
Teacher rating(1st) & Successful & 29 & 15.68 & 185 \\
& 1SD below mean & 156 & 84.32 & \\
SSRS(1st)(2) & Above 1SD below mean & 80 & 44.94 & 178 \\
& Below 25th percentile & 90 & 55.06 & \\
Reading score(2) & Above 25th percentile & & & \\
& Avg. score below 1.5 & 34 & 18.75 & 181 \\
Report card & Avg. score 1.5 and above & 147 & 81.22 & \\
& 1SD below nean & & & \\
Performance & Above 1SD below mean & 141 & 85.45 & 165 \\
& & & & \\
\hline \hline
\end{tabular}

depending upon the specific variable reviewed. The overall percentage of students with special placements was 17.3 percent (40 out of 231 recorded placements). However, because the students that left the district were not tracked, It is likely that the number of specially placed students was actually higher than reported in this study. This supposition is supported in that 39 of the 40 students identified as special placements (from the total $\underline{N}=241$ ) were still in district at the end of first-grade. The 39 placed students still within the district at the end of first grade 
would represent 21.2 percent of the student population ( $\underline{N}=184$ ) within the district at the end of first grade. Additionally, it does not seem statistically logical that all except one of the students leaving the district would be non-placed students (especially given the 30 percent exit mobility rate).

The percent of students whose performance score indicated concern was 14.6 percent, arid their report card score placed 18.8 percent at-risk; other measures indicated less favorable outcomes. Forty-four and nine tenths percent of the students scored in the lower qulartile of the GatesMacGinitie, and 27.7 percent were considered not successful by their first-grade teacher.

Typical special placement procedures require a perception that a student be at-risk (having academic difficulty), and that the student havel some objective measure or indicator of below average performance (a test score). Thus, it would seem logical to conclude that students scoring in the at-risk categories on both of these measures (teacher ratings and reading score), but not currently placed in special programs, would be the most atrisk group of non-placed students. Given high numbers in the at-risk $\mid$ category $\mid$ for both teacher ratings (51) and reading score $(80)$, it is my assumption that the placement rate will go higher as the students move through grade two. 


\section{SECONDARY STUDY QUESTIONS}

This section of Chapter IV addresses my findings related to the three secondary study questions. I have included the study's secondary questions to give background and clarity to the study's primary study questions.

\section{Correlations Among Variables}

Question 1 asked for the correlations among the study's variables. To address this question, Pearson's product moment, Kendall's tau-b, and phi correlational analysis. procedures were used as appropriate.

Phi correlations between the demographic variables are reported in Table XIV. Two statistically significant though weak relationships were found: the correlation between age and $\operatorname{sex}(\underline{x}=.22 ; p \leq .001)$ and the correlation between parent marital status and income $(\underline{\underline{r}}=.21 ; p \leq .01)$. Boys tended to be older than girls, and students from families with two natural parents tended not to be eligible for free or reduced lunch.

Table XV further highlights the significant demographic variable relationships. Adding particular clarity to the age/sex relationship is the percent of boys to girls in the older category. Over 28 percent of the boys fall into this category compared to slightly more than 11 percent of the girls. The relationship between parent marital status and income (free and reduced lunch) is clarified in identifying 
TABLE XIV

PHI CORRELATIONS AMONG DEMOGRAPHIC VARIABLES

\begin{tabular}{llcll}
\hline \hline Variable & Sex & Age (3) & Parents & Lunch \\
\hline Sex & 1.000 & & & \\
Age (3) & $.215 * *$ & 1.000 & & \\
Parents & -.069 & .124 & 1.000 & \\
Lunch & -.079 & .014 & $.208 *$ & 1.000 \\
\hline \hline $\begin{array}{l}\text { * Significant at p } .001 . \\
\text { * Significant at p } .01 .\end{array}$ & & & \\
\end{tabular}

TABLE XV

SUBCATEGORY SUB-GROUP COMPARISONS FOR DEMOGRAPHIC VARIABLES WITH SIGNIFICANT CORRELATIONS

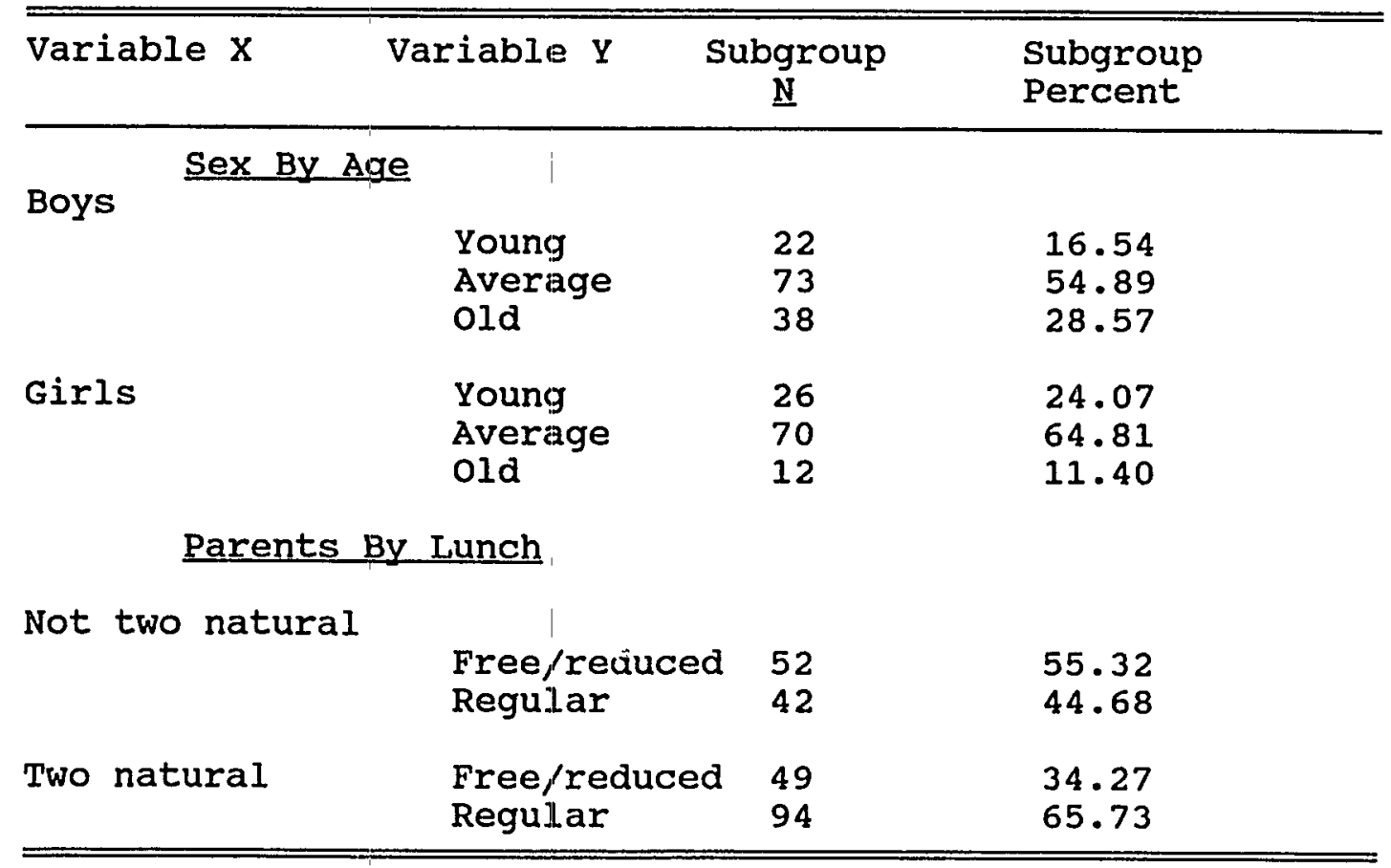


that 55 percent of the children from families with other than two natural parents are eligible for free and reduced lunch, with only 34 percent of the children from homes with two natural parents qualifying for subsidized lunches.

Table XVI reports Pearson product moment correlations among the predictor variables. Correlations ranged from a low of .39 between the school success Rating scale (kindergarten) and the Gates-MacGinitie Reading Readiness Test (first-grade, fall administration) to a high of .62 found between the Preschool Screening System (PSS) and kindergarten teacher ratings.

TABLE XVI

CORRELATIONAL MATRIX FOR PREDICTOR VARIABLES

\begin{tabular}{lllll}
\hline \hline & & \multicolumn{2}{c}{ Predictor } & \\
\hline Criterion & Screening Test & SSRS(K) & Reading Readiness & Teacher Ratings \\
\hline Screening Test & 1.000 & & & \\
SSRS(K) & .475 & 1.000 & & \\
Reading Readiness & .562 & .386 & 1.000 & 1.000 \\
Teacher Ratings(K) & $.621(.383)$ & $.581(.506)$ & $.540(.452)$ & \\
\hline \hline
\end{tabular}

Kendall tau-b correlation ().

All significant at the $\mathrm{p}<.001$ level.

It is important to subsequent discussion to note that the PSS and Kindergarten Teacher Ratings had the strongest predictor to predictor relationship. All predictor to 
predictor relationships were statistically significant at the $\mathrm{p} \leq .001$ level. Though highly significant, the magnitude of the correlations were low to moderate, suggesting the possibility of limited reliability of the predictors, or that the predictors measure different factors. In addition to the Pearson's product moment correlations, Kendall's taub correlations are reported in parentheses in Table XVI for kindergarten teacher ratings, which is more appropriately treated as an ordinal scale. These tau-b correlations were also significant at the $\mathrm{p} \leq .001$ level.

Table XVII displays phi correlations between the criterion variables. The correlations ranged from a low of . 21 between program placement and the School success Rating Scale to a high of .84 between report card grade and student performance. The low correlation between program placement and the School Success Rating Scale (1st Grade) suggests a minimal relationship between those items on the scale and the criterion used by the district to place students in special programs. However, all of the other criterion variables had a weak relationship with program placement, the highest of which was teacher ratings at .43 .

I had expected a stronger relationship between program placement and the criterion variables (variables commonly associated with special program placement). A cursory review of the correlations could imply that students are placed in special programs as a composite of several factors 
(teacher perception, reading level, report card grades, and ability to perform routines) with no single factor of particular importance, or that they are placed for reasons other than those of analysis in this study.

TABLE XVII

CORRELATIONAL MATRIX FOR CRITERION VARIABLES

Placenent Teacher Rating(1ST) Reading R\& diness Report Card Performance SSRS(1st)

Placenent $\quad 1.000$

Teacher Rating(1st).429

1.000

Reading Score(2) $\quad .340$

.451

1.000

Report card $\quad .376$

.515

.478

1.000

Performance $\quad .376$

.620

.458

$.840 \quad 1.000$

$\operatorname{SSRS}(1 S T)(2)$

$.213 *$

.387

.266

.387

.546

1.000

Note: All significant at $p \leq .001$ except as indicated by *. * significant at $p \leq .002$.

Student performance correlations with the criterion variables (except placement) were moderate to strong in magnitude (.46 to .84$)$. The reader is reminded that this was expected in that performance is an aggregate variable, summed from all criterion variables except placement. The Gates-MacGinitie Reading Readiness Test had moderate strength relationships (.45 to .48$)$ with teacher ratings, report card, and student performance. The School Success Rating Scale (first grade) also had moderate strength 
relationship (.39 to .55) with teacher ratings, report card, and student performance. However, these two measures (SSRS and reading readiness) correlated with each other at only .27, suggesting that they measure different factors, both of which relate to the other criterion variables. This can possibly be explained in that the Gates-MacGinitie measures reading (as defined by the authors) while the SSRS(1st) measures the students' ability to follow routines. Both of these variables could influence a teacher's perception, which in turn could affect ratings of success, report card, and the aggregate variable of student performance, and do so without having to be directly related to each other.

Table XVIII presents Pearson's product moment correlations and Kendall's tau-b correlations between predictor and criterion variables. With one exception ( $\mathrm{p} \leq .01)$, all of these correlations are statistically significant at the $\mathrm{p} \leq .001$ level. The Preschool Screening System correlated highest with the Gates-MacGinitie Reading Test (.54). The PSS correlated with Program Placement at a magnitude of .30. The predictor, School Success Rating Scale (kindergarten), correlated .52 with the School Success Rating Scale (1st Grade) and correlated at .29 with program placement. Teacher ratings from kindergarten had $a$ tau-b correlation of .45 with first grade teacher rating. The highest tau-b correlations with program placement reported was with teacher ratings $(.31)$ and reading readiness $(.30)$. 
TABLE XVIII

CORRELATIONS BETWEEN PREDICTOR AND CRITERION VARIABLES

\begin{tabular}{lllll}
\hline & \multicolumn{4}{c}{ Predictor } \\
\cline { 2 - 5 } Criterion & $\begin{array}{c}\text { Preschool Screening Systen } \\
\text { Raw Score }\end{array}$ & $\begin{array}{c}\text { Student Success Rating Scale } \\
\text { Total Rindergarten }\end{array}$ & $\begin{array}{c}\text { Teacher Rating } \\
\text { Rindergarten }\end{array}$ & $\begin{array}{c}\text { Gates-Kaccinitie rall } \\
\text { Reading Readiness }\end{array}$ \\
\hline Placement & $.304(.251)$ & $.287(.246)$ & $.327(.313)$ & $.355(.299)$ \\
Teacher Rating(1st) & $.394(.394)$ & $.442(.377)$ & $.475(.452)$ & $.381(.332)$ \\
Perfornance & $.419(.352)$ & $.323(.268)$ & $.305(.290)$ & $.286(.294)$ \\
Report Card & $.515(.427)$ & $.355(.297)$ & $.362(.346)$ & $.313(.298)$ \\
Reading Score & .540 & .332 & $.556(.350)$ & .697 \\
SSRS (1st) & .319 & .515 & $.410(.378)$ & $.217 \mathrm{~K}$ \\
\hline \hline
\end{tabular}

Note: Pearson product moment correlations with Kendall's tau-b reported in ( ).

All significant at $p \leq .001$ except as noted by *. * significant at $\mathrm{p} \leq$. 01 level.

Thus, we can predict at this point that either teacher ratings or the Gates-MacGinitie Reading Readiness Test will be the best single predictor of program placement. The Gates-MacGinitie fall NCE scores correlated with the School Success Rating Scale (first grade) at only .22 , the weakest of the predictor/criterion variable relationships. This low correlation is not unexpected in that the GatesMacGinitie is measuring academic achievement while the School Success Rating Scale (first grade) is measuring the ability to follow social routines. The remainder of the correlations are weak to moderate, implying at this stage of 
analysis that no single study predictor will provide an adequate prediction rate ( 80 percent specificity and sensitivity) for students placed in special programs.

Table XIX presents correlations between the demographic variables and the criterion variables. The significant phi correlations are: sex with report card (.15) and teacher rating (.23); age with program placement (.24), teacher rating (.23), and School success Rating Scale (.27); and lunch with report card (.16), teacher ratings (.15), and School success Rating Scale (.18). These significant correlations are weak, but suggest potential differences on criterion performance within the demographic variable subgroups.

TABLE XIX

PHI CORRELATIONS FOR DEMOGRAPHIC TO CRITERION VARIABLES

\begin{tabular}{|c|c|c|c|c|c|c|}
\hline \multirow{2}{*}{$\begin{array}{l}\text { CRITERIOH VARIABLRS } \\
\text { Desographic Variable }\end{array}$} & \multirow[b]{2}{*}{ Placenent } & \multirow[b]{2}{*}{ Perfornance } & \multirow[b]{2}{*}{ Report Card } & \multirow[b]{2}{*}{ Teacher Rating } & \multirow[b]{2}{*}{ Reading Score(2) } & \multirow[b]{2}{*}{$\operatorname{SSRS}(1 \mathrm{st})(2)$} \\
\hline & & & & & & \\
\hline Sex & .088 & .135 & $.154 \pm$ & $.231 \mathrm{kt}$ & .123 & .097 \\
\hline Parent & -.038 & .005 & .030 & .140 & .089 & .078 \\
\hline $\operatorname{lgg}(3)$ & $.239 \$ \$$ & .143 & .034 & .2344 & .095 & $.265 \pm 4$ \\
\hline Lunch & .105 & .134 & $.162 \star$ & $.151 *$ & .114 & $.181 *$ \\
\hline $\begin{array}{r}* * * \text { Signifi } \\
\text { ** Signifi } \\
\text { * Signifi }\end{array}$ & ant a & $\begin{array}{l}p \leq \\
p \leq \\
p \leq\end{array}$ & & & & \\
\hline
\end{tabular}


This indication of relationship leads dirsctly to Study Question 2, where I looked for differences in criterion variable performance as the result of differences between demographic variable sub-groups.

\section{Student Differences by Demographic Variable}

Question 2 asked, "Are student differences on measures of student success related to student differences in demographic variables?" I conducted one-way analysis of variance tests for the School success Rating Scale (first grade) and the Gates-MacGinitie Reading Test (spring administration) with the demographic variables of age, sex, parent marital status and lunch. Table XX reports the Fratios and probability for the individual analysis of variance tests. Significant differences were found for age ( $p \leq .015$ ) on the School Success Rating Scale, and for lunch on the Gates-MacGinitie (spring administration) ( $p \leq .04)$. The significant relationships noted in Table $\mathrm{XX}$ are further clarified in Table XXI. This table presents means and standard deviations for the School Success Rating Scale (first grade) and the Gates-MacGinitie Reading Test (spring) for those demographic variable subgroups reporting significant differences. Cursory examination of the means indicate that older students were rated lower on the School Success Rating Scale (mean=171.3) than younger students (mean=206.6). 
TABLE XX

TEST OF SIGNIFICANCE FOR DEMOGRAPHIC VARIABLES USING ANALYSIS OF VARIANCE

\begin{tabular}{|c|c|c|c|c|c|c|c|}
\hline \multicolumn{2}{|c|}{ Variables } & \multirow{2}{*}{ Source } & \multirow[t]{2}{*}{ SS } & \multirow[t]{2}{*}{$\mathrm{OF}$} & \multirow{2}{*}{ MS } & \multirow{2}{*}{$\underline{E}$} & \multirow[t]{2}{*}{$\mathrm{P}$} \\
\hline Denographic & Criterion & & & & & & \\
\hline $\operatorname{Age}(3)$ & SSRS(1st) & $\begin{array}{l}\text { Between } \\
\text { Within }\end{array}$ & $\begin{array}{r}16505.770 \\
346371.599\end{array}$ & $\begin{array}{c}2 \\
181\end{array}$ & $\begin{array}{l}8252.885 \\
1913.655\end{array}$ & 4.313 & $.015 k$ \\
\hline $\operatorname{lgg}(3)$ & Reading score & $\begin{array}{l}\text { Between } \\
\text { hithin }\end{array}$ & $\begin{array}{r}148.337 \\
90906.380\end{array}$ & $\begin{array}{c}2 \\
184\end{array}$ & $\begin{array}{r}74.168 \\
494.056\end{array}$ & 0.150 & .861 \\
\hline Sex & SSRS(1st) & $\begin{array}{l}\text { Between } \\
\text { within }\end{array}$ & $\begin{array}{r}7533.820 \\
33532.550\end{array}$ & $\begin{array}{c}1 \\
182\end{array}$ & $\begin{array}{l}7553.820 \\
1952.327\end{array}$ & 3.896 & .051 \\
\hline Sex & Reading score & $\begin{array}{l}\text { Between } \\
\text { within }\end{array}$ & $\begin{array}{r}1764.448 \\
89290.269\end{array}$ & $\begin{array}{c}1 \\
185\end{array}$ & $\begin{array}{r}1764.448 \\
482.650\end{array}$ & 3.656 & .057 \\
\hline Lunch & SSRS(1st) & $\begin{array}{l}\text { Betrieen } \\
\text { Within }\end{array}$ & $\begin{array}{r}5649.788 \\
356417.731\end{array}$ & $\begin{array}{c}1 \\
181\end{array}$ & $\begin{array}{l}5649.788 \\
1969.159\end{array}$ & 2.869 & .092 \\
\hline Lunch & Reading score & $\begin{array}{l}\text { Betreen } \\
\text { within }\end{array}$ & $\begin{array}{r}1992.447 \\
89019.967\end{array}$ & $\begin{array}{c}1 \\
184\end{array}$ & $\begin{array}{l}992.447 \\
483.804\end{array}$ & 4.118 & $.044 k$ \\
\hline Parent & SSRS(1st) & $\begin{array}{l}\text { Between } \\
\text { Hithin }\end{array}$ & $\begin{array}{r}4222.970 \\
358654.400\end{array}$ & $\begin{array}{c}1 \\
182\end{array}$ & $\begin{array}{l}4222.970 \\
1970.629\end{array}$ & 2.143 & .145 \\
\hline Parent & Reading score & $\begin{array}{l}\text { Between } \\
\text { hithin }\end{array}$ & $\begin{array}{r}1528.357 \\
89526.342\end{array}$ & $\begin{array}{c}1 \\
185\end{array}$ & $\begin{array}{r}1528.375 \\
483.926\end{array}$ & 3.158 & .077 \\
\hline
\end{tabular}

liote: * Indicates significant difference. 
TABLE XXI

MEANS, STANDARD DEVIATIONS, AND RANGES FOR DEMOGRAPHIC SUBGROUPS HAVING SIGNIFICANT DIFFERENCES ON THE SCHOOI SUCCESS RATING SCALE AND THE GATES-MACGINITIE READING TEST

\begin{tabular}{llrrrr}
\hline \hline $\begin{array}{l}\text { Criterion } \\
\text { Variable }\end{array}$ & $\begin{array}{l}\text { Derographic } \\
\text { Subgroup }\end{array}$ & $\mathbb{N}$ & Range & Mean & $\begin{array}{l}\text { Standard } \\
\text { Deviation }\end{array}$ \\
\hline SSRS-1st Grade & Age (Younger) & 35 & $143-240$ & 206.571 & 32.128 \\
SSRS-1st Grade & Age (Average) & 172 & $23-240$ & 196.598 & 41.697 \\
SSRS-1st Grade & Age (Older) & 37 & $18-240$ & 171.324 & 57.320 \\
& & & & & \\
Reading Score & Lunch (Rree/Reduced) & 21 & $1-99$ & 34.860 & 22.33 \\
Reading Score & Lunch (Regular) & 116 & $1-99$ & 40.750 & 21.79 \\
& & & & & \\
\hline \hline
\end{tabular}

Students with free or reduced lunch (mean=34.9), as a group, scored lower on the Gates-MacGinitie than students from families with incomes not qualifying for subsidized lunches (mean=40.8). These data suggest that older students, from lower income families, are more at-risk than other subgroups within this study. Because of the numbers of males in the older group (Table XI), I suspect that older males from low-income families are more at-risk than other groups. This conclusion is generally supported by the literature on at-risk populations.

of noteworthiness, the standard deviations were consistently higher for all subgroups having the lowest means (indicating more variance among the lower scoring subgroups) .

Chi square tests of independence are reported for nominal and ordinal level demographic and criterion 
variables in Table XXII. I found significant differences for age with program placement ( $p \leq .001)$, SSRS ( $p \leq .002)$, and first grade teacher ratings $(p \leq .007)$; and for sex with report card and teacher ratings( $p \leq .002)$. Lunch (family income) was significantly related to the criterion variables of report card ( $p \leq .030)$ teacher ratings(1st) ( $p \leq .041)$, and first grade SSRS ( $p \leq .014)$.

The significant difference I found for reading score by lunch (Table $\mathrm{XX}$ ) was not evident when I converted reading score to a two-level ordinal scale (Table XXII).

\section{TABLE XXII}

\section{SIGNIFICANT CHI SQUARE RESULTS BETWEEN DEMOGRAPHIC VARIABLES AND CRITERION VARIABIES}

\begin{tabular}{lccc}
\hline \hline Variable & Chi Square Value & DP & Probability \\
\hline Age (3) by Placerent & 13.186 & 2 & $.001^{\star}$ \\
Age (3) by Teacher Rating(1st) & 10.071 & 2 & $.007 \star$ \\
Age (3) by SSRS(1st)(2) & 2.933 & 2 & $.002^{\star}$ \\
Sex by Report Card & 4.267 & 1 & $.039 \star$ \\
Sex by Teacher Rating(1st grade) & 9.833 & 1 & $.002 \star$ \\
Lunch by Report Card & 4.736 & 1 & $.030 \star$ \\
Lunch by Teacher Rating(1st grade) & 4.180 & 1 & $.041^{\star}$ \\
Lunch by SSRS(1st)(2) & 5.978 & 1 & $.014^{\star}$ \\
\hline
\end{tabular}

* Significant at the .05 level. 
Table XXIII assists in clarifying the direction of the significant differences indicated by the chi square tests reported in Table XXII. In this Table, I list the percent of at-risk and not-at-risk students as measured by specific criterion variables (program placement, teacher rating, and report card). As noted in the table, older students (34.7 percent) are more likely to be placed in special programs than younger (14 percent) or average (12 percent) age children. They are also more likely to be rated as "notsuccessful" by their teachers than average or young age students ( 47.4 percent to 24.6 and 16.7 percent, respectively), and more likely to be rated lower on the SSRS in ability to complete routines. Males were twice as likely as females to get lower marks on their report cards $(24.2$ percent to 12.2 percent) and by teacher ratings (36.9 percent to 16.1 percent). Similarly, students on free or reduced lunch were more likely than their "regular" lunch peers to be marked as at-risk on report cards (26.3 percent to 13.5 percent) and by teacher ratings ( 36.0 percent to 22.2 percent), and on the School Success Rating Scale (23.3 percent to 10 percent). I interpret these data to support my earlier supposition that older males from low income families are more likely to be perceived as at-risk than other students. 
TABLE XXIII

\section{DIRECTION OF SIGNIFICANT CHI SQUARE RELATIONS BETWEEN DEMOGRAPHIC AND CRITERION VARIABLES}

\begin{tabular}{|c|c|c|c|c|c|}
\hline Criterion Variable & | & $\begin{array}{l}\text { Derographic variable } \\
\text { subgroup }\end{array}$ & $\underline{\mathbb{N}}$ & $\begin{array}{l}\text { \& at-risk by criterion } \\
\text { variable score }\end{array}$ & $\begin{array}{l}\text { \& Not-at-risk by criterion } \\
\text { variable score }\end{array}$ \\
\hline Progran Placeasent & । & Age younger & 43 & 13.95 & 86.05 \\
\hline Progran Placenent & | & dge average & 139 & 12.23 & 87.77 \\
\hline Program Placeirent & I & Age older & 49 & 34.69 & 65.31 \\
\hline Teacher Ratings(1st) & ! & Age younger & 26 & 16.67 & 83.33 \\
\hline Teacher Ratinogs(1st) & ! & Age average & 110 & 24.55 & 75.45 \\
\hline Teacher Ratings(1st) & ! & Age older & 38 & 47.37 & 52.63 \\
\hline $\operatorname{SSRS}(1 s t)(2)$ & । & Age younger & 35 & 2.86 & 97.14 \\
\hline $\operatorname{SSRS}(1 \mathrm{st})(2)$ & । & Age average & 115 & 13.39 & 86.61 \\
\hline $\operatorname{SSRS}($ Ist)(2) & । & Age older & 37 & 32.43 & 67.57 \\
\hline Report Card & । & Sex (rale) & 99 & 24.24 & 75.76 \\
\hline Report Card & 1 & Sex (ferale) & 82 & 12.20 & 87.80 \\
\hline Teacher Ratings(1st) & & Sex (nale) & 103 & 36.87 & 63.11 \\
\hline Teacher Ratings(Ist) & & Sex (fenale) & 81 & 16.05 & 83.95 \\
\hline Report Card & | & Iunch (free/reduced) & 76 & 26.32 & 73.68 \\
\hline Report Card & I & Lunch (regular) & 104 & 13.54 & 86.54 \\
\hline Teacher Ratings(1st) & & Lunch (free/reduced) & 75 & 36.00 & 64.00 \\
\hline Teacher Ratings(1st) & & Lunch (regular) & 108 & 22.22 & 77.78 \\
\hline $\operatorname{SSRS(1st)(2)}$ & | & Lunch (free/reduced) & 73 & 23.29 & 76.71 \\
\hline $\operatorname{SSRS(1st)(2)}$ & | & Lunch (regular) & 110 & 10.00 & 90.00 \\
\hline
\end{tabular}


Thus, Study Question 2 is answered in that there was a significant effect by: sex with the report card and teacher rating (first grade); age with the School success Rating scale (first grade), program placement, teacher rating (first grade); and lunch with the Gates-MacGinitie Reading Test (spring administration), report card, teacher rating (first grade), and School Success Rating Scale. These findings correspond to the significant correlations reported between demographic and criterion variables in Table XIV (plus adding lunch with reading score).

Discriminant Analysis, Sensitivity, and Specificity: Model Explanatjon

Before addressing questions three through six, some discussion of discriminant analysis, sensitivity, and specificity is warranted. I intend for this discussion to provide improved clarity and ease in reading the tables related to answering questions three through six.

Discriminant analysis is a statistical method that attempts to distinguish between two or more groups. To discriminate between the groups, data are collected on a set of variables that measure characteristics on which the groups are expected to differ (e.g., a student at-risk of school failure should differ from not-at-risk students on reading test scores). In my study, variables were collected that were presumed to distinguish between successful (notat-risk students) and unsuccessful (at-risk) students. The 
procedure seeks to find a single dimension on which the two groups cluster separately. Discriminant analysis attempts this outcome by forming one or more linear combinations of the discriminating variables. This procedure is similar to a multiple regression equation, but with a cut-off score for inclusion or exclusion rather than a continuum of scores. Thus the process of discriminant analysis is to identify a single variable or a set of variables that provide satisfactory levels of discrimination for cases with known group memberships. This information can then be used to predict future group membership.

Hypothetically, if we find measures that do well in classifying whether or not a student has a special class placement, we should be able to use this information to predict the likelihood of similarly scoring students being placed in special programs in the future. To check the adequacy of the discriminant functions related to my predictors, I compared students classified by the criterion variables with the predictions to determine the percentage of agreement. This comparison reflects overall accuracy or agreement between prediction and classification for each criterion variable. Where the overall agreement met or exceeded 80 percent, sensitivity and specificity were analyzed.

To conduct these comparisons a 2-by-2 crosstab format was used (illustrated in Figure 2). 


\begin{tabular}{|c|c|c|c|}
\hline \multirow[b]{2}{*}{$\begin{array}{l}\text { Student classified at-risk } \\
\text { criterion variable cutoff } \\
\text { students }\end{array}$} & $\begin{array}{l}\text { Discrininant Bquation } \\
\text { Predicts Student At-Risk }\end{array}$ & $\begin{array}{l}\text { Discrininant Bquation } \\
\text { Predicts Student Not at-Risk }\end{array}$ & \multirow[b]{2}{*}{$\begin{array}{l}\text { Row } \mathbb{N}=\text { Total } \\
\text { number of } \\
\text { students } \\
\text { classified } \\
\text { at-risk }\end{array}$} \\
\hline & $\begin{array}{l}\text { \& of agreenent: predicted } \\
\text { at-risk neasured at-risk } \\
\text { (accuracy) }\end{array}$ & $\begin{array}{l}\text { \& of disagreesent: aeasured } \\
\text { at-risk predicted not-at-risk } \\
\text { (error) }\end{array}$ & \\
\hline \multirow[t]{2}{*}{$\begin{array}{l}\text { Student classified not-at- } \\
\text { risk by criterion } \\
\text { variable cutoff }\end{array}$} & $\begin{array}{l}\quad \text { I } \\
\text { \& of disagreenent: predicted } \\
\text { at-risk reasured not-at-risk } \\
\text { (error) }\end{array}$ & $\begin{array}{l}\text { \& of agreenent: predicted not- } \\
\text { at-risk neasured not-at-risk } \\
\text { (accuracy) }\end{array}$ & $\begin{array}{l}\text { Ror } \underline{N}=\text { Total } \\
\text { number of } \\
\text { students } \\
\text { classified } \\
\text { not-at-risk }\end{array}$ \\
\hline & $\begin{array}{l}\text { Colun } \underline{\mathbb{H}}=\text { = Total number of } \\
\text { students predicted at-risk }\end{array}$ & $\begin{array}{l}\text { Column } \underline{N}=\text { Iotal Number of } \\
\text { students predicted not-at-risk }\end{array}$ & Total 픈 \\
\hline
\end{tabular}

Figure 2. Crosstab concept for discriminant analysis. Tables addressing primary study questions are based on this concept.

Review of the figure reveals that column totals define the number of students predicted by the discriminant equation to be either at-risk or not-at-risk. The row totals define the number of students classified by the criterion variable as either at-risk or not-at-risk.

Within the crosstab concept, questions regarding prediction accuracy can be addressed. The first question deals with the percentage of agreement and disagreement within the cells bassed on the total $\underline{N}$. In this case the sum of all four cells is equal to 100 percent, and the sum of cells 1 and 4 is the total agreement rate between prediction and measurement, and the sum of cells 2 and 3 is the total error of the prediction with measurement. The tables that follow that discuss the "overall" prediction/measurement 
agreement are referring to this type of analysis. While this information is important, and reports the overall accuracy of a predictor (or predictor combination), my study seeks to also address the next level of analysis, sensitivity and specificity.

Sensitivity, as defined earlier, is the percent of students at-risk that are correctly identified by the predictor measure. However, this can be viewed two ways. First, it can be asked what percent of the students classified as at-risk (row 1 total) by the criterion measure were predicted by the discriminant equation as at-risk. In terms of the 2-by-2 crosstab format, this question indicates that the sum of cells 1 and 2 would equal 100 percent. Therefore, cell $1 \underline{\mathrm{N}}$ divided by row 1 total $\underline{\mathrm{N}}$ equals the percent of agreement for criterion variable sensitivity. Cell $2 \underline{N}$ divided by the total $\underline{N}$ of row 1 is the error percentage for criterion sensitivity.

The second way to view sensitivity is to ask what percent of the students predicted at-risk were classified by the criterion variable as at-risk. To determine the answer to this question one must take cell $1 \underline{N}$ and divide by the total $\mathbb{N}$ of column 1 . This ratio identifies the sensitivity by prediction. The percent of prediction error is determined by taking the $\underline{N}$ of square 3 and dividing that number by the total $\underline{N}$ of column 1 .

Specificity refers to the percentage of students not- 
at-risk who are correctly classified by the predictor measure. Both criterion specificity and prediction specificity are computed in similar fashion to criterion sensitivity and prediction sensitivity, by using row 2 and column 2 data (respectively).

This 2-by-2 crosstab concept for overall accuracy, criterion variable sensitivity and specificity, and for prediction sensitivity and specificity is made most clear through example. Figure 3 presents an example of a 2-by-2 crosstab in which 100 students were compared on two variables. The predictor variable identified 35 students at-risk (column 1 total). The criterion variable classified 45 students as at-risk (row 1 total) and 55 students as notat-risk (row 2 total). Dividing the number of students in each cell by the total $\underline{N}$ permits us to determine the overall accuracy.

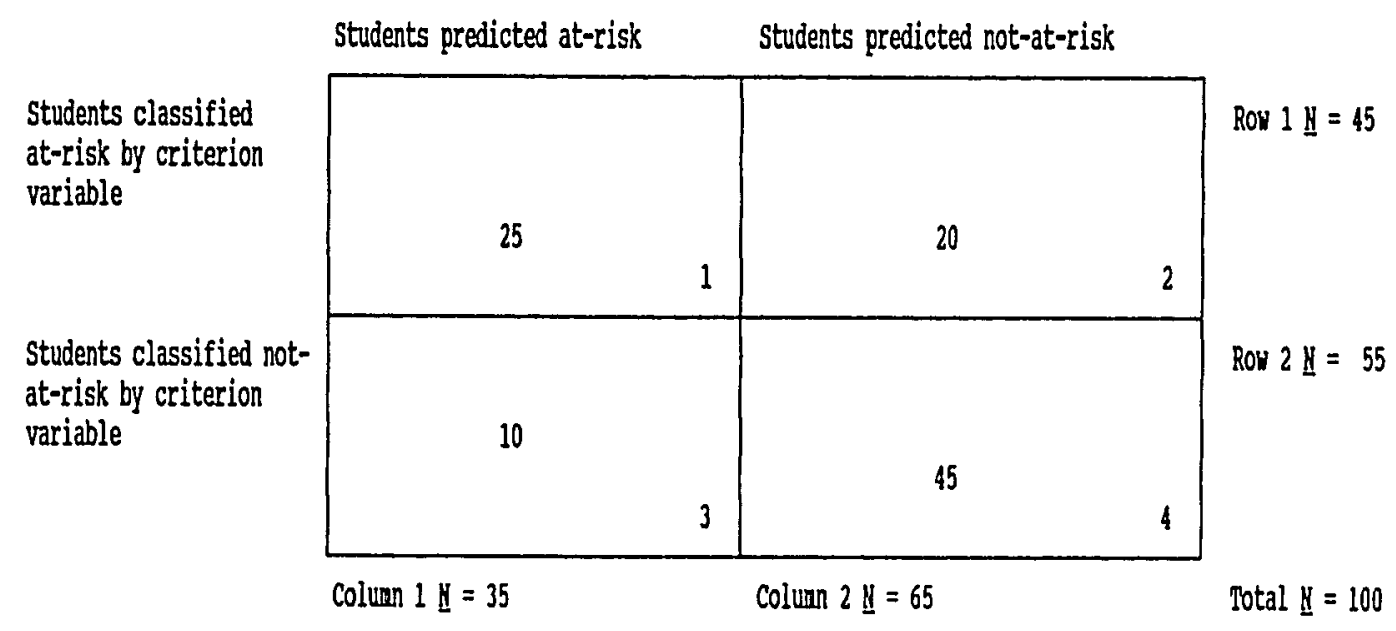

Figure 3. An example of a 2 by 2 crosstab. 
Because the example used a total $\mathbf{N}$ of 100 , the number in each cell also equals the overall percentage of each cell (illustrated in Figure 4 ).

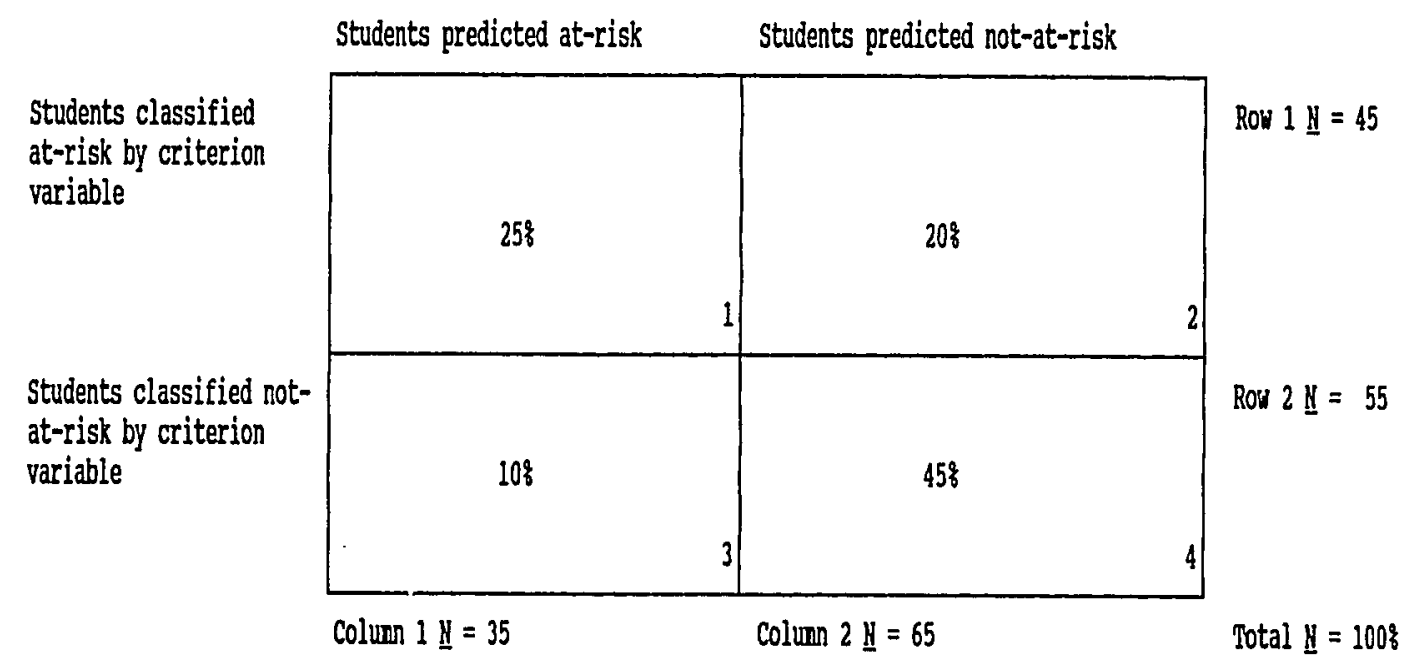

Figure 4. An example of 2 by 2 crosstab with overall prediction accuracy and error computed.

As illustrated, the percent of cell 1 added to the percent of cell 4 equals the overall total agreement between prediction and classification (70 percent). The overall error in agreement is computed by adding cells 2 and 3 together (30 percent).

To determine the criterion sensitivity I used the numbers in row 1 (Figure 3 ). Forty-five students were classified at-risk. Twenty-five of those students were predicted to be at-risk, and 20 were predicted to be notat-risk. Thus, 55.6 percent of the students classified atrisk were accurately predicted and 44.4 percent of the 
classified at-risk students were inaccurately predicted notat-risk, as illustrated in Figure 5 .

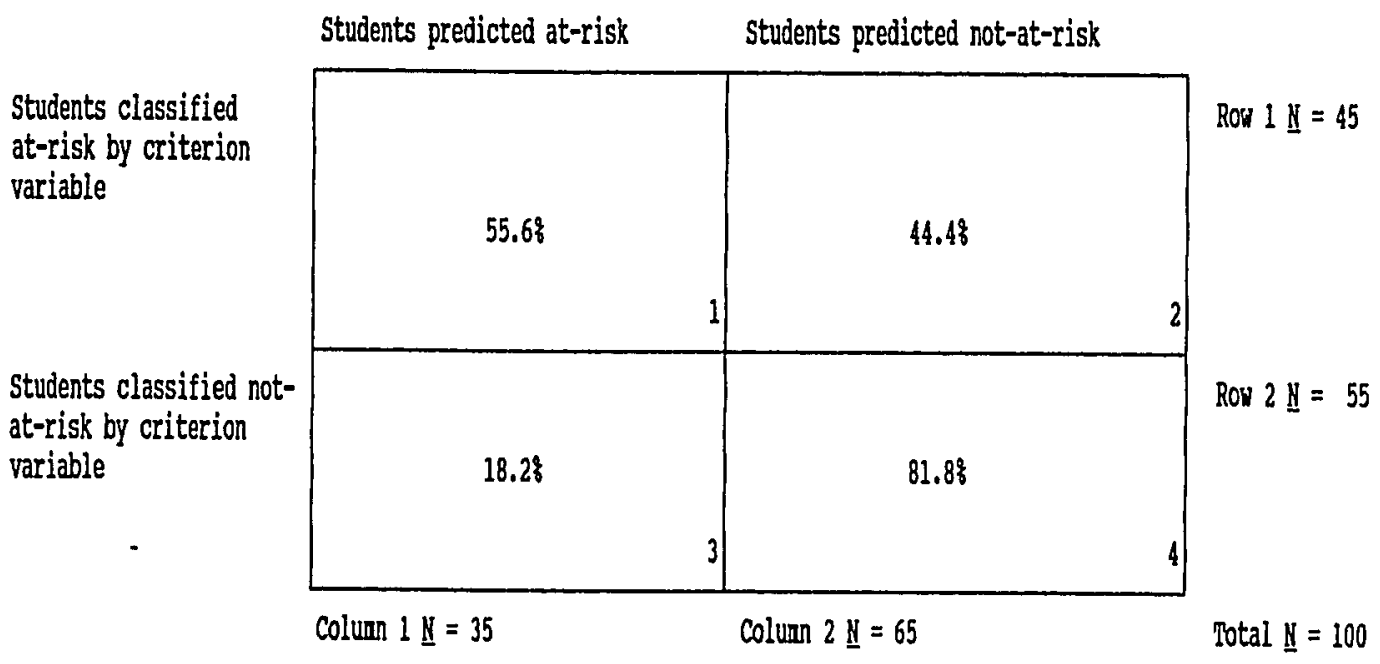

Figure 5. An example of a 2 by 2 crosstab with criterion sensitivity computed.

Looking at the prediction sensitivity, I used column 1 total from Figure 3. Thirty-five students were predicted to be at-risk, 25 were classified at-risk and 10 were classified not-at-risk. Therefore, I computed that 71.5 percent of the students predicted at-risk were classified at-risk, and 28.5 percent of the students predicted at-risk were classified not-at-risk (Figure 6.). It can therefore be concluded that 71 percent of the students predicted at risk were accurately identified (prediction sensitivity), however, only 55 percent of the students classified as at risk were predicted (criterion sensitivity).

Determination of criterion and prediction specificity would follow similar logic applied to column 2 and row 2 , 
respectively. From this example, it appears clear to me the need to discuss both criterion and prediction sensitivity and specificity as I address questions related to prediction accuracy.

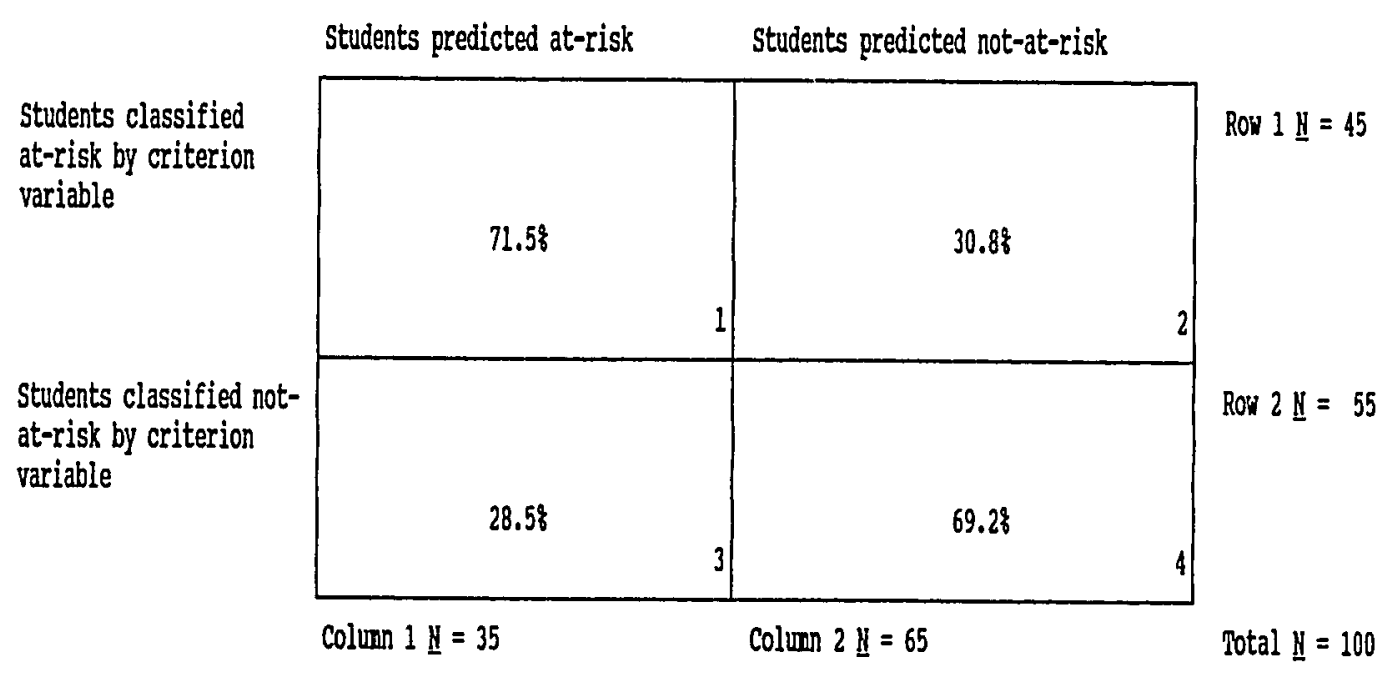

Figure 6 . An example of 2 by 2 crosstab with prediction sensitivity computed.

\section{Prediction Accuracy of Demographic Variables}

Question 3 asked, in general, how accurately do the demographic variables predict performance on the criterion variables? This question is now applicable to just those demographic and criterion variable combinations previously identified as having significant correlations (Table XIX, p. 112 ) or reporting significant differences by demographic variable subgroup (Table XXII, p. 116).

The overall predictive accuracy of the demographic variables to criterion variable ranged from a low of 53 percent to high of 78 percent. Sex, which discriminated at- 
risk from not-at-risk students, was the low prediction at 53 percent with report card scores. For discriminating at-risk from not-at-risk students, age had the highest prediction accuracy rate with a 78 percent accuracy for school success Rating Scale (1st grade), 76 percent accuracy for program placement, and a 71 percent accuracy for teacher ratings (1st grade). Lunch appears to have mild predictive accuracy rates, with 63 percent for the School success Rating scale (1st grade), 61 percent for teacher rating (1st grade), and 61 percent for report card.

Review of Table XXIV reveals that predictive accuracy increases from the 50 percent range with sex as the predictor, to the 60 percent range with family income as the predictor, to the 70 percent range with age as the predictor.

The demographic variable of age appears at this stage of analysis to have potential predictive use for program placement, School success Rating Scale (1st grade), and teacher ratings (1st grade). None of the demographic variables produced an overall identification accuracy level above 80 percent, and therefore no demographic variable has a sensitivity and specificity rate at or above the 80 percent level (See Table XXIV). Further discussion of age, sex, and lunch occurs with the analysis of question 6, which seeks to identify the most effective student at-risk identification process. 
TABLE XXIV

OVERALL ACCURACY OF THE DEMOGRAPHIC VARIABLES:

DISCRIMINANT ANALYSIS PREDICTIONS BY PERCENT OF TOTAL $\underline{\mathbf{N}}$

\begin{tabular}{|c|c|c|c|c|c|c|c|}
\hline \multirow[b]{2}{*}{$\begin{array}{l}\text { Predictor } \\
\text { by criterion } \\
\text { variable }\end{array}$} & \multicolumn{4}{|c|}{ Crosstab cell Dercents } & \multirow[b]{2}{*}{$\begin{array}{l}\text { Predictive } \\
\text { Accuracy } \\
(1+4)\end{array}$} & \multirow[b]{2}{*}{$\begin{array}{r}\text { Predictive } \\
\text { Brror } \\
(2+3)\end{array}$} & \multirow[b]{2}{*}{$\underline{\mathbb{N}}$} \\
\hline & Cell 1 & Cell 2 & Cell 3 & Cell 4 & & & \\
\hline Sex by report card & 13.26 & 2.82 & 44.14 & 39.78 & 53.04 & 46.94 & 181 \\
\hline Sex by teacher rating(1st) & 20.65 & 7.07 & 35.33 & 36.96 & 57.60 & 42.40 & 184 \\
\hline Lunch by report card & 11.11 & 7.78 & 31.11 & 50.00 & 61.11 & 38.89 & 180 \\
\hline Lunch by teacher rating(Ist) & 14.75 & 13.2 & 26.23 & 13.12 & 60.65 & 39.35 & 185 \\
\hline Iunch by SSRS(1st)(2) & 9.29 & 6.01 & $30.60^{\circ}$ & 54.10 & 63.39 & 36.61 & 183 \\
\hline Age(3) by teacher rating(1st) & 9.78 & 17.93 & 10.78 & 61.41 & 71.19 & 28.81 & 184 \\
\hline age(3) by placenent & 7.36 & 9.99 & 13.85 & 68.83 & 76.19 & 23.81 & 231 \\
\hline Age(3) by SSRS(1st)(2) & 6.52 & 8.70 & 13.59 & 71.20 & 77.77 & 22.29 & 184 \\
\hline
\end{tabular}

Cell 1: Crosstab Cell 1 \& divided by Total 1 . Predicted and classified at-risk.

Cell 2: Crosstab Cell $2 \mathbb{N}$ divided by Total N. Predicted not-at-risk, classified at-risk. Cell 3: Crosstab Cell $3 \underline{\underline{H}}$ divided by Total ․ㅡ. Predicted at-risk, classified not-at-risk. Cell 4: Crosstab Cell 4 프 divided by Total N. Predicted and classified not-at-risk.

PRIMARY STUDY QUESTIONS

I proposed three primary questions for research and analysis. The primary questions sought to identify the degree of predictive accuracy of the stated predictor variables, singularly and in combination. The central purpose of this research study was to determine whether any of the predictors or predictor combinations would produce an at-risk student identification process with a sensitivity and specificity rate at or above the 80 percent accuracy rate. 


\section{PSS Sensitivity and specificity}

Question 4 is the central question of my study and asks for the predictive accuracy of the Preschool screening System (PSS). Program placement, student performance (an aggregate variable), teacher ratings of success, the GatesMacGinitie Reading Readiness Test, report card, and the School Success Rating Scale(1st grade) are the criterion variables measuring school success.

Table XXV reports the accuracy levels of the PSS by total percent of criterion to prediction agreement. This table includes the number of students for which data were collected for both the PSS and the criterion variable, as well as the percent of total $\underline{N}$ students falling into each crosstab cell. The overall accuracy of the PSS in predicting classification on the secondary predictors is also included in the table.

Overall PSS predictive accuracy levels found in Table XXV range from a low of 65 percent for the Gates-MacGinitie Reading Test (spring NCE) to a high of 80 percent in predicting the report card average. The overall predictive rates of the PSS to criterion variables are of moderate strengths (65-80 percent range). Program Placement accuracy was 72 percent. Apparently the PSS is slightly more accurate in predicting overall student performance (79 percent) than in predicting the placement of children in special programs (district behavior). 
The PSS accuracy for predicting secondary predictor classification ranged from 74 percent with teacher rating and reading readiness to 76 percent with the school success Rating scale.

TABLE XXV

OVERALL ACCURACY OF THE PSS: BY PERCENT OF TOTAL $\underline{N}$

\begin{tabular}{|c|c|c|c|c|c|c|c|}
\hline \multirow[b]{2}{*}{ Predictor } & \multicolumn{4}{|c|}{ Crosstab cell percents } & \multirow[b]{2}{*}{$\begin{array}{c}\text { Predictive } \\
\text { Accuracy } \\
(1+4)\end{array}$} & \multirow[b]{2}{*}{$\begin{array}{c}\text { Predictive } \\
\text { Error } \\
(2+3)\end{array}$} & \multirow[b]{2}{*}{$\underline{1}$} \\
\hline & Cell 1 & Cell 3 & Cell 2 & Cell 4 & & & \\
\hline \multicolumn{8}{|l|}{ Criterion Variables } \\
\hline Progran placesent & 9.66 & 3.98 & 24.43 & 61.93 & 71.59 & 28.41 & 176 \\
\hline Performance & 10.78 & 1.54 & 19.23 & 68.46 & 79.24 & 20.77 & 130 \\
\hline Teacher rating (1st) & 19.29 & 5.71 & 20.05 & 55.05 & 74.24 & 25.76 & 140 \\
\hline Reading score (2) & 28.57 & 13.53 & 21.80 & 36.09 & 64.66 & 25.43 & 133 \\
\hline Report card & 15.22 & 2.17 & 17.39 & 65.22 & 80.44 & 19.56 & 138 \\
\hline $\operatorname{SSRS}(1 \mathrm{st})(2)$ & 10.71 & 5.00 & 27.86 & 56.43 & 67.14 & 32.86 & 140 \\
\hline \multicolumn{8}{|l|}{ Secondary Predictors } \\
\hline Teacher rating $(\mathrm{K})$ & 19.29 & 5.71 & 20.00 & 55.00 & 74.29 & 25.71 & 166 \\
\hline Reading readiness & 31.76 & 9.46 & 16.22 & 42.57 & 74.33 & 25.68 & 148 \\
\hline $\operatorname{SSRS}(\mathbb{R})$ & 11.90 & 3.57 & 20.24 & 64.29 & 76.19 & 23.81 & 168 \\
\hline
\end{tabular}

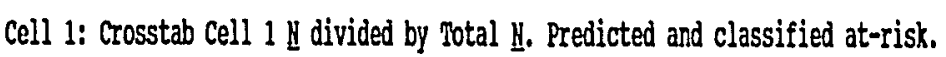

Cell 2: Crosstab Cell $2 \underline{\underline{I}}$ divided by Total $\underline{\underline{N}}$. Predicted not-at-risk, classified at-risk. Cell 3: Crosstab Cell $3 \mathbb{1}$ divided by Total ‥ Predicted at-risk, classified not-at-risk. Cell 4: Crosstab Cell 4 N divided by Total N Predicted and classified not-at-risk.

Table XXVI presents criterion sensitivity and specificity for the Preschool screening system (PSS). The reader is reminded that criterion sensitivity and specificity refers to the percent of students classified as 
TABLE XXVI

\section{ACCURACY OF THE PSS PREDICTIONS: CRITERION VARIABLE SENSITIVITY AND SPECIFICITY}

\begin{tabular}{|c|c|c|c|c|c|}
\hline Variable & $\begin{array}{l}\text { Classified at-risk } \\
\text { by criterion variable }\end{array}$ & $\begin{array}{l}\text { Classified } \\
\text { not-at-risk }\end{array}$ & Sensitivity & Specificity & $\underline{\mathbb{N}}$ \\
\hline \multicolumn{6}{|l|}{ Criterion } \\
\hline Progran & 24 & 152 & 70.87 & 71.71 & 176 \\
\hline Performance & 16 & 114 & 87.50 & 78.07 & 130 \\
\hline Teacher Rating(1st) & 35 & 105 & 77.14 & 73.33 & 140 \\
\hline Reading Score(2) & 56 & 77 & 67.86 & 62.34 & 133 \\
\hline Report Card & 24 & 114 & 87.50 & 78.95 & 138 \\
\hline $\operatorname{SSRS}(1 \mathrm{st})(2)$ & 22 & 118 & 68.18 & 66.95 & 140 \\
\hline \multicolumn{6}{|l|}{ Secondary Predictor } \\
\hline Teacher rating(K) & 28 & 138 & 82.14 & 77.54 & 166 \\
\hline Reading readiness $(2)$ & 61 & 87 & 77.05 & 72.41 & 148 \\
\hline $\operatorname{SSRS}(\mathrm{R})(2)$ & 26 & 142 & 76.92 & 76.06 & 168 \\
\hline
\end{tabular}

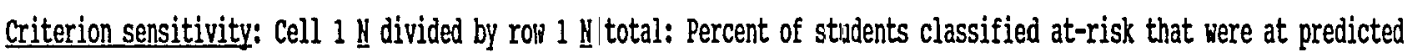
at-risk.

Criterion specificity: Cell $4 \underline{\mathrm{N}}$ divided by roi $2 \underline{\mathrm{N}}$ /total: Percent of students classified not-at-risk that were predicted not-at-risk.

at-risk and not-at-risk that were also predilcted at-risk or not-at-risk. Nearly 88 percent of the students classified as at-risk by report card and student performance were predicted to be at-risk. | Of the students cllassified as notat-risk by report card and student performance, 79 and 78 percent, respectively, were also predicted to be not-atrisk. Program placement had criterion sensitivity of 71 percent and criterion specificity of 72 percent. Teacher 
ratings (1st grade) agreements were also in the 70 percent range (sensitivity, 77 percent; specificity, 73 percent), but criterion sensitivity and specificity for reading scores and the School Success Rating (1st) dipped into the 60 percent accuracy range.

The PSS had strong agreement with students classified by the secondary predictors, with criterion sensitivity and specificity respectively, 82 and 78 percent for teacher ratings; 77 and 72 percent for reading readiness; and, 77 and 76 percent for SSRS(K).

The relative evenness between the criterion sensitivity and specificity found in Table XXVI was not found with the prediction sensitivity and specificity reported in Table XXVII. Prediction sensitivity and specificity refers to the percent of students predicted at-risk or not-at-risk that were also classified by the criterion variable as at-risk or not-at-risk.

Prediction sensitivity reported for the PSS reported in Table XXVII ranged from a low of 28 percent with SSRS(1st) to a high of 66 percent on reading readiness (secondary predictor). This identifies that considerably higher numbers of students were predicted at-risk than were classified as at-risk by the criterion variables. In contrast, those students that were predicted to be not-atrisk were generally classified in the same category. 
TABLE XXVII

ACCURACY OF THE PSS: PREDICTION SENSITIVITY AND SPECIFICITY

\begin{tabular}{|c|c|c|c|c|c|}
\hline Variable & $\begin{array}{l}\text { Predicted at-risk } \\
\text { by predictor(s) }\end{array}$ & $\begin{array}{l}\text { I Predicted not-at-risk } \\
\text { by predictor(s) }\end{array}$ & Sensitivity & Specificity & Total II \\
\hline \multicolumn{6}{|l|}{ Criterion } \\
\hline Student perfornance & 39 & 91 & 39.90 & 97.80 & 130 \\
\hline Placenent & 60 & 116 & 28.33 & 93.97 & 176 \\
\hline Teacher rating(1st) & 55 & 85 & 49.09 & 90.51 & 180 \\
\hline Reading score(2) & 67 & 66 & 56.72 & 72.73 & 133 \\
\hline Report card & 45 & 93 & 46.67 & 96.77 & 138 \\
\hline SSRS(1st) & 54 & 86 & 27.78 & 91.86 & 140 \\
\hline \multicolumn{6}{|l|}{ Secondary oredictor } \\
\hline Teacher Rating( $R$ ) & 54 & 112 & 42.59 & 95.54 & 166 \\
\hline Reading readiness(2) & 71 & 77 & 66.20 & 81.82 & 148 \\
\hline $\operatorname{SSRS}(\mathbb{R})(2)$ & 54 & 114 & 37.04 & 94.74 & 168 \\
\hline
\end{tabular}

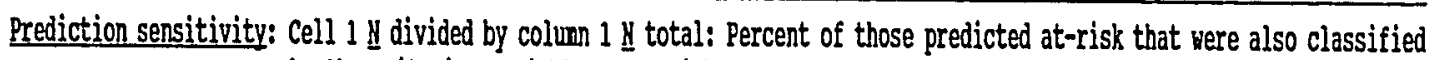
by the criterion variable as at-risk.

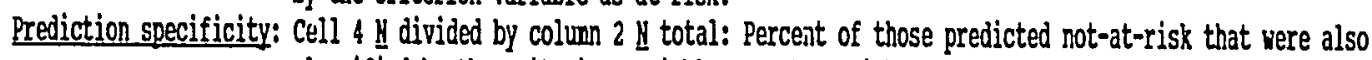
classified by the criterion variable as not-at-risk.

That is, with the exception of reading score (73 percent), specificity was accurate, ranging from a low of 82 percent on reading readiness to a high of 98 percent on student performance.

Program placement specificity was reported at 94 percent, with sensitivity at only 28 percent. It can therefore be concluded that the PSS is very accurate in predicting who will not be placed in special programs. The PSS was even more accurate in predicting who will not be 
at-risk as measured by the aggregate variable of student performance (98 percent).

The PSS sensitivity and specificity for the secondary predictors was similar to that reported for the criterion variables. Sensitivity was weak at 37 percent for the kindergarten SSRS, 43 percent for kindergarten teacher ratings, and 66 percent for reading readiness. Specificity was strong at 82 percent for reading readiness, 95 percent for kindergarten SSRS, and 96 percent for kindergarten teacher ratings. These findings are consistent with Table XXVI in identifying that the majority of the predictive error is in the prediction of at-risk students.

No overall accuracy in discriminating criterion performance was found above the 79 percent level for the PSS. While no dual 80 percent accuracy level was identified for the PSS predictions, strong criterion sensitivity and specificity combined with high prediction specificity suggests high potential for the use of the PSS instrument in an at-risk student identification process.

\section{Predictive Accuracy of the Secondary Predictors}

Question 5 asked for the predictive accuracy of the kindergarten teacher ratings, the School success Rating Scale (kindergarten administration), and the GatesMacGinitie Reading Readiness Tests, in identifying at-risk and not-at-risk students as indicated by the criterion variables. To answer this question discriminant analysis 
equations were developed for each predictor by the systat: computer program. Predictions were cross-tabulated by the criterion variables in comparison with students classified as at-risk and not-at-risk. The overall accuracy of the crosstab predictions are reported in Table XXVIII.

As indicated, the predictions for the kindergarten teacher ratings predictions exceeded 80 percent on all criterion variables except reading scores (68 percent). However, the School Success Rating Scale (kindergarten) failed to produce an overall prediction accuracy level as high as 75 percent on any of the six criterion variables, The Gates-MacGinitie Reading Readiness Tests had an overall agreement accuracy rate of 81 percent in predicting GatesMacGinitie Reading Achievement scores (reading score); but ranged from 62 to 76 percent accuracy with the other criterion variables. Considering all predictor and demographic variables, kindergarten teacher ratings appear to be the strongest single predictor for overall accuracy. Interestingly, the SSRS(K) appears to be slightly more accurate than the Gates-MacGinitie Reading Readiness Test in overall prediction of students that will be placed in special programs, despite the higher correlation between the Gates Reading Readiness Test and placement reported earlier in this chapter. 
TABLE XXVIII

OVERALL ACCURACY OF SECONDARY PREDICTORS: PREDICTIONS BY PERCENT OF|TOTAL $\underline{\mathbf{N}}$

\begin{tabular}{|c|c|c|c|c|c|c|}
\hline \multirow[t]{2}{*}{ Variable } & \multicolumn{4}{|c|}{ crosstab cell percents } & \multirow[t]{2}{*}{ Accuracy } & \multirow[t]{2}{*}{ Total N } \\
\hline & Cell 1 & Cell 2 & Cell 3 & Cell 4 & & \\
\hline \multicolumn{7}{|c|}{ Rindergarten Teacher Ratings } \\
\hline Placerent & 6.59 & 9.89 & 8.79 & 74.73 & $81.32 \star$ & 182 \\
\hline Performance & 4.93 & 8.45 & 7.75 & 78.87 & $83.80 \star$ & 142 \\
\hline Teacher Ratings(1st) & 11.76 & 3.92 & 12.42 & 71.90 & $83.66 *$ & 153 \\
\hline Reading score & 11.64 & 2.05 & 30.14 & 56.16 & 67.80 & 153 \\
\hline Report card & 7.28 & 7.89 & 9.93 & 74.83 & $82.11 *$ & 151 \\
\hline $\operatorname{SSRS(1st)}$ & 7.89 & 7.89 & 7.89 & 76.32 & $84.21 *$ & 152 \\
\hline \multicolumn{7}{|c|}{ School Success Rating Scale(R) } \\
\hline Placerent & 10.18 & 3.59 & 29.94 & 56.29 & 66.47 & 167 \\
\hline Perforrance & 8.59 & 2.34 & 25.00 & 64.06 & 72.65 & 138 \\
\hline Teacher rating(Ist) & 18.25 & 5.11 & 20.44 & 56.20 & 74.45 & 137 \\
\hline Reading score & 25.38 & 16.15 & 19.23 & $\$ 9.23$ & 64.61 & 147 \\
\hline Report card & 12.59 & 3.70 & 25.19 & 59.52 & 71.01 & 135 \\
\hline $\operatorname{SSRS}(1 \mathrm{st})$ & 12.95 & 2.88 & 21.58 & 62.59 & 65.54 & 152 \\
\hline \multicolumn{7}{|c|}{ Gates-KacGinitie Reading Readiness Test } \\
\hline Placenent & 13.51 & 5.95 & 31.89 & 4.8 .65 & 62.16 & 185 \\
\hline Performance & 11.93 & 1.90 & 29.75 & 56.96 & 68.35 & 158 \\
\hline Teacher rating(1st) & 18.71 & 6.43 & 29.24 & 45.61 & 64.32 & 171 \\
\hline Reading score & 39.39 & 4.25 & 15.15 & 41.21 & $80.60 *$ & 165 \\
\hline Report card & 13.95 & 2.91 & 29.07 & 54.07 & 68.02 & 172 \\
\hline $\operatorname{SSRS}(1 \mathrm{st})$ & 12.95 & 2.88 & 21.58 & 62.59 & 75.54 & 168 \\
\hline
\end{tabular}

Cell 1: Crosstab cell 1 divided by total Nㅡㄴ

Cell 2: Crosstab cell $2 \underline{\underline{N}}$ divided by total $\underline{\mathrm{N}}$ Cell 3: Crosstab cell 3 H divided by total H Cell 4: Crosstab cell 4 II divided by total II Note: Cell $1+$ Cell $4=$ Accuracy of prediction Note: Cell $2+$ Cell $3=$ frror of prediction * At or above required accuracy level. 
For program placement, prediction accuracy ranged from 62 percent by reading readiness to 66 percent by the SSRS(K) to the single predictor high of 81 percent by kindergarten teacher ratings. Overall accuracy in predicting student performance followed a similar, though slightly higher, progression of scores with 68 percent (reading readiness), 73 percent (SSRS-K), and 84 percent (kindergarten teacher ratings) accuracy levels identified in Table XXVIII.

Prediction of teacher ratings by the SSRS(K) were also higher than the predictions of teacher ratings by the GatesMacGinitie Reading Readiness Test. However, the GatesMacGinitie was a stronger predictor of the SSRS(1st) scores than was the kindergarten SSRS. These findings encourage more investigation into the School success Rating scale. Table XXIX reports criterion sensitivity and specificity for the secondary predictors. Kindergarten teacher ratings have strong specificity ranging from 88 percent (for program percent) to 96 percent (for first grade teacher ratings). However, criterion sensitivity was low, ranging from 28 percent for first grade teacher ratings to only 50 percent agreement on the SSRS (1st grade). Given that criterion sensitivity refers to the percent of students classified at-risk, the majority of students classified as at-risk were predicted by kindergarten teacher ratings to be not-at-risk. 
TABLE XXIX

CRITERION SENSITIVITY AND SPECIFICITY

FOR SECONDARY PREDICTOR VARIABLES

\begin{tabular}{llllll}
\hline $\begin{array}{l}\text { Criterion } \\
\text { Variable }\end{array}$ & $\begin{array}{l}\text { Classified at-risk } \\
\text { by criterion variable }\end{array}$ & $\begin{array}{c}\text { Classified not- } \\
\text { at-risk by } \\
\text { criterion variable }\end{array}$ & Sensitivity & Specificity & Total N \\
\hline
\end{tabular}

Teacher Rating (R)

$\begin{array}{llrlll}\text { Placeanent } & 28 & 154 & 42.86 & 88.31 & 182 \\ \text { Perfornancet } & 18 & 124 & 38.89 & 90.32 & 142 \\ \text { Teacher rating(1st)* } & 61 & 85 & 27.87 & 96.47 & 146 \\ \text { Reading score } & 65 & 96 & 29.23 & 94.79 & 161 \\ \text { Report card* } & 26 & 125 & 42.31 & 90.40 & 151 \\ \text { SSRS(1st) } & 24 & 128 & 50.00 & 90.63 & 152\end{array}$

School Success Rating Scale: Kindergarten

$\begin{array}{llllll}\text { Placement } & 23 & 144 & 73.91 & 65.28 & 167 \\ \text { Perforaance } & 14 & 114 & 78.57 & 71.93 & 128 \\ \text { Teacher rating(1st) } & 32 & 105 & 78.13 & 73.33 & 137 \\ \text { Reading score } & 54 & 76 & 61.11 & 67.11 & 130 \\ \text { Report card } & 22 & 113 & 77.27 & 69.91 & 135 \\ \text { SSRS(1st) } & 22 & 117 & 81.82 & 74.36 & 139\end{array}$

Gates-HacGinitie Reading Readiness

\begin{tabular}{llcccc} 
Placenent & 36 & 149 & 69.44 & 60.40 & 185 \\
Perforaance & 21 & 137 & 85.71 & 65.69 & 158 \\
Teacher rating(1st) & 43 & 128 & 74.42 & 60.94 & 171 \\
Reading score & 72 & 93 & 90.28 & 73.12 & 165 \\
Report card & 29 & 143 & 82.76 & 65.03 & 172 \\
SSRS(1st) & 23 & 145 & 65.22 & 55.86 & 168 \\
\hline \hline
\end{tabular}

Criterion sensitivity: Cell $1 \underline{N}$ divided by Row $1 \mathbb{N}$ total: Percent of students classified at-risk that were at predicted atrisk.

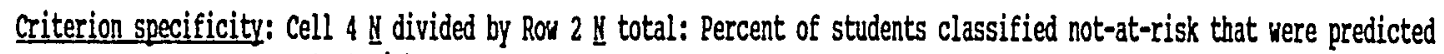
not-at-risk.

Thus, it can be interpreted that kindergarten teachers

were highly accurate in predicting who will be not-at-risk,

but inaccurate in predicting who will be at-risk.

The SSRS(K) and the Gates-MacGinitie Reading Readiness

Test had a more balanced criterion sensitivity and 
specificity, with sensitivity being slightly higher for most criterion variables. For the SSRS(K), sensitivity ranged from 61 to 82 percent and specificity ranged from 65 to 74 percent. The SSRS(K) sensitivity and specificity agreement was highest with the SSRS(1st) (82 and 74 percent respectively). For program placement, the criterion sensitivity and specificity were 74 percent and 65 percent, respectively. Student performance sensitivity and specificity levels were 79 and 72 percent, respectively. For first-grade teacher ratings, the criterion sensitivity and specificity levels were 78 and 73 percent, respectively. For the reading and report card criterion variables, either on or both sensitivity levels were below .70 percent. For the Gates-MacGinitie Reading Readiness Tests, the highest criterion sensitivity ( 90 percent) and the highest specificity (73 percent) levels were on the Gates-MacGinitie Reading Achievement Tests (reading score). Criterion sensitivity ranged from 65 to 90 percent; specificity ranged from 56 to 73 percent. Gates-MacGinitie sensitivity and specificity agreements for program placement were 69 percent and 60 percent, respectively. For student performance, they were 86 and 66 percent, respectively. Thus, none of the secondary predictor variables met the dual criterion sensitivity and specificity standards of 80 percent. Both ffirst-grade teacher ratings and the SSRS (first grade) failed to meet either the sensitivity standard (74 percent 
and 65 percent, respectively) on the specificity standard (61 percent and 56 percent, respectively). Report cards met the 80 percent sensitivity standard ( 83 percent), but failed to meet this standard for specificity ( 65 percent).

Prediction sensitivity and specificity for the secondary predictors is reported in Table XXX. The number of students predicted by the discriminant equation as atrisk and not-at-risk are also reported. The percent of students predicted at-risk vary by criterion measure and by predictor.

Kindergarten teacher ratings prediction of at-risk students (sensitivity) ranged from 37 percent for student performance to 85 percent for first-grade teachej ratings. Program Placement sensitivity was predicted at 40 percent, report card at 48 percent, the first-grade sSRs at 50 percent, and the Gates-MacGinitie reading score at 79 percent. Specificity for kindergarten teacher ratings was 65 percent for first grade teacher ratings, 66 percent for reading score, 88 percent for report card, 89 percent for program placement, and 91 percent for the first grade school Success Rating Scale and student performance.

The kindergarten School Success Rating Scale (SSRS K) had prediction sensitivity ranging from 25 percent to 57 percent. Prediction/specificity ranged from 71 percent to 96 percent. Specificity sensitivity and specificity rates were: 25 and 94 percent for program placement, 26 and 96 
percent for student performance, 47 and 92 percent for first-grade teacher ratings, 57 and 71 percent for reading score, 33 and 95 percent for the first-grade school success Rating scale. In comparing the SSRS(K) with teacher ratings I noted that sensitivity was generally lower for the SSRS, but specificity was generally higher.

The Gates-MacGinitie Reading Readiness Test had generally low prediction sensitivity ranging from 19 percent to 39 percent (except for the Gates-MacGinitie reading score at 72 percent). Specificity ranged from 88 percent to 97 percent. Respectively, sensitivity and specificity for program placement was 30 percent and 89 percent, student performance was 38 percent and 97 percent, first grade teacher ratings were 39 percent and 88 percent, reading score was 72 percent and 91 percent, report card was 32 and 95 percent, and the first-grade SSRS was 19 percent and 91 percent.

I could not identify a consistent pattern for the sensitivity predictions. No secondary predictor showed greater usability above the others. Generally speaking, none of the secondary predictors was clearly superior to the PSS. 
TABLE XXX

PREDICTION SENSITIVITY AND SPECIFICITY FOR SECONDARY PREDICTOR VARIABLES

\begin{tabular}{|c|c|c|c|c|c|}
\hline $\begin{array}{l}\text { Criterion } \\
\text { Variable }\end{array}$ & $\begin{array}{l}\text { Classified at-risk } \\
\text { by criterion variable }\end{array}$ & $\begin{array}{l}\text { Classified } \\
\text { not-at-risk } \\
\text { by criterion variable }\end{array}$ & Sensitivity & Specificity & Total 픈 \\
\hline \multicolumn{6}{|c|}{ Teacher Rating: Rindergarten } \\
\hline Placenent & 30 & 152 & 40.00 & 89.47 & 182 \\
\hline Performance & 19 & 123 & 36.84 & 91.07 & 142 \\
\hline Teacher rating(1st) & 20 & 126 & 85.00 & 65.08 & 146 \\
\hline Reading score & 24 & 137 & 79.17 & 66.42 & 161 \\
\hline Report card & 23 & 128 & 47.83 & 88.28 & 151 \\
\hline SSRS(Ist) & 24 & 128 & 50.00 & 90.63 & 152 \\
\hline \multicolumn{6}{|c|}{ School Success Rating Scale; Kindergarten } \\
\hline Placenent & 67 & 100 & 25.37 & 94.00 & 167 \\
\hline Performance & 43 & 85 & 25.58 & 96.47 & 128 \\
\hline Teacher rating(1st) & 53 & 84 & 47.17 & 91.67 & 137 \\
\hline Reading score & 67 & 80 & 56.72 & 71.25 & 147 \\
\hline Report card & 51 & 84 & 33.33 & 94.05 & 135 \\
\hline $\operatorname{ssRS(1st)}$ & 48 & 91 & 37.50 & 95.06 & 139 \\
\hline \multicolumn{6}{|c|}{ Gates-Yaccinitie Reading Readiness } \\
\hline Placerent & 84 & 101 & 29.76 & 89.11 & 185 \\
\hline Performance & 65 & 93 & 37.69 & 96.77 & 158 \\
\hline Teacher rating(1st) & 82 & 89 & 39.02 & 87.64 & 171 \\
\hline Reading score & 90 & 75 & 72.22 & 90.67 & 165 \\
\hline Report card & 74 & 98 & 32.43 & 94.90 & 172 \\
\hline $\operatorname{SSRS}(1 \mathrm{st})$ & 79 & 89 & 18.99 & 91.01 & 172 \\
\hline
\end{tabular}

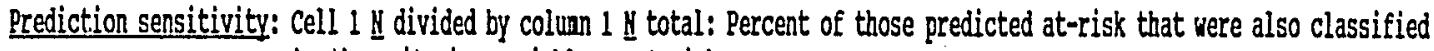
by the criterion variable as at-risk.

Prediction specificity: Cell $4 \mathbb{N}$ divided by coluan $2 \mathbb{I}$ total: Percent of those predicted not-at-risk that were also classified by the criterion variable as not-at-risk. 
Tables XXIX and XXX identify considerable variation in the number of students predicted at-rj.sk, and classified as at-risk. This variation contributes to the difficulty in developing an at-risk identification procedure. However, while no secondary predictor had the desired dual sensitivity and specificity rate of 80 percent, the high specificity rates suggest the potential for an identification process with high overall accuracy using predictors in combination.

\section{Most Accurate Predictions}

My sixth research question sought to identify the best predictor or predictor combination for each criterion variable. I considered "best combination" to be the least number of predictors required to obtain an overall accuracy rate of 80 percent, with dual sensitivity and specificity rates above 80 percent. In the absence of a dual 80 percent rate, the best combination was considered to be the predictors having the highest criterion sensitivity and specificity accuracy rate, and an overall accuracy rate above 80 percent.

To accomplish this task, I ran systat computer analysis for each criterion variable, using all predictors and demographic variables in a single discriminant equation. I then reviewed these calculations to identify the predictors and demographic variables that had significant univariate - $_{-}$ 
tests by criterion variable. The tables in Appendix D report the univariate analysis of each predictor with each criterion variable. Each table in Appendix D presents the significant predictor analysis for a specific criterion variable. Tables in this appendix include the sum of squares, degrees of freedom, F-ratios, and probabilities as they relate to significance of the predictor and demographic variables.

The probability associated with each predictor or demographic variable which was found to be significant in the analysis of variance with a criterion variable is reported in Table XXXI . This table serves as a summary of the analysis of variance tables in Appendix D. Each of the four predictor variables (screening test, teacher ratings(K), SSRS(K), and reading readiness) was identified by analysis of variance as a potential contributor to a prediction equation for each of the criterion variables: program placement, student performance, teacher ratings, reading test, report card, and SSRS(1st grade). In addition, age(3) was identified as a potential contributor to a prediction equation for student performance, teacher ratings, and SSRS(1st). Lunch was identified as a potential contributor to a prediction equation for two criterion variables: teacher ratings and SSRS(1st). Finally, parent marital status for SSRS(1st) and sex for teacher ratings were identified as potential contributors to prediction 
equations.

TABLE XXXI

SIGNIFICANT PREDICTOR/DEMOGRAPHIC VARIABLES

FOR PREDICTING THE CRITERION VARIABLES

\begin{tabular}{|c|c|c|c|c|c|c|}
\hline \multirow{2}{*}{$\begin{array}{l}\text { Predictor } \\
\text { Variable }\end{array}$} & \multicolumn{6}{|c|}{ Criterion Variable Probability } \\
\hline & $\begin{array}{l}\text { Program } \\
\text { Placement }\end{array}$ & $\begin{array}{l}\text { Student } \\
\text { Performance }\end{array}$ & $\begin{array}{l}\text { Teacher } \\
\text { Ratings }\end{array}$ & $\begin{array}{l}\text { Reading } \\
\text { Test }\end{array}$ & $\begin{array}{l}\text { Report } \\
\text { Card }\end{array}$ & $\begin{array}{l}\text { SSRS } \\
\text { (1st) }\end{array}$ \\
\hline 1. Screening test & .001 & .001 & .001 & .001 & .001 & .003 \\
\hline 2. Teacher rating(K) & .001 & .003 & .001 & .001 & .001 & .001 \\
\hline 3. $\operatorname{SSRS}(\mathrm{K})$ & .001 & .001 & .001 & .001 & .001 & .001 \\
\hline 4. Reading readiness & .001 & .001 & .001 & .001 & .001 & .044 \\
\hline 5. $\operatorname{Age}(3)$ & & .016 & .008 & & & .001 \\
\hline 6. Lunch & & & .040 & & & .001 \\
\hline \multicolumn{5}{|c|}{ 7. Parent marital status } & & .046 \\
\hline 8. Sex & & & $.00 ?$ & & & \\
\hline
\end{tabular}

All potential prediction combinations of the significant predictor variables presented for the criterion variables in Table XXXI were computed through systat discriminant analysis equations. I reported the predictions attaining an overall accuracy rate of 80 percent in Table XXXII.

Review of Table XXXII indicates that performance on all criterion variables could be predicted with an overall accuracy rate greater than 80 percent. Student performance, teacher ratings(1st), report card, and the school success Rating Scale(1st) had multiple predictions above the 80 
percent level. Program placement and performance on the Gates-MacGinitie Reading Tests each had only two predictor combinations producing the 80 percent accuracy level. The predictor with highest overall accuracy in predicting program placement ( 81 percent) was kindergarten teacher ratings. The combination of kindergarten teacher ratings and reading readiness was the next highest predictor of program placement ( 80 percent). The accuracy of the kindergarten teacher ratings encourages further research into how early in the kindergarten year the teachers could make their predictions.

The four predictor variables and the demographic variable, age, combined to produce an overall accuracy rate of 85 percent for student performance. The second best overall prediction combination was the PSS with the kindergarten teacher ratings ( 84 percent), followed closely by the screening test with SSRS(K) and age ( 84 percent). The single predictor of kindergarten teacher ratings produced an overall accuracy rate of nearly 84 percent. The best overall accuracy predictor of first grade teacher ratings was the combination of Preschool screening System (PSS), kindergarten teacher ratings, and the GatesMacGinitie reading readiness scores ( 87 percent). Interestingly, the PSS, age, and parent marital status had nearly the same prediction accuracy ( 86 percent). This is of interest in that this second most accurate prediction can 
be done at entry into kindergarten, while the first prediction requires the Gates-MacGinitie score which is not obtained until entry into first grade.

As could be expected, the Gates-MacGinitie Reading Readiness Test was the most accurate predictor of the GatesMacGinitie Reading Test Score ( 83 percent). Similar to program placement, the combination of kindergarten teacher ratings and the Gates-MacGinitie Reading Test was the only other accurate predictor at 82 percent.

Report card could be predicted by a combination of the PSS, kindergarten teacher rating, and the Gates-MacGinitie Reading Readiness Test, to an overall accuracy of 86 percent. The PSS and kindergarten teacher ratings accuracy was nearly as high at 84 percent, and this second highest prediction can be made at the end of kindergarten.

The School Success Rating Scale discrimination could be predicted at an overall accuracy rate by 36 combinations of the predictor and demographic variables. The overall accuracy of these predictions ranged as high as 87 percent. This score was produced by a combination of all predictor and demographic variables except sex. The predictors kindergarten teacher ratings and Gates Reading Readiness Tests produced similar accuracy ( 85 percent) and included 14 more students in the equation. 
TABLE XXXII

PREDICTIONS WITH OVERALL ACCURACY ABOVE 80 PERCENT

\begin{tabular}{|c|c|c|c|c|}
\hline Predictor/Predictor Combination & Cell 1 & Cell 4 & Accuracy & $\underline{N}$ \\
\hline \multicolumn{5}{|c|}{ Progran Placement } \\
\hline 2 & 6.59 & 74.73 & 81.32 & 182 \\
\hline 2,4 & 11.88 & 68.13 & 80.01 & 160 \\
\hline \multicolumn{5}{|c|}{$\underline{\text { Student Performance }}$} \\
\hline $1,2,3,4,5$ & 10.32 & 75.40 & 85.40 & 126 \\
\hline 1,2 & 9.38 & 75.00 & 84.38 & 128 \\
\hline $1,3,5$ & 10.16 & 74.22 & 84.36 & 128 \\
\hline 2 & 4.93 & 78.87 & 83.80 & 142 \\
\hline $1,2,4,5$ & 10.24 & 72.44 & 82.68 & 127 \\
\hline 2,5 & 7.04 & 75.35 & 82.39 & 142 \\
\hline $1,3,4,5$ & 10.32 & 71.43 & 81.75 & 126 \\
\hline $1,2,5$ & 10.16 & 71.09 & 81.25 & 128 \\
\hline $1,4,5$ & 8.66 & 72.44 & 81.10 & 127 \\
\hline $1,2,4$ & 9.52 & 71.43 & 80.95 & 126 \\
\hline 1,5 & 10.00 & 70.77 & 80.77 & 130 \\
\hline $1,3,4$ & 8.66 & 71.65 & 80.31 & 127 \\
\hline $1,2,3,4$ & 7.94 & 72.44 & 80.16 & 126 \\
\hline $2,4,5$ & 9.29 & 70.71 & 80.00 & 140 \\
\hline \multicolumn{5}{|c|}{ Gates-HacGinitie Reading Score } \\
\hline 4 & 38.79 & 44.24 & 83.03 & 165 \\
\hline 2,4 & 35.66 & 46.15 & 81.81 & 143 \\
\hline \multicolumn{5}{|c|}{ Report Card } \\
\hline $1,2,4$ & 13.53 & 72.18 & 85.71 & 133 \\
\hline 1,2 & 13.33 & 71.11 & 84.44 & 135 \\
\hline $1,2,3,4$ & 12.78 & 70.68 & 83.46 & 133 \\
\hline 2,3 & 10.45 & 72.39 & 82.84 & 134 \\
\hline $1,2,3$ & 12.69 & 70.15 & 82.84 & 133 \\
\hline 1,3 & 13.33 & 68.89 & 82.22 & 135 \\
\hline 2 & 7.28 & 74.83 & 82.11 & 151 \\
\hline $1,3,4$ & 13.43 & 68.66 & 82.09 & 134 \\
\hline 1,4 & 14.07 & 67.41 & 81.48 & 135 \\
\hline 1 & 15.22 & 65.22 & 80.44 & 133 \\
\hline
\end{tabular}


TABLE XXXII

PREDICTIONS WITH OVERALL ACCURACY ABOVE 80 PERCENT (continued)

\begin{tabular}{|c|c|c|c|c|}
\hline Predictor/Predictor Conbination & Cell 1 & Cell 4 & Accuracy & $\underline{11}$ \\
\hline \multirow{2}{*}{\multicolumn{5}{|c|}{ ఇeacher Ratings(1st) }} \\
\hline & & & & \\
\hline $1,2,4$ & 17.16 & 69.40 & 86.56 & 134 \\
\hline $1,5,8$ & 17.65 & 68.38 & 86.03 & 136 \\
\hline $1,2,8$ & 17.52 & 67.88 & 85.40 & 137 \\
\hline $1,2,5$ & 18.25 & 67.15 & 85.40 & 137 \\
\hline $1,2,3,5$ & 18.25 & 67.15 & 85.40 & 135 \\
\hline $1,2,3$ & 16.91 & 68.38 & 85.29 & 134 \\
\hline $1,2,3,4$ & 16.42 & 67.91 & 84.33 & 134 \\
\hline $1,6,8$ & 17.16 & 67.16 & 84.32 & 135 \\
\hline $1,3,5,6$ & 17.16 & 67.16 & 84.32 & 134 \\
\hline 2,8 & 15.33 & 68.67 & 84.00 & 153 \\
\hline $2,5,8$ & 14.67 & 68.67 & 83.84 & 150 \\
\hline $2,3,8$ & 11.76 & 71.90 & 83.66 & 153 \\
\hline $1,2,3,4,8$ & 11.76 & 71.90 & 83.66 & 134 \\
\hline $1,4,5,6$ & 17.16 & 66.42 & 83.58 & 134 \\
\hline $1,2,3,4,5,6$ & | 17.16 & 66.42 & 83.58 & 134 \\
\hline 2,4 & 12.67 & 70.67 & 83.34 & 150 \\
\hline $2,4,6$ & 12.67 & 70.67 & 83.84 & 150 \\
\hline $2,3,6$ & 12.42 & 70.59 & 83.01 & 153 \\
\hline $2,3,4$ & 14.93 & 67.91 & 82.84 & 134 \\
\hline $1,2,3,4,5$ & 15.67 & 67.16 & 82.83 & 134 \\
\hline $2,3,5$ & 14.67 & 68.00 & 82.67 & 150 \\
\hline 1,2 & 14.60 & 67.88 & 82.48 & 137 \\
\hline $1,2,6$ & 14.60 & 67.88 & 82.48 & 137 \\
\hline 2,3 & 13.24 & 69.12 & 82.36 & 136 \\
\hline $1,3,4$ & 18.52 & 63.70 & 82.22 & 135 \\
\hline $1,2,5,6$ & 17.52 & 63.50 & 81.07 & 137 \\
\hline $1,2,3,4,5,8$ & | 13.97 & 66.91 & 80.88 & 136 \\
\hline $1,2,4,5$ & 17.04 & 63.70 & 80.74 & 135 \\
\hline $2,6,8$ & 14.93 & 67.16 & 82.09 & 134 \\
\hline $2,4,5$ & 14.93 & 67.16 & 82.09 & 134 \\
\hline $2,4,8$ & 14.93 & 67.16 & 82.09 & 150 \\
\hline $2,3,4,5$ & 14.93 & 67.16 & 82.09 & 134 \\
\hline
\end{tabular}


TABLE XXXII

PREDICTIONS WITH OVERALL ACCURACY ABOVE 80 PERCENT (continued)

\begin{tabular}{|c|c|c|c|c|}
\hline Predictor/Predictor Combination & Cell 1 & Cell 4 & Accuracy & $\underline{\mathbb{1}}$ \\
\hline \multicolumn{5}{|c|}{$\underline{\operatorname{SSRS}(1 \mathrm{st}) 2}$} \\
\hline $1,2,3,4,5,6,7$ & 11.19 & 75.37 & 86.56 & 134 \\
\hline 2,4 & 6.76 & 78.38 & 85.14 & 148 \\
\hline $1,2,3$ & 6.72 & 78.37 & 85.08 & 134 \\
\hline $2,3,4$ & 9.70 & 75.37 & 85.07 & 134 \\
\hline $1,2,3,4$ & 9.70 & 75.37 & 85.07 & 134 \\
\hline 1,2 & 8.70 & 76.09 & 84.79 & 138 \\
\hline $1,2,7$ & 8.70 & 76.09 & 84.79 & 138 \\
\hline 2 & 7.89 & 76.32 & 84.21 & 152 \\
\hline 2,6 & 7.89 & 76.32 & 84.21 & 152 \\
\hline 2,7 & 7.89 & 76.36 & 84.21 & 152 \\
\hline $2,6,7$ & 7.89 & 76.32 & 84.21 & 152 \\
\hline 3,5 & 13.04 & 71.01 & 84.05 & 138 \\
\hline 2,3 & 10.22 & 73.72 & 83.94 & 137 \\
\hline $2,3,4,6$ & 10.14 & 73.65 & 83.79 & 134 \\
\hline $2,4,5,6,7$ & 10.14 & 73.65 & 83.79 & 148 \\
\hline $2,4,5$ & 9.46 & 74.32 & 83.78 & 148 \\
\hline $1,3,4,5$ & 11.85 & 71.85 & 83.70 & 135 \\
\hline $2,3,4,5,6$ & 10.45 & 73.13 & 83.58 & 134 \\
\hline $2,3,4,5,6,7$ & 10.45 & 73.13 & 83.58 & 134 \\
\hline $1,2,5$ & 10.87 & 72.46 & 83.33 & 138 \\
\hline $1,2,6$ & 10.14 & 73.19 & 83.33 & 138 \\
\hline $1,2,5,6,7$ & 10.14 & 73.19 & 83.33 & 138 \\
\hline $1,3,4,5,6,7$ & 11.11 & 71.85 & 82.96 & 135 \\
\hline $2,5,6$ & 9.87 & 73.03 & 82.90 & 152 \\
\hline $2,5,6,7$ & 9.87 & 73.03 & 82.90 & 152 \\
\hline $1,2,4,5$ & 9.70 & 73.13 & 82.83 & 134 \\
\hline $1,2,5,6$ & 11.59 & 71.01 & 82.60 & 134 \\
\hline $1,2,4,6$ & 11.19 & 71.64 & 82.83 & 134 \\
\hline $1,2,4,5,6,7$ & 11.19 & 71.64 & 82.83 & 134 \\
\hline $2,3,4,5$ & 10.45 & 71.62 & 82.09 & 134 \\
\hline $3,5,6,7$ & 11.59 & 70.29 & 81.88 & 138 \\
\hline $3,4,5$ & 11.85 & 69.63 & 81.48 & 135 \\
\hline $3,4,5,6$ & 11.85 & 69.63 & 81.48 & 135 \\
\hline $3,4,5,6,7$ & 11.11 & 70.37 & 81.48 & 135 \\
\hline 3,6 & 12.32 & 68.12 & 80.44 & 138 \\
\hline $3,5,6$ & 12.32 & 68.12 & 80.44 & 138 \\
\hline
\end{tabular}

Numbers in the predictor column correspond as indicated below:
1 Preschooi Screening Test(PSS)
2 Teacher Ratings( $\mathrm{K}$ )
$3 \operatorname{SSRS}(\mathrm{K})$
4 Reading Readiness
5 Age
6 Lunch
7 Parent Marital status
8 Sex 
From the identified prediction combinations with an overall accuracy of 80 percent, the "best fit" predictor for each criterion variable was identified. I accomplished this by reviewing the sensitivity and specificity crosstab tables for each of the predictor/predictor combinations found in Table XXXII.

While all criterion variables could be predicted with an overall accuracy of 80 percent, no criterion variable had both criterion and prediction sensitivity and specificity at or above the desired 80 percent level. Student performance, teacher ratings, report card and SSRS(1st) did all have prediction combinations that produced criterion sensitivity and specificity above the desired dual 80 percent rate.

Table XXXIII presents the predictor combinations producing the highest sensitivity and specificity rates for each criterion variable. This table includes overall accuracy, criterion and prediction sensitivity and specificity, and the number of student for which the prediction could be made.

Program placement sensitivity and specificity was best predicted by the combination of kindergarten teacher ratings and Gates-MacGinitie|Reading Readiness scores (Table XXXIII). This seems|logical in that criterion for entry into special programs requires the perception of need and some objective support of that perception. Neither the criterion sensitivity (73 percent) and specificity ( 81 
percent), nor the prediction sensitivity ( 43 percent) and specificity ( 94 percent) met the recommended criteria (dual 80 percent scores) for inclusion as an identification process. However, given that nearly 94 percent of the students predicted to be not at-risk were classified not-atrisk, therefore we can see that the error in this discriminant prediction is in over identification of at-risk students.

Student performance was best predicted by the PSS and kindergarten teacher ratings; criterion sensitivity, criterion specificity, and prediction specificity were above 80 percent, but prediction sensitivity was 43 percent. The PSS, SSRS(K), and Gates Reading Readiness scores combined to best predict first-grade teacher ratings (criterion sensitivity, criterion specificity and prediction specificity were above 80 percent, but prediction sensitivity was 41 percent).

Teacher ratings were most accurately predicted by the combination of the PSS, the SSRS(K), and the GatesMacGinitie ( 82.22 percent). Criterion sensitivity and specificity both exceeded the 80 percent level with prediction specificity at 96 percent. The prediction specificity was 57 percent, indicating an over identification of at-risk students.

The Gates-MacGinitie Reading Score was best predicted by the Gates-MacGinitie Reading Readiness Score. Similar to 
program placement, the criterion sensitivity ( 89 percent) and specificity ( 78 percent) failed to attain the dual 80 percent level. The prediction specificity was at the 90 percent level, with sensitivity at 76 percent, implying over identification of at-risk students. This finding of high prediction specificity and lower sensitivity is consistent with all "best predictions" for all of the criterion variables. This result suggests that is easier for the predictors of this study to discriminate who is not-at-risk, than it is to identify who is at-risk.

Report card was best predicted by the combination PSS, kindergarten teacher ratings, and the Gates reading readiness scores (criterion sensitivity, 82 and specificity, 86; prediction sensitivity 55, and specificity 96). Interestingly, the age of the child, combined with the School Success Rating Scale (Kindergarten), produced the most accurate prediction of the first-grade school success Rating scale (criterion sensitivity and specificity 86 , 84 percent, respectively; prediction sensitivity and specificity of 49 , and 97 percent respectively). This was the only prediction where sensitivity and specificity were enhanced by the inclusion of a demographic variable. Results from this study indicate that the variable age warrants further study. 
TABLE XXXIII

PREDICTIONS WITH THE HIGHEST ACCURACY

SENSITIVITY AND SPECIFICITY

\begin{tabular}{|c|c|c|c|c|c|}
\hline Predictor combination & Overall accuracy & $\begin{array}{c}\text { Type } \\
\text { criterion/prediction }\end{array}$ & \multirow[t]{2}{*}{ Sensitivity } & \multirow[t]{2}{*}{ Specificity } & $\underline{\mathbb{N}}$ \\
\hline \multirow{4}{*}{2,4} & \multirow{4}{*}{80.01} & Placement & & & \multirow{4}{*}{160} \\
\hline & & & & & \\
\hline & & Criterion & 73.08 & 81.34 & \\
\hline & & Prediction & 43.18 & 93.97 & \\
\hline \multirow{4}{*}{1,2} & \multirow{4}{*}{84.79} & tudent Performance & & & \multirow{4}{*}{136} \\
\hline & & & & & \\
\hline & & Criterion & 80.00 & 84.96 & \\
\hline & & Prediction & 41.38 & 96.97 & \\
\hline \multirow{4}{*}{$1,3,4$} & \multirow{4}{*}{82.22} & eacher Ratings(1st) & & & \multirow{4}{*}{135} \\
\hline & & & & & \\
\hline & & Criterion & 83.33 & 81.90 & \\
\hline & & Prediction & 56.82 & 94.51 & \\
\hline \multirow{4}{*}{4} & \multirow{4}{*}{83.03} & Reading Score & & & \multirow{4}{*}{143} \\
\hline & & & & & \\
\hline & & Criterion & 88.89 & 78.49 & \\
\hline & & Prediction & 76.19 & 90.12 & \\
\hline \multirow{4}{*}{$1,2,4$} & \multirow{4}{*}{85.71} & Report Card & & & \multirow{4}{*}{133} \\
\hline & & & & & \\
\hline & & criterion & 81.82 & 86.49 & \\
\hline & & Prediction & 54.55 & 96.00 & \\
\hline \multirow{4}{*}{3,5} & & SSRS(1st) & & & \multirow{4}{*}{138} \\
\hline & 84.05 & & & & \\
\hline & & Criterion & 85.71 & 83.76 & \\
\hline & & Prediction & 48.65 & 97.03 & \\
\hline \multicolumn{2}{|c|}{$\begin{array}{ll}1 & \text { Screening Test } \\
2 & \text { Teacher Ratings(K) } \\
3 & \text { SSRS(K) } \\
4 & \text { Reading Readiness }\end{array}$} & $\begin{array}{l}5 \\
6 \\
7 \\
8\end{array}$ & $\begin{array}{l}\text { Age } \\
\text { Lunch } \\
\text { Parent } \\
\text { Sex }\end{array}$ & larital $\mathrm{S}$ & atus \\
\hline
\end{tabular}




\section{SUMMARY OF CHAPTER IV}

Chapter IV presented an analysis of the data from information collected over a two-year period on the Washougal School District class of 2001. Data were collected on four demographic variables, four predictor variables, and five criterion variables in an attempt to develop an at-risk student identification process. At-risk indicators were: placement in special programs or retention: scores below the 25 percentile on the Gates-MacGinitie Reading Tests; a first-grade teacher rating of "not successful"; and scores one standard deviation below the mean on the School success Rating Scale, report card, and student performance.

I proposed six questions for inquiry, but no hypothesis was formulated. Three of the questions were secondary and sought to provide background on the variables of study. The three primary questions sought to determine whether the predictor and/or demographic variables could be used to predict at-risk students by the start of first grade.

Findings indicated that overall classifications of atrisk/not-at-risk could be predicted with 80-85 percent accuracy, depending upon the criterion measure analyzed. Four of the criterion variables met the dual criterion sensitivity and specificity standard of 80 percent: student performance, teacher ratings (1st grade), report card, and SSRS(1st). Program placement and Gates-MacGinitie Reading 
Tests did not meet the dual 80 percent rate. Prediction sensitivity was below the 80 percent mark for all six criterion variables, but all prediction specificity rates exceeded 90 percent. This combination of adequate criterion sensitivity and specificity with high prediction specificity could be adapted for use as an identification procedure once an acceptable level of over-identification of at-risk students was set. 
CHAPTER V

SUMMARY, CONCLUSIONS AND RECOMMENDATIONS

SUMMARY

The purpose of my study was to determine if data routinely collected during the kindergarten year and at entry into first-grade could be used to predict whether a child would be perceived as successful or not successful by the end of first grade. The presenting problem was therefore: to determine the sensitivity and specificity of the chosen predictor variables, and then to analyze these findings as to whether or not they were accurate enough to use as an initial identification process for subsequent c.lasses. The need for immediate continued research on this topic was established through the review of literature, which highlighted the extent of the at-risk problem locally and nationally. The growing numbers of at-risk students combined with the minimal impact of the educational programs mandates the need to identify these students in time to prevent school failure. However, clear identification procedures are not currently available and previous studies have raised substantial questions regarding standardized early identification procedures.

I chose four predictor variables (one primary and three 
secondary) for study in conjunction with four demographic variables and five measures of student success. A sixth criterion measure, student performance, was created during the data analysis process and represents a composite of four of the five criterion variables. I adopted Meisel's (1985) and Lanaghorst's (1989) recommendation that the 80 percent sensitivity and specificity level be used as the cutoff score for determining adequacy of a screening instrument or procedure. A linear progression or overview of this study was presented on page 8 in Table $I$.

The data collected and the subsequent analysis were used to answer six questions. Three of these questions were secondary or background questions and three of these questions were primary study quastions.

This exploratory research concentrated on an analysis of data related to the prediction of school success. The study was limited to data on the class of 2001 from two elementary schools within the Washougal School District. The six questions and a summary of the findings are presented below. A more detailed report of my findings can be located in Chapter IV of this study.

\section{Question 1}

What are the correlations within and between the sets of variables? Pearson product moment, Kendall tau-b, and phi correlations were reported based upon the type of comparison (interva) data to interval data, interval to 
ordinal, ordinal to ordinal, or nominal to ordinal). The predictor variables were the Preschool screening system, kindergarten teacher ratings of success, the School Success Rating Scale, and the Gates-MacGinitie Reading Readiness Test. The demographic variables were age, gender, parents marriage status, and free or reduced lunch (representing disadvantaged family income). The criterion variables were placement in special programs, student performance, firstgrade teacher ratings, report card composite scores, the Gates-MacGinitie Reading Achievement Tests, and the School Success Rating Scale (spring of first-grade administration). The predictor and criterion variables were all significantly correlated, both within and between the sets of variables at the $p \leq .001$ levels. The demographic variables had significant relationships between age and sex, and between lunch (representing income) and parents' marital status. Significant correlations between demographic and criterion variables were reported: age with program placement, teacher ratings, and the school success Rating Scale; sex with report card; and lunch with teacher ratings and School Success Rating Scale.

Though significant, the relationships within and between the variables reported here were moderate to weak in strength. These correlations were indicators of which predictor and demographic variables would contribute to the 
predictor combinations identified in the discriminant analysis equations.

\section{Question 2}

Are student differences on measures of student success correlated to student differences in demographic variables? Analysis of variance and chi square results generally indicated that demographic variables with significant correlations with the criterion variables also had significant subgroup differences. It was noted that older students were rated lower or performed more poorly on some measures than average or younger children. Boys were more likely to have special placements and to be rated lower by their teachers than were girls. Generally speaking, students on free or reduced lunch were more likely to be rated lower by their teachers, and to receive lower report card marks than other students.

\section{Question 3}

What is the predictive accuracy of the demographic variables? Discriminant analysis was conducted with demographic variables reporting significant correlations with the criterion variables. Overall predictive accuracy was below the 80 percent level on all tests conducted. However, it is noted that age produced accuracy rates in the 70 percent range for the criterion variables of program placement, teacher ratings, and School Success Rating Scale. 
Question 4

What is the predictive accuracy of the Preschool Screening system in identifying student success as measured by the criterion variables? Discriminant analysis was conducted for the PSS with secondary prediction and criterion variables. The overall level of accuracy by specific variable ranged from 64.66 percent with the GatesMacGinitie Spring Scores to 80.22 percent with the variable report card. The majority of the overall prediction accuracy scores were in the 70 percent range. Criterion sensitivity and specificity findings identified moderate strength relationships with criterion agreement ( 70 percent range), but prediction sensitivity was weak (60 percent range and below).

Question 4 was the central question to my study. A high PSS prediction accuracy would have permitted focused intervention to begin at the outset of kindergarten. While the PSS showed potential for combination with other variables, it did not by itself produce the needed accuracy levels to be an independent identification process.

\section{Question 5}

What is the predictive accuracy of the Kindergarten Teacher Ratings, the school success Rating Scale, and the Gates-MacGinitie in identifying student success as measured by the criterion variables? overall accuracy varied by predictor and criterion variable. Kindergarten teacher 
ratings accuracy indicated the most promise as a single predictor variable with four of the six criterion variables, with overall prediction criterion agreement above 80 percent. Sensitivity rates for the secondary predictors were moderate to weak (similar to PSS), but specificity rates for most of the criterion variables exceeded 90 percent. No single predictor reported sensitivity at or above the 80 percent ievel.

Given the high accuracy of kindergarten teacher ratings and the ease by which these data can be collected, teacher ratings may be a key to the identification of at-risk students. However, more clarity through research is needed to determine whether students are placed in special programs based on at-risk factors or as the result of other factors affecting teacher perception.

\section{Question 6}

Which combination of predictor variables determines the most accurate identification rate of sensitivity and specificity for at-risk children? Each criterion variable could be predicted with an overall accuracy of 80 percent or greater. The most accurate overall predictor or predictor combinations were:

1) Program placement: kindergarten teacher ratings, 81 percent,

2) Student performance: All four predictors in combination, 86 percent, 
3) First grade teacher ratings: Preschool screening System, kindergarten teacher rating, GatesMacGinitie fall raw score in combination, 87 percent,

4) Gates-MacGinitie Reading Score: Gates-MacGinitie fall raw score, kindergarten teacher rating in combination, 83 percent,

5) Report card: All four predictors in combination, 87 percent, and

6) Student Success Rating Scale: Gates-MacGinitie fall raw score and kindergarten teacher rating, 85 percent.

The best overall predictor or predictor combination did not necessarily produce the highest sensitivity and specificity rates. The predictor combinations that produced the most accurate sensitivity and specificity levels are listed below:

1. Program placement: Kindergarten teacher ratings with with the Gates-MacGinitie Reading Readiness Test,

2. Student performance: The PSS with kindergarten teacher ratings,

3. First grade teacher ratings: The PSS with the SSRS(K) and the Gates-MacGinitie Reading Readiness Test,

4. Reading Score: the Gates-MacGinitie Reading Readiness Test,

5. Report card: The PSS with kindergarten teacher ratings 
and the Gates-MacGinitie Reading Readiness Test, and 6. School Success Rating Scale (1st): The SSRS(K) with age.

Age was the only useful demographic variable for enhancing sensitivity and specificity of a criterion variable (SSRS first-grade). In retrospect, the best indicator of at-risk used in this study was special program placement. This conclusion is based on the assumption that students placed in remedial or special programs are the most academically at-risk. Because teacher perception and reading scores are linked to special placements through standard program procedures, they are probably the next best indicators for students at-risk of school failure. If this supposition is accurate, then the demographic variables gave no direct aid in the identification or prediction of those criterion variables most characteristic of at-risk children.

Inherent in question six was whether the prediction accuracy was adequate for use as an identification process. The criterion sensitivity and specificity reported for the "best combination" predictor by criterion variable in Table XXXIII (p. 154) is generally adequate for use (program placement criterion sensitivity of 73 percent requires caution). The prediction specificity rates are also adequate. However, the prediction sensitivity rate, reported there are generally well below the needed 80 percent level. 
Predictor combinations having adequate criterion sensitivity and specificity with high prediction specificity can be used as an identification process, if over identification of at-risk students is acceptable. The degree of over identification that is acceptable depends upon the type of interventions planned and the resources available. Thus, the decision to use, or not to use, the predictor combinations identified in this study lies with the Washougal School District.

\section{CONCLUSIONS AND RECOMMENDATIONS}

The issue of "use" requires further discussion and definition of the term "success" as it relates to the criterion variables and the predictors used in this study. The criterion variables were chosen in attempt to account for three types or levels of school success, conceptually. 1. Program placement represents the least level of success or in other terms identifies the most at-risk students. This conclusion is so in that research indicates that these children have the highest probability of continued school failure and subsequently, a life of minimal income earnings, and minimal personal and social value (minimal success). 2. Teacher perception of their student's ability was measured by report card grades, the School Success Rating Scale, and the simple "successful" "not successful" ratings. These teacher perception measures represent how adults 
within the educational system differentiate successful from not successful students. A teacher perception of "not successful" will probably result in some type of action by the teacher. This action has the potential to be either positive or negative for the student.

3. The third type of success measure collected was the Gates-MacGinitie Reading Achievment Tests. This instrument represented actual academic achievement without teacher interpretation.

Thus, what I was attempting to define as student success, and then to predict, was: 1) a positive teacher perception that the child was achieving at grade level, 2) student achievement above the lower quartile, and 3) the lack of action by the district to help a student (student placement in special programs). My supposition is that a student perceived by their teacher as successful is unlikely to be referred for district action regardless of actual academic achievement. This lack of action suggests that we need to know a great deal more about teacher perception. Interestingly, using kindergarten teacher ratings (teacher perception) and the Gates-MacGinitie Reading Readiness Test (student achievement), 80 percent of the student placements could be correctly predicted. This finding could be interpreted to mean that students perceived or rated by their teacher as not successful, and confirmed as low achievers by an objective measure (standardized 
test), have a high probability of being placed in a special program (district behavior). However, students scoring in the same academic range, but not perceived as at-risk are not placed in special programs. This would begin to explain why the predictors predict more students to be at-risk then are classified as at-risk.

I also suspect that first-grade teachers conferred with a student's kindergarten teacher regarding any referral to special programs. If a first-grade teacher could confirm their concern for a student with another teacher, they were probably more likely to refer a student for further assessment. This supposition could help explain the accuracy of kindergarten teacher ratings, and does suggest a greater role of the kindergarten teacher in the placement of students in special programs. This finding of high prediction accuracy from teacher ratings is consistent with findings reported by Glazzard (1977) and discussed in Chapter II of this study.

Also of interest is that the Preschool Screening system in combination with the School success Rating Scale and the Gates-MacGinitie Reading Readiness Test could fairly well (82 percent) predict how first grade teachers would classify their students. This I interpreted to mean that students delayed in developmental maturation and unable to follow school routines (as defined as the SSRS), also probably had some difficulty learning to read. They were therefore 
viewed by their teacher as not successful. This interpretation would begin to imply that teachers look at factors other than just academic achievement. This interpretation could also suggest that primary teachers believe they can assist children with academic problems, but not when complicated by other factors. If I am correct, it would help explain the low correlations between placement and the other criterion variables.

It was of no surporise that this study revealed that the Gates-MacGinitie Readiness Test was the best predictor of the Gates-MacGinitie Reading Score (reading ability). However, high correlation found between Gates-MacGinitie scores at the beginning of first grade and at the end of first grade implies that students who start first grade as low academic achievers stay low achievers. This would support findings that teachers and the educational system have a maintenance effect on children, high achievers staying high achievers, and low achievers staying low achievers. This finding does require some thought and further research to address whether teachers seek to make their students successful, what basis teachers use to determine if the student is successful, and why teachers in general are fairly ineffective in making "unsuccessful" students "successful." This finding may be somewhat explained by the data processing procedures used by school districts. School systems compile and process the data into 
formats not easily managed by teachers, resulting in little use of data other than teacher perception. Thus, data other than teacher perception is seldom used to improve achievement.

In conducting this study I acquired insights relevant to the decision-making process. To say that information should serve as the basis for decision making is stating what I consider as intuitively obvious. Information, however, is more than the collection of random data. One must organize and process information for usefulness. While I found that the data studied within this project was routinely collected by the Washougal School District staff, it was neither compiled, processed at a central location, nor used as a data bank for decision makers.

Easterday (1969) presented research that indicated that the form in which one presents information directly influences the behavior of the decision maker. Information that is neither compiled nor processed has little opportunity to influence the decision making of anyone. I suspect that the Washougal School District is not the exception to, but rather the rule when it comes to rural districts having a planned information gathering, organizing, and processing plan.

When Gastright (1989) spoke of the dropout problem requiring district-specific study, I believe he was implying that data had to be centrally compiled and routinely 
analyzed in order for district staff to understand the dynamics of their own situations. Without the systematic framework for the collection and analysis of data, evaluation of interventions will be subject to the specific data maintained by various decision makers, resulting in inconsistent and haphazard program modification and development.

Rudman (1976) concluded that the quality of decisions is dependent on the quality of the information sources as well as the quality of the decision making process. It is my conclusion that teachers and administrators must not only be knowledgeable in gathering data regarding their at-risk student population, but they must have planned the processing methods for the accumulated data in order to lower the current dropout rates.

Based on the review of the literature and the findings of my study, the following conclusions and recommendations are provided:

1. The at-risk istudent population is growing at a considerably faster rate than the not at-risk population. The rise in numbers of children living in poverty, the extended numbers of children abused and neglected annualiy, the increase in non-English speaking immigrants, and the "drug baby" explosion combined with a general increase of teen mothers are all contributing to an expanded population of people at risk of life long failure. The current 
inability of public education to address the needs of children with these life factors further contributes to a national problem by permitting the expansion of an uncompetitive work-force pool. This in turn places the nation itself in peril.

Further district-specific research regarding identification and intervention techniques is warranted as we as a nation struggle to determine ways to address and improve the blight of at-risk subgroups.

2. There is considerable discussion in the literature regarding early identification. However, there are few definitive conclusions as to specific criterion or predictor measures of at-risk, In my study I found that the numbers and percents of students classified as at-risk varied by criterion variable analyzed. This variance ranged as high as 25 percent of the total population under study. This finding led me to conclude that further study is required to clarify what are the key variables related to at-risk prediction, Additionally, further study is needed to discern whether educational "at riskness" is the resultant of life trauma, or a long-term cumulative phenomenon, or both, or something else entirely.

3. I believe that much of $\mid$ disagreement regarding accuracy of at-risk prediction within the literature can be reconciled by reviewing individual researchers' statistical methods for determining significant and meaningful findings. 
For example, many of the correlations reported between variables in this study were statistically significant, but they were not large enough to be practically significant in predicting at-risk youth. Researchers reporting at the correlational level of study will identify statistically significant predictors, but which are of little practical use. Another example is found in the overall identification levels reported in this study. Accuracy in overall

identification was reported at or above an 80 percent level for each criterion variable studied. Researchers reporting at this level of investigation could conclude significant and meaningful prediction rates. However, failure to analyze the error in sensitivity and specificity could result in adaption of procedures that excessively overidentified students in one category or the other. 4. I concluded that the Preschool screening system, kindergarten teacher ratings, the school success Rating Scale, and the Gates-MacGinitie Reading Readiness Test did not produce the desired 80 percent accuracy on all three levels of criteria for use as an early identification procedure. They did generate accuracy levels 80 percent or higher for overall prediction criterion sensitivity and specificity, as well as prediction specificity. Prediction sensitivity was below the desired 80 percent level. This combination of adequate accuracy levels does permit the use of some specific combinations of the predictor variables to 
be used as an identification process if over-identification is reasonable, and if the identification process leads to ethical intervention practices (i.e., not for retention and not for tracking purposes).

I encourage further research on these predictors and, if possible, an application study by the district where similar predictor data are obtained, predictions made, and then students followed to determine classifications at the end of first grade (cross validation study is highly recommended if use of these predictors should take place). 5. I found that the information I used in this study was readily available at the building level. However, this information was not compiled or processed for decision making purposes. This then poses the question, "What information or processes do decision makers in rural districts use as they develop programs, authorize resources, and seek to intervene in the at-risk dilemma?" I believe the answer to this question to be extremely noteworthy and deserving of extended research.

6. This study has been exploratory in nature and provided the Washougal School District an information base on their class of 2001. I encourage the district to continue to collect data on the variables studied here, as well as to expand the information base on their at-risk population. Specific follow-up regarding the mobility rate identified in this study is warranted. If the mobility rate continues to 
expand as this class moved through second and third grade, it is possible that the student turnover rate could be as high as 60 percent during the primary years. This simple demographic variable has far reaching implications for atrisk identification and intervention.

7. Given that the district has an inclusion policy for all students age five, by September 1 of the entry year, further investigation on the reported high accuracy of age as a predictor of program placement is also warranted. Interest on this topic is further generated in that only one student placed in special programs had been retained, implying that someone or some process is fairly accurately identifying atrisk children and encouraging delayed entry to the school system. 
REFERENCES

Adelman, H. S., \& Feshbach S. (1971). Predicting reading failure: Beyond the readiness model. Exceptional children, 1, 349-354.

Austin, S. \& Meister, G. (1990). Responding to children at risk: A guide to recent reports. Research for Better Schools. Philadelphia, Pa.

Bachman, J., Green S., \& Wirtamen, I. (1971). Youth in transition, Vol. III: Dropping out - Problem or Symptom? Ann Arbor, Institute for Social Reserch.

Barrett, T. C. (1965, Fall). The relationship between measures of pre-reading visual discrimination and first-grade achievement: a review of literature. Reading Research Quarterly, 1, 51-76.

Beck, L., \& Muia, J.A. (1980). A portrait of a tragedy: Research findings on the dropout. The High School Journal, 64, 65-72.

Becker, I. (1976). Conceptual tempo and the early detection of learning problems. Journal of Learning Disabilities, 2, 433-442.

Benson, C. P., \& Weigal D. J. (1981). Ninth-grade adjustments and achievement as related to mobility. Educatinal Research Quarterly, $\underline{5}$, (4), 15-19.

Berlin, G., \& Sum A. (1988). Toward a more perfect union: Basic skills, poor families, and our economic future. Ford Foundation, New York, N.Y.

Berrueta-Clement, J. K., Schweinhart, L. J., Barnett, W. S., Epstein, A. S., Weikart, D. P. (1984). Changed lives: The effects of the Perry Preschool program on youths through age 19. Monographs of the High/Scope Research Foundation, ‥ Ypsilanti, MI : High/Scope Press.

Billings, J. (1989, December). Superintendent's Message. Education News: Washington state, p. 2 . 
Blyth, D. A., Simmons, R. G., \& Bush, D. (1978). The transition into early adolescence: A longitudinal comparison of youth in two educational contexts. Sociology of Education, 51, 149-162.

Book, R. M. (1980). Identification of eduationally at-risk children during the kindergarten year: A four-year follow-up study of group test performance. Psychology in the schools, 17, 153-158.

Brophy, J. E. (1982). Research on the self-fulfilling prophecy and teacher expectations. The Institute for Research on Teaching. (ERIC Document Reprodiction Service No. ED 221 530). East Lansing, MI.

Brophy, J. E. \& Good, T. L. (1970). Teachers' communication of differential expectations for children's classroom performance. Journal of Educational Psychology, 61, 5, 365-374.

Brouillet, F. B. (1983, December). Achieving excellence for al1. Letter presented at washington State School Director's Association semirar in Seattle, Washington.

Butler, O. (1989). Early help for kids at risk: Our nation's best investment. NEA Today, Issues 89 , I, 51-53.

California State Department of Education Task Force (1988). Here they come ready or not, Report of the school readiness Task Force (ISBN 0-8011-0737-7). Sacramento, CA: California Department of Education.

Capuzzi, D., \& Gross D. R. (1989). Youth at risk: Resource for counselors, teachers and parents. Alexandria, VA: American Association for Counseling and Development.

Cardenas, J. (1985). "Barriers to Excellence: our children at Risk." Educational Leadership, Z, 5-8.

Carnegie Council on Adolescent Development (1989). Turning points: Preparing American youth for the 2lst century. New York, New York: Carnegie Corporation. 
Carnine, D., Carnine, L., Karp, J., \& Weisberg, P. (1988). Kindergarten for the economically disadvantaged: The direct instruction component. In $C$. Warger (Ed.), Public school early childhood programs (pp. 73-96). Alexandria, VA: ASCD.

Chow, C. (1988, March). The Challenge of at-risk students. A memo from the Washington State Office of the Superintendent of Public Instruction. (Bulletin 21-88).

Colarusso, R., Plankenhorn, A., \& Brooks, R. (1980). Predicting first-grade achievement through formal testing of 5-year-old high-risk children. The Journal of Special Education, 14, 355-361.

Committee for Economic Development, Research and Policy Committee (1987). Children in Need: Investment strategies for the Educationally Disadvantaged. Washington, D. C: Author.

Conrath, J. (1987, April) . Harvesting what we know: Thinking through programs for at-risk youth. Thrust, $42,33-55$.

Cooper, H. (1979). Pygmalion grows up: A model for teacher expectation communication and performance influence. Review of Educational Research, $\underline{49}, 3$, $389-410$.

Coulson, J. E., Hanes, S. C., Ozenne, D. G., Bradford, C., Doherty, W. J., Duck, G. A., \& Hemenway, J. A. (1977). The third year of Emergency School Aid Act (ESAA) implementation. Santa Monica, CA: System Development Corporation.

Cowgill, M., Friedland, S., \& Shapiro, M. A. (1973). Predicting learning disabilities from kindergarten reports. Journal of Learning Disabilities, $\underline{6}$, 5055 .

de Hirsch, K.; Jansky, J. J., \& Langford, W. S. (1966). Predicting reading failure. New York: Harper \& Row.

Drillien, C. M. (1970). Complications of pregnancy and delivery. In J. Wortis (Ed.), Mental retardation: An annual review. 1. New York: Grune \& Stratton. 
Dicuian, G. \& Butler, J. A. (1987). Effective schooling and at-risk youth: What the research shows. (NWREL, Topical Synthesis No. 1). Portland, OR: Northwest Regional Educational Laboratory.

Dykstra, R. (1967). The use of reading readiness tests for diagnosis and prediction: A critique. In T. C. Barrett (Ed.), The evaluation of children's reading achievement. Neward, Del.: International Reading association.

Easterday, G. A. (1969). Information, decision making, and role behavior in a simulated education environment. (Doctoral Dissertation, University of Iowa).

Edmonds, R. (1979). Effective schools for the urban poor. Educational Leadership, 36 , (8), pp. 15-24.

Edgar, E. (1987). Secondary programs in special education: Are many of them justifiable? Exceptional Children, 53, 555-561.

Edgar, E., \& Hayden, A. H. (1985). Who are the children special education should serve and how many children are there? Journal of Special Education, 18, 523-539.

Education for All Handicapped Children Act, Public Law 94142 (1975). U. S. Congress, Senate, 94th Congress, first session. Washington D. C.

Eggeland, B., DiNello, M., \& Carr, D. (1970). The relationship of intelligence, visual-motor, pisycholinguistic and reading readiness skills with aichievement. Educational and Psychological Measurement, 30, 451-458.

Eggert, L. L., Herting, J. R. \& Nicholas, L. J. (1988) . Reconnecting At-Risk Youth: Drug Users and Dropouts. Grant Project funded by Nation Institute on Drug Abuse. Rockville, MD: NIDA.

Federici, L., Sims, H., \& Bashian, A. (1976). Use of the MiSSST and the Myklebust Pupil Rating Scale with first grade black urban children. Psychology in the Schools, 13, 386-389.

Ferinden, W. E., Jacobson, S., Linden, N.J. (1970). Early identification of learning disabilities. Journal of Learning Disabilities, 3 , 589-593. 
Feshbach, S., Adelman, D. \& Fuller, W. W. (1974). Early identification of children with high risk of reading failure. Journal of Learning Disabilities, 7 , 49-54.

Fine, M. (1986). Why urban adolescents drop into and out of public high school. Teachers College Record, 87, 393-409.

Fitzsimmons, S. J., Cheever, J., Leonard, E. \& Macunovich, D. (1969). School failures: Now and tomorrow. Developmental Psychology, 1, 134-146.

Fotheringham, J. J. (1987, March). The new student profile: Implications for Future Education Programs. Report presented at a Washington Association of School Administrators meeting. Seattle, WA.

Fromberg, D. P. (1989). Kindergarten: current circumstances affecting curriculum. Teachers college Record, $90,392-403$.

Frymier, J. (1990, April). [Presentation for Phi Delta Kappa Regional Chapter, At-risk youth], Vancouver, WA.

Frymier, J., \& Gansneder, B. (1989). The Phi Delta Kappan study of student at risk. Phi Delta Kappan, 71, 2, 142-146.

Gastright, J. F. (1989). Don't base your dropout program on somebody else's problem. Research Bulletin, Phi Delta Kappa, (8), 1-4.

Glass, E. C. \& Smith, M. L. (1977). pull out in compensatory education. Washington, DC: Department of Health, Education and Welfare.

Glazzard, M. (1977). The effectiveness of three kindergarten predictors for first-grade achievement. Journal of Learning Disabilities, $10,36-40$.

Goodlad, J. (1983). A place called school. New York: McGraw-Hill.

Grissom, J. B., \& Shepard, L. A. (1988). Repeating and dropping out of school. In Flunking Grades: Research and policies on retention. London, Falmer Press. 
Hahn, A. (1987). Reaching out America's dropout: What to do? Phi Delta Kappan, 69, 256-267.

Hainsworth, P. K. \& Hainsworth, M. L. (1980). Preschool screening system: start of a longitudinal preventive approach (Monograph), Early Recognition Intervention systems. Pawtucket, RI.

Hainsworth, P. K., \& Siqueland, M. L. (1969). Early identification of children with learning disabilities: The Meeting street School screening Test. Providence, RI., Crippled Children and Adults of Rhode Island.

Haring, N., \& Ridgeway, R. (1967). Early identification of children with learning disabilities. Exceptional Children, 33, 387-395.

Henig, M. S. (1949). Predictive value of a reading readiness test and teacher forecasts. Elementary School Journal, 50, 41-46.

Hildreth, G., Griffiths, N. , \&: McGauvran, M. (1969). Metropolitan readiness tests. Harcourt, Brace, Jovanovich, Inc.

Hill, T. (1978, July). Summer drop-off and the effectiveness of compensa,tory instruction. Paper presented at the National conference on Urban Education, st. Louis, MO.

Hinton, G. G., \& Knight, R. M. (1971) . Children with learning problems: Academic history, academic prediction, and adjusiment three years after assessment. Exceptional Children, 3, 513-519.

Hodgkinson, H. L. (1985). All on system: Demographics of education, kindergarten through graduate school. Washington, DC: Institute for Educational Leadership.

Hodgkinson, H. L. (1989). The same client: The demographics of education and service delivery systems. Washington, DC: Institute for Educational Leadership.

Hodgkinson, H. L. (1990). Washington: The state and its educational system. Washington DC: Institute for Educational Leadership. 
Howe, H. (1984 April). "Giving equity in the excellence game." A Martin Buskin Memorial lecture delivered at the Education Writers Assn. National Seminar, Philadelphia, PA.

Ireton, H., \& Shing-Lun, K., \& Kampen, M. (1981). Minnesota preschool inventory of children at risk for kindergarten failure. Psychology in the Schools, 18, 393-401.

Johnson, W. B. (1986, June). Demographics as destiny: The U. S. work force in the year 2000. The Hudson Institute, Indianapolis, IN.

Joiner (1977). A technical analysis of the variation in screening instruments and programs in New York State. New York: City University of New York, New York Center for Advanced Study in Education, (ERIC .Document Reporduction Service No. ED 154 596).

Kapelis, L. (1975). Early identification of reading failure: a comparison of two screening tests and teacher forcasts. Journal of Learning Disabilities, $\underline{8}, 39-42$.

Keogh, B. F., \& Becker, L. (1973). Early detection of learning problems: Questions, cautions, and guidelines. Exceptional Children, 40, 5-11.

Keogh, B., Hall, R., \& Becker, L. (1974). Early identification of exceptional children for educational programming (technical report). Los Angeles: University of California.

Keogh, B. K., \& Smith, C. E. (1970). Early identification of educationally high potential and high risk children. Journal of Psychology, $9,285-290$.

Kolb, C. E. M., \& LeTendre, M. J., (1990). Better schooling for the children of poverty: Alternatives to conventional wisdom (Contract No. LD88054001). Washington, DC; U.S. Department, office of Planning, Budget and Evaluation.

Langhorst, B. H. (1989). Assessment in early childhood education. Portland, OR: Northwest Regional Educational Laboratory.

Leeson, F. (1989, September 18). Crack babies get head start on a hard time. The oregonian, p. A15. 
Levirie, R. S. (1989, Spring). An assessment tool for early intervention in cases of truancy. Social Work in Education, 6 , pp. 133-150.

Liechtenstein, S. (1988 February/March). Dropouts: A secondary special education perspective. counterpoint, p. 13 .

Lindeman, D. P., Goodstein, H. A., Sachs, A., \& Young, C. C. (1984). An evaluation of the yellow brick road test through a full prediction-performance comparison matrix. Journal of School Psychology, 22, 111-117.

Lindquist, G. (1982). Preschool screening as a means of predicting later achievement scores. Journal of Learning Disabilities, 15, 331-332.

MacGinitie, H. \& MacGinitie, R. (1989). Gates-MacGinitie reading tests. Third Edition, The Riverside Publishing Company. Chicago, IL.

Mann, D. (1987). Can we help dropouts? Thinking about the Undoable. In propouts, pushouts, and other Casualties (Fp. 223-239). Bloomington, IN: Phi Delta Kappa.

Mccarthy, D. (1972). Mccarthy scales of children's abilities. The Psychological Corporation, New York, NY.

McCormick, K. (1989, January). An equal chance: Educating at-risk children to succeed. (Monograph). National School Board Association.

Meisels, S. J. (1985). Developmental screening in early childhood: A guide. Washington DC: NAEYC.

Meisels, S. J. (1987). Uses and abuses of developmental screening and school readiness testing. Young children, 42 (2), pp. 1-4, 68-73.

Meisels, S. J., Wiske, M. S. \& Tivnan, T. (1984). Predicting school performance wit the early screening inventory. Psychology in the schools, 21, (1), pp. 25-33.

Moilanen, C. (1986). Students in alternative public high schools: Educational histories prior to alternative school entry. (Doctoral dissertation, Portland State University/University of Oregon, 1986). 
Monroe, M. (1932). Children who cannot read. Chicago: University of Chicago Press.

National Association for the Education of Young children. (1988). Position statement on standardized testing of young children 3 through 8 years of age. Young children, 43, 42-47. (Adopted: November, 1987).

National Association of Secondary School Principals. (1988). A student at Risk, (Video).

National Commission on Excellence in Education. (1983). Nation at Risk: The imperative for educational reform. Washington, DC: U.S. Government Printing office.

National Council of Juvenile and Family Court Judges. (1987). Deprived Children: A Judicial Response. Reno, NV: Planning and Development office.

National Institute on Drug Abuse. (1988). Drug prevention curriculum: A guide to selection and prevention. Washington, DC: Department of Education.

Natriello, G., McDill, E. L., Pallas, A. M. (1990). Schooling disadvantaged children: Racing against catastrophe. New York: Teacher College Press.

Newberger, C., Melnicoe, L. \& Newberger, E. (1986). The American family in crisis: Implications for children. Current Problems in Pediatrics, 16, pp. 671-737.

Niswander, K. P., \& Gordon, M. (1972). The women and their pregnancies, 1, Philadelphia: Saunders.

Office of Educational Research and Improvement (1987). Dealing with dropouts: The Urban Superintendent's call to action. Washington, DC: U.S. Government Printing office.

Office of Financial Management (1989, December). Four-year dropout rates by school building, public schools, State of Washington school year 1987-88. Olympia, WA.

Olsen, L. (1987). Coalition of educators urges with efforts for "at-risk" youths. Education Week, 6, (37), pp. 1, 12 . 
Oregon State System of Higher Education, Teaching research Division (1987). A study of Oregon's early school leavers executive summary. Salem, OR.

Panther, E. (1967). Prediction of first-grade reading achievement. Elementary School Journal, 68, 4448 .

Peck, N. L., \& Eberhard, R. G. (1988). Dropout prevention strategies. The Practioner, 25, (2), pp. 1-6.

Pellicano, R. (1987). At risk: A view of "Social advantage". Educational Leadership.

Phlegar, J. M. (1987). Good beginnings for young chiluren: Early identification of high-risk youth and programs that promote success (Contract No, 40086-0005). Washington, DC: Office of Educational Research and Improvement (ED).

Pope, J. G. (1978, March). Kindergarten screen project: $\underline{A}$ five year follow-up study. Paper presented at the Tenth annual Convention of the National Association of School Psychologists, New York, NY. (Abstract)

Quest Staff (1989). The school success rating scale instrumert. Unpublished interdepartmental report, Portland, OR: Portland State University.

Raywid, M. A. (1981). The first decade of public school alternatives. Phi Delta Kappan, 62, pp. 551-559.

Raywid, M. A. (1984). Synthesis of research on schools of choice. Educational Leadership, 41, 7, 77-78.

Robj.nson, N. M. , \& Robinson, H. B. (1965). A follow-up study of children of low birth weight and control children at school age. Pediatrics, 35, pp. 425433 .

Robinson, N. M. , \& Robinson, H. B. (1976). The mentally retarded child: A psychological approach, (2nd ed.). New York: McGraw-Hill.

Rosenthal, R., \& Jacobson, L. (1968). Pygmalion in the classroom: Teacher expectations and pupils' intellectual development. New York: Holt, Reinhart \& Winston. 
Rosenthal, R., \& Rubin, D. B. (1978). Interpersonal expectancy effects: The first 345 studies. The Behavioral and Brain Sciences, 3, 377-415.

Rudman, H. C. (1976). How to use standardized tests for decision making. The National Elementary Principal, 55, (3), pp. 59-64.

Sandler, L., Jamison, D., Delisher, O., Cohen, L., Emkey, K., \& Keith, H. (1972). Developmental test performance of disadvantaged children. Exceptional Children, 39, 201-208.

Schaller, J.|(1975). The relationship between geographic mobility and school behavior. Man-Environment Systems, $\underline{5}, 185-187$.

Schorr, I. B. (1988). Within our reach: Breaking the cycle of disadvantage. New York: Doubleday.

Schweinhart, L. C. (1988). A school administrator's guide to early childhood programs. Ypsilanti, MI: The High/Scope Press.

Shepard, L. A., \& Smith, M. L. (1986). Synthesis of research on school readiness and kindergarten retention. Educational Leadership, 44, (3), pp. 78-86.

Shepard, L. \& Smith, M. L. (1988). Escalating academic demand in kindergarten: Counterproductive policies. The Elementary School Journal, 89, (2), $135-145$.

Slavin, R. E., Karweit, N., \& Madden, N. A. (1989). Effective programs for students at risk. Massachusetts: Allyn/Bacon.

Slavin, R. E. \& Madden, N. A. (1989). What works for students at risk: A research synthesis. Educational Leadership, 46, 5, 4-13.

Slavin, R. E. \& Madden, N. A. (1989). Effective classroom programs for students at risk. In R. Slavin, $N$. Kawet and N. A. Madden (Eds.), Effective programs for students at risk (pp. 23-47). Massachusetts: Allyn/Bacon.

Smedley, S. L. (1987). Educational standardized testing and the Washington state testing program. (Doctoral Dissertation, Brigham Young University, 1987). 
Smey-Richman, B. (1989). Teacher expectations and lowachieving students. Philadelphia: Research for Better Schools.

Stevens, R. \& Pihl, R. O. (1982). The identification of the student at-risk For failure. Journal of Clinical Psychology, 38, 540-545.

Swanson, B., Payne, D., \& Jackson, B. (1981). A predictive validity study of the Metropolitan Readiness Tests and the Meeting street School screening Test against first grade Metropolitan Achievement Test scores. Educational and Psychological Measurement, 41, 575-578.

Sum, A. (1983). Educational attainment, academic ability, and the employability and earnings of young persons: Implications for the planning and design of JTPA youth programs. Brandeis University.

Thurlow, M. L., O'Sullivan, P. J., \& Ysseldyke J. E. (1986). Early screening for special education: How accurate? Educational Leadership, 7, 93-95.

Timberlake, C. (1983). Attitudinal differences of black female secondary students that may influence their graduation from high school. The High School Journal, 656, pp.67-73.

U.S. Department of Commerce, Bureau of the Census. (1986). Money income and poverty status of families and persons in the United States: 1985 (Current Population reports, Series P-60, No. 154). Washington D.C. Government Printing House

U.S. Department of Education. (1986). What works: Schools without drugs. Washington, DC: Department of Education.

U.S. Department of Education. (1990). Better schooling for the children of poverty: Alternatives to conventional wisdom. Washington, DC: Department of Education.

U.S. Department of Health and Human Resources. (1985). The impact of head start on children, families and communities: Head start synthesis project (DHHS publication No. DHDS 85-31193). Washington, DC: U. S. Government Printing office. 
Viadero, D. (1989, October 25). Drug-exposed children pose special problems: School systems are not ready to deal with it. Education Week, pp. 1, 10-11.

Walsh, M. (1989, April 25). Nearly one-quarter of children age 6 live below the poverty level, study finds. Education Week, p. 5 .

Washington state office of the Superintendent of Public Instruction (1987). Report to the legislature on the study of students with special needs: categorical instruction services. Executive summary and recommendations. Olympia, WA.

Washington state office of the Superintendent of Public Instruction (1988). Dropout rates and graduation statistics by count and school district for school year 1986-87. Olympia, WA.

Washington, V. (1980). Teachers in integrated classrooms: Profiles of attitudes, perceptions, and behavior. The Elementary School Journal, 80, 4, 193-201.

Washougal School District (1989). ECIA, Chapter 1 Needs Assessment. Washougal, WA Author.

Webster, K.C. (September, 1987). Preliminary discussion paper: Youth at-risk. (Report for Department of Social and Health Services, Washington state) Olympia, WA: Author.

Wilkinson, L. (1988). SYSTAT. SYSTAT, Inc. Evanston, IL.

Zigmond, N., \& Thornton, H. (1985). Follow-up of post secondary age learning disabled graduates and dropouts. Learning Disabilities Research, 1, 5055 . 
APPENDIX A

MOILANEN'S DESCRIPTORS OF

DROPOUT CHARACTERISTICS

1986 


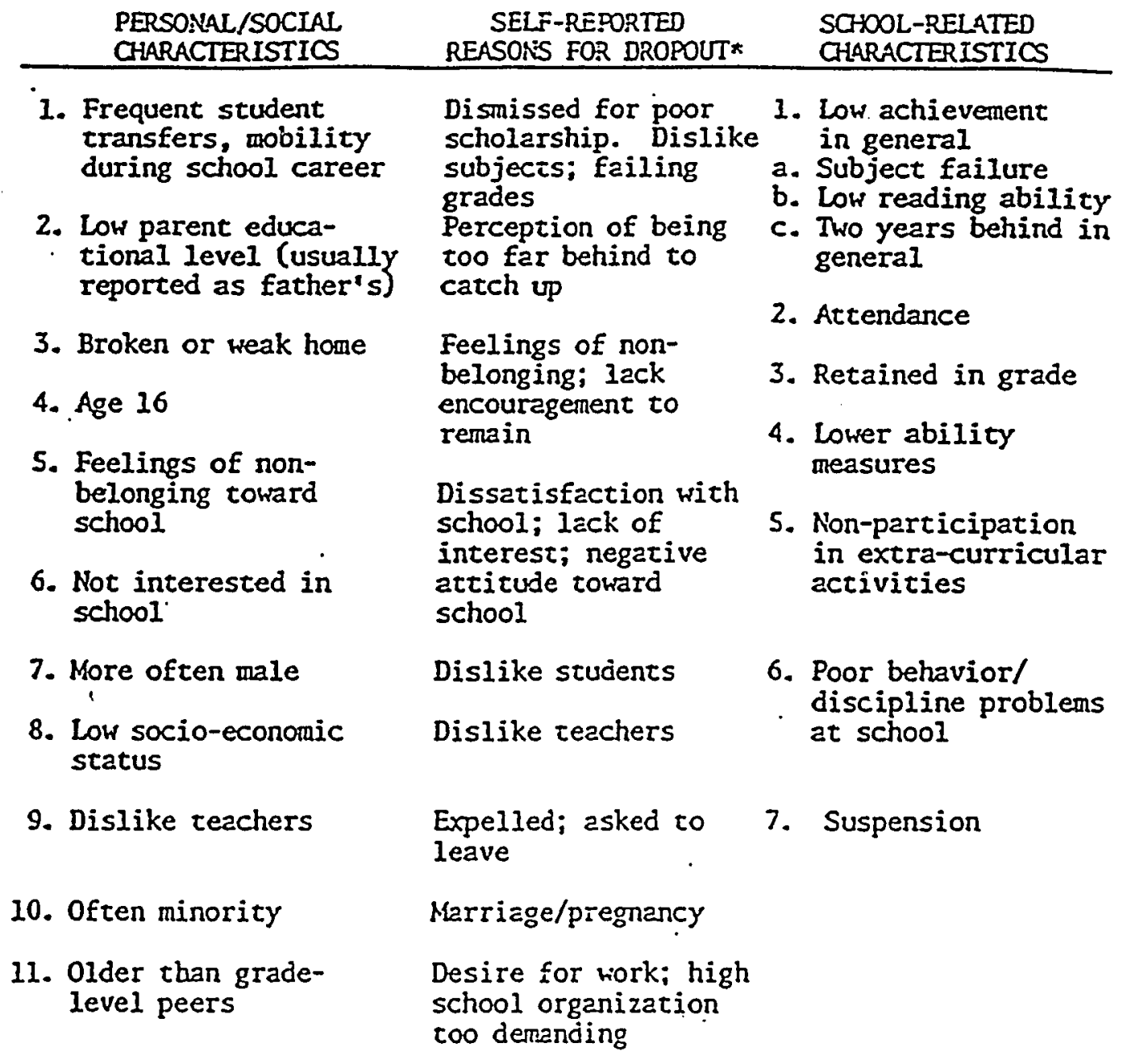

12. Older siblings dropped out

13. Social/emotional problems; maladjustment; poor self-concept

14. Delinquency

Figure 2. Frequently reported dropout characteristics and self-reported reasons for dropout

* Snepp, (195j); U.S. Depariment of Labor, (1960); Thomburg, (1975); Oregon Department of Edicazion (1980); Mahen E Johnson, (198j). 
ÀPPENDIX B

THE SCHOOL SUCCESS RATING SCALE INSTRUMENT

DEVIELOPMENTAL REPORT

BY QUEST STAFF 


\section{DEVELOPHENT OF THE}

SCHOOI SUCCESS RATIRG SCATE

The School Success Rating Scale (SSRS) was developed to provide an instrument to predict and measure 1st grade success based on functional school routines. This instrument. is not a measure of academic knowledge. Further research is needed to determine the relationship between performance of school routines and academic knowledge. The SSRS measures the student's ability to independentIy perform important school routines and the quality of performance of school routines. The following document describes the SSRS reliability and validity methods and results. section I is the reliability and validity methods, section II is the results section and section III describes the rationale for revisions to the SSRS instrument.

\section{RELIABIIITY AND VAIIDITY IIETHODS}

1) Reviewed the Iiterature regarding school routines and functional curriculum.

2) Conducted environmental inventories in a variety of elementary schools. Elementary schools included rural, urban and suburban schools.

2. Project QUEST staff and local school district teachers and specialists conducted six environmental inventories in 6 different elementary schools. The process. for completing the inventories included: developing a list of elementary school environments (e.g. gya, cafe, hall); physically observing students activities in each environment: developing lists of school routines from the observation information and reviewing the list of school routines with several members of the QUEST and school district staff.

b. A generic Iist of elementary school routines was developed by reviewing the six environmental inventories and deleting all duplicate school routines. Some school routines were revised for clarity and consistency of wording between routines.

3) Conducted content validity analysis of school routines.

a. Developed a process for lst grade teachers to rate the school routines for content validity. content validity ratings included: Independent Performance: Importance for success in school: Problems students have at the beginning and at the end on a routine and if the they have an opportunity to observe the routine. 
b. All routines from the generic list of elementary sichool routines were rated for content validity by six Ist grade. teachers from 3 local schools. Teachers were askied to independently rate each school routine in the following manner:

1. Is this a routine you" would expect the student to perform INDEPENDENIII? Expect Independence from:
No students
some students
Many students
271 students

2. Isi the routine IMPORTANI for student success in your school?

Important for school success:

Not important

Somewhat important

Often important

Very important

3/4. Do students have RROBIEMs with this Ioutine at: the BEGINIIING \& END of Ist grade?

'Problems at the Beginning:

Problems at the End:

No students

Some students

Many students

AlI students

5. Do Yoin OBSERVE this routine?

Dpportunity to observe:

\author{
Never \\ - Sometimes \\ often \\ Always
}

6. Rank /order the top 3 routines for each school setting (environment) by importance for school success.

7. Rank order the top 3 school settings (environments) by importance for school success. 
c. Developed Iist of school routines appropriate to include on the school success Rating scale from the content validity data.

1. Calculated an average ranking score for each routine within each school setting. Average rank score was. calculated by using the rank order data provided by the teachers. For each school setting the teachers ranked their top three routines 1,2 or 3 . If a routine was given a rank of $I$ it was given a weighted score of 3 , the rank of 2 was given a weighted score of 2 and a rank of 3 was.given a weighted score of 1 .

2. Developed a rank ordered list of school routines by school setting.

3. Selected 27 of the top rated school routines for inclusion on the SSRS. AII school routines which had an average rank score above 3 and are conducted in the top ranked school setting (classroom) were included on the SSRS. "AlI school routines which had an average rank score above 4 and are conducted in the ind, 3rd or 4th highest ranked school setting (hall, playground and school worker) were included on the SSRS. AII school routines which had an average rank score of 5 or better were included on the SSRS regardless of where the routine is conducted.

4. The wording of the 27 selected school routines was revised based on input from the 6 first grade teachers.

d. Conducted content validity analysis for each of the 27 school routines selected for inclusion on the SSRS.

1. Teacher. rating data regarding the importance of the school routines was analyzed for percent of agreement.

2. The content validity analysis reviewed the average percent of agreement between the six teachers regarding the importance an item has for success in school, Problems students have at the beginning and at the end of the first grade and if teachers have an opportunity to observe the routine. 
4) Developed the School Success Rating Scale.

a. The 27 highest rated items from the content validity analysis were listed as School Routines. on the SSRS.

b. Developed the rating scales for the SSRS.

1. A review of the Iiterature identified two majox content areas in which to rate each schonI routine: 1) level of independent performance and.2) guality of performance.

2. Level of independent performance was rated using the following question: student performs the routine without unnecessary adult assistance:

No parts

Some parts

lany parts

AlI parts

3. Quality of performance as defined by the literature included: Follows directions and rules; Participates as required; Interacts with others spontaneously and appropriately: solves problems; Makes choices: and Transitions to next routine. Teachers were asked to rate each school routine for each of the guality indicators listed above using the following scale:

I Never independent and appropriate

2 Sometimes independent and appropriate

3 Frequently independent and appropriate

4 . Always independent and appropriate

NA Not applicable to this routine 
5) Conducted criterion-Related validity, Item Analysis.Validity, construct validity, split-Half reliability (internal consistency of test). Inter-rater reliability, and cronbach's alpha (homogeneity of test).

a. During the first week of May (end of the school year) six first to review their class list of stidents and indicate beside each students name the level success each student currently was having in school. The teachers rated each student on the following school success. scale: Iess successful, Moderately successful and Very "successful. Six students were randomly selected using the table of random numbers trom eacin eachers class list for use in this study. Of the six students 2 were randomiy selected from the Iess successful category, 2 from the Moderately successful category and 2 from the very successfuI category.

b. During the 2nd week of May the teachers were asked to complete the sSRs on their six randomly selected students. The teachers were not informed about the purpose of the sSRs, the student selection process nor were they reminded about which students they had rated Low, Moderate and Highly successful.

c. The ssirs was structured to provide an Independent Performance total score, six Quality of Performance total scores, 27 routine total scores and 189 individual iter scores.

d. Spliti-half reliability was conducted by splitting each total score into two halves. The items were numbered and the odd numbered items were included in one half and the even numbered itens in the second half. A pearson product Moment correlation and a spearman Brown correlation was conducted between the odd and even numbered items for each total score.

e. Inter-rater reliability was conducted by requesting that another teacher who also new one of the students were was originaliy rated complete the SSRS. Twenty three SSRS scores were obtained from several independent raters. pearson Product Moment Correlations weré computed for each total score between the original rater and the second independent rater.

f. Cronbach's Alpha was conducted by computing the tota? test reliability when each of the individual items was excluded from the total SSRS score.

g. Criterion-Related validity was conducted between the 
teachers initial rating of the students overall success and each of the sSRs total scores.

h. predictive validity was conducted by concucting a discriminant analysis between the six best predictors (from the criterion-related analysis) and the teachers initial rating of the students overall success.

i. Construct validity (internal validity) was. conducted with a factor analysis of total routine scores and a second factor analysis of total performance and quality scores.

6) The SSRS was then revised based on the reliability and validity assessment. 
II. RESULTS

Internal consistency was calculated by completing the split-half technique. Splj.t-half relfability for the SSRS was found to be $r(36)=.999$ and Spearman Brown $r(36)=.999$. The mean total score and standard deviation for the ODD numbered test items was $M=268.762$, $S D=48.42$ and the $E V E N$ numbered test items was $M=267.367, S D=48.295$.

Item consistency was calculated using Cronbach's Alpha. Cironbach's Alpha for each test item ranged between .995 and .996 .

Inter-rater relfability was performed by correlating each total score obtained from two different raters using the Pearson product Moment correlation. Inter-rater reliability ranged between $r(23)=.549$ and $r(23)=.711$. The second rater was found to have far less knowledge about the students and thus rated many routines as N/A (Not Applicable). This may partially account the moderate relationship found between raters.

The content validity analysis is summarized in Table 1. Table 1 shows the average percent of agreement between six ist grade teachers regarding the importance a school routine is perceived to have in relation to school success.

Criterion-Related validity was calculated by conducting a one-way analysis of variance between the teachers initial rating of the students overall success and conducting planned comparisons for each of the SSRS total scores. Table 2 shows the F-ratios for each routine and the significance level of each planned comparison between all combinations of the students rated low, medium and high. A review of rable 2 shows that items $01,02,03,04$ and $Q 5$ significantly discriminated between all three levels of success.

Predictive validity was conducted by using a discriminant analysis between the teachers initial rating and the best SSRS predictors. School routines $Q 1, Q 2,03,04,011,014$ were used to develop the SSRS success prediction. The results of this analysis are shown in Table 3. The overall percent of correctly classified subjects by the SSRS was $70 \%$.

Construct validity. was conducted by completing a factor analysis of all total routine scores and a second factor analysis with the total performance and quality scores. The factor analysis of all total routine scores found two factors: 1) Classrooin Routines and 2) Non-Classroom School Routines to explain $80 \%$ of the total variance. The factor analysis of total performance and quality scores to load on three factors: 1) Problem solving and choice Making; 2) Interaction with others and Transitions and 3) Following Directions, Participation and Performance. These three factors explained $98.12 \%$ of the total variance. 
III. SSRS REVISIONS

Revisions to the SSRS were made based on the reliability and validity data.

Revisions to SSRS Routines (items) :

The content validity analysis and the criterion-related validity analysis provided the information needed to revise the list of school routines and to reword the original Iist of school routines. The revised SSRs includes.. only items which had at least $83 \%$ agreement between the teachers as items important for success in school and items which were significantly able to discriminate between levels of school success. A few new items were added to the SsRs as a result of the content validity analysis. Items which were added received at least $83 \%$ agreement between the teachers as items important for success in school. Table 4 shows a comparison of routines and related validity data between the original SSRS and the revised SSRS routines.

Revisions to SSRS Performance and Quality rating system (Colum heạiings) :

The factor analysis of the performance and quality rating system provided some of the needed information to revise the colum headings. The factor analysis found the following Quality of performance scores to load together:

Colum B). Follows Directions \& Rules

Column C). Participates as Required

Colum E) - Solves Problems

Colum F). Makes Choices

The revised ssRs combined column B) + column C) into one colum and combined Colum E) + Column F) into one column.

A review of the raw data collected from Column D), Interacts with others spontaneously and Appropriately, found that many teachers rated.this colum as $N / A$ (Not Applicable) for many school routines. Teachers commented on the need to rate students who "refrain" from interacting as wéll as to rate students who "spontaneously" interact. This colum was reworded to allow teachers to rate all types of appropriate interactions. 
TABIE 1

CONIENT VATIOIFY ARATYSIS

\begin{tabular}{|c|c|c|}
\hline INDEx: & SCHOOI ROUIINE & $\begin{array}{l}\text { TMPORTAKCE } \\
\text { FOR SCEOOL } \\
\text { (PERCENT OI }\end{array}$ \\
\hline $\begin{array}{l}Q 1 \\
22\end{array}$ & $\begin{array}{l}\text { Iange group instruct } \\
\text { SmaII group instruct }\end{array}$ & $\begin{array}{l}100 \% \\
100 \%\end{array}$ \\
\hline $\begin{array}{l}Q 3 \\
Q 4\end{array}$ & $\begin{array}{l}\text { Does Independent rork } \\
\text { Uses Iearning centers }\end{array}$ & $\begin{array}{l}\text { 100\% } \\
\text { 100\% }\end{array}$ \\
\hline $\begin{array}{l}\mathbf{Q 5} \\
\mathbf{Q 6}\end{array}$ & $\begin{array}{l}\text { Does free choice act. } \\
\text { Does classmoom jobs }\end{array}$ & $\begin{array}{l}100 \% \\
60 \%\end{array}$ \\
\hline $\begin{array}{l}27 \\
28\end{array}$ & $\begin{array}{l}\text { Wajks in Ijne with a group } \\
\text { falies Irom place to } \\
\text { place by self }\end{array}$ & $\begin{array}{l}100 \% \\
100 \%\end{array}$ \\
\hline $\begin{array}{l}Q 9 \\
010\end{array}$ & $\begin{array}{l}\text { Gets a drink } \\
\text { Select/checkout/return } \\
\text { books }\end{array}$ & $\begin{array}{l}47 \% \\
100 \%\end{array}$ \\
\hline Q11 & $\begin{array}{l}\text { Watch movie/video } \\
\text { Independent reading }\end{array}$ & $\begin{array}{l}83 \% \\
100 \%\end{array}$ \\
\hline Q23 & $\begin{array}{l}\text { Play on playground } \\
\text { equipment }\end{array}$ & $100 \%$ \\
\hline Q14 & Play by self & 832 \\
\hline $\begin{array}{l}\text { Q15 } \\
\text { Q16 }\end{array}$ & $\begin{array}{l}\text { Play with others } \\
\text { sing with a group }\end{array}$ & $\begin{array}{l}1.00 \% \\
0 \%\end{array}$ \\
\hline $\begin{array}{l}\text { Q17 } \\
\text { Q18 }\end{array}$ & $\begin{array}{l}\text { Iisten to music } \\
\text { Get/eat/clean-up } \\
\text { lunch }\end{array}$ & $\begin{array}{l}0 \% \\
100 \%\end{array}$ \\
\hline $\begin{array}{l}Q 19 \\
Q 20\end{array}$ & $\begin{array}{l}\text { Go to and from bus } \\
\text { Ride the bus }\end{array}$ & $\begin{array}{l}100 \% \\
100 \%\end{array}$ \\
\hline $\begin{array}{l}Q 21 \\
Q 22\end{array}$ & $\begin{array}{l}\text { Use the computers } \\
\text { Use the restroom }\end{array}$ & $\begin{array}{l}0 \% \\
100 \%\end{array}$ \\
\hline Q23 & $\begin{array}{l}\text { Do errands to office/ } \\
\text { nurse/classrooms }\end{array}$ & $50^{\circ}$ \\
\hline Q24 & Group exercises/drilis & $50 \%$ \\
\hline $\begin{array}{l}Q 25 \\
Q 26 \\
Q 27\end{array}$ & $\begin{array}{l}\text { Group garnes } \\
\text { watch assembly events } \\
\text { perforn in school programs }\end{array}$ & $\begin{array}{l}100 \% \\
83 \% \\
80 \%\end{array}$ \\
\hline
\end{tabular}


TABLE 2 .

CRTIERTON-RETATED VATTOTIY ANATYSTS

\begin{tabular}{|c|c|c|c|c|c|c|}
\hline Ireafe & SCEOOL ROUIDNE & F-RATIO & SIGK & $\begin{array}{l}\text { DLARINED } \\
\text { IOFTIID }\end{array}$ & $\begin{array}{l}\text { COMPARTSC } \\
\text { IOFIASOST }\end{array}$ & $\begin{array}{l}\text { ONS } \\
\text { 2IIDXASOST }\end{array}$ \\
\hline $\begin{array}{l}\text { Q1 } \\
\text { Q2 }\end{array}$ & $\begin{array}{l}\text { Lange group instruct } \\
\text { Smail group Instruct }\end{array}$ & $\begin{array}{l}14.67 \\
18.586\end{array}$ & $\begin{array}{l}.001 \\
.001\end{array}$ & $\begin{array}{l}.022 \\
.002\end{array}$ & $\begin{array}{l}.001 \\
.001\end{array}$ & $\begin{array}{l}.003 \\
.006\end{array}$ \\
\hline $\begin{array}{l}\text { Q3 } \\
\text { Q4 }\end{array}$ & $\begin{array}{l}\text { Does independent work } \\
\text { Uses Iearning centers }\end{array}$ & $\begin{array}{l}14.661 \\
14.128\end{array}$ & $\begin{array}{l}.001 \\
.001\end{array}$ & $\begin{array}{l}.022 \\
.018\end{array}$ & $\begin{array}{l}.001 \\
.001\end{array}$ & $\begin{array}{l}.003 \\
.005\end{array}$ \\
\hline $\begin{array}{l}Q 5 \\
Q 6\end{array}$ & $\begin{array}{l}\text { Does free choice act. } \\
\text { Daes classroom jobs }\end{array}$ & $\begin{array}{l}9.09 \\
6.535\end{array}$ & $\begin{array}{l}.001 \\
.004\end{array}$ & $\begin{array}{l}.037 \\
.017\end{array}$ & $\begin{array}{l}.001 \\
-001\end{array}$ & $\begin{array}{l}.034 \\
\text { (NS) }\end{array}$ \\
\hline 27 & $\begin{array}{l}\text { Farks in Iine with a } \\
\text { group }\end{array}$ & 3.527 & & (NS) & .014 & (ks) \\
\hline Q8 & $\begin{array}{l}\text { palks from place to } \\
\text { place by self }\end{array}$ & 6.004 & .006 & .007 & .004 & (NS) \\
\hline Q9 & $\begin{array}{l}\text { Gets a drink } \\
\text { Select/checkout/return } \\
\text { books }\end{array}$ & $\begin{array}{l}2.857 \\
10.943\end{array}$ & $\begin{array}{l}\text { (NS) } \\
-002\end{array}$ & $\begin{array}{l}(\mathrm{NA}) \\
-001\end{array}$ & $\begin{array}{l}(\mathrm{NA}) \\
.001\end{array}$ & $\begin{array}{l}\text { (NA) } \\
\text { (NS) }\end{array}$ \\
\hline Q11 & $\begin{array}{l}\text { Hatch novie/video } \\
\text { Independent reading }\end{array}$ & $\begin{array}{l}11.136 \\
15.059\end{array}$ & $\begin{array}{l}.001 \\
.001\end{array}$ & .001 & $\begin{array}{l}.001 \\
.001\end{array}$ & $\begin{array}{l}\text { (ISS) } \\
\text { (NS) }\end{array}$ \\
\hline Q13 & $\begin{array}{l}\text { Play on playground } \\
\text { equipnent }\end{array}$ & 6.479 & .004 & (NS) & .001 & (Nis) \\
\hline Q14 & Play by self & 4.341 & .021 & (NS) & .006 & (1TS) \\
\hline $\begin{array}{l}\text { Q15 } \\
\text { Q16 }\end{array}$ & $\begin{array}{l}\text { Play with others } \\
\text { sing with a group }\end{array}$ & $\begin{array}{l}6.887 \\
2.219\end{array}$ & $\begin{array}{l}-003 \\
\text { (ISS) }\end{array}$ & $\begin{array}{l}-035 \\
\text { (NA) }\end{array}$ & $\begin{array}{l}.001 \\
(21 A)\end{array}$ & $\begin{array}{l}\text { (NSi) } \\
\text { (NA) }\end{array}$ \\
\hline $\begin{array}{l}\text { Q17 } \\
\text { Q18 }\end{array}$ & $\begin{array}{l}\text { Wisten to music } \\
\text { Get/eat/clean-up } \\
\text { lunch }\end{array}$ & $\begin{array}{l}\text { (ID) } \\
2.022\end{array}$ & $\begin{array}{l}\text { (ID) } \\
\text { (NS) }\end{array}$ & $\begin{array}{l}\text { (ID) } \\
\text { (NA) }\end{array}$ & $\begin{array}{l}\text { (ID) } \\
(\mathrm{NA})\end{array}$ & (ID) \\
\hline $\begin{array}{l}Q 19 \\
Q 20\end{array}$ & $\begin{array}{l}\text { Go to and from bus } \\
\text { Ride the bus }\end{array}$ & $\begin{array}{l}5.594 \\
7.402\end{array}$ & $\begin{array}{l}.0 .0 .8 \\
.002\end{array}$ & $\begin{array}{l}.007 \\
.005\end{array}$ & $\begin{array}{l}.006 \\
.001\end{array}$ & $\begin{array}{l}\text { (IS) } \\
\text { (MS) }\end{array}$ \\
\hline $\begin{array}{l}Q 21 \\
Q 22\end{array}$ & $\begin{array}{l}\text { Use the computers } \\
\text { Use the restroon }\end{array}$ & $\begin{array}{l}\text { (ID) } \\
4.891\end{array}$ & $\begin{array}{l}\text { (ID) } \\
.014\end{array}$ & $\begin{array}{l}\text { (ID) } \\
\text { (NS) }\end{array}$ & $\begin{array}{l}\text { (ID) } \\
-004\end{array}$ & $\begin{array}{l}\text { (ID) } \\
\text { (IAS) }\end{array}$ \\
\hline Q23 & $\begin{array}{l}\text { Do errands to office/ } \\
\text { nurse/classrooms }\end{array}$ & 5.249 & .01 & .026 & .004 & (IS) \\
\hline (24 & Group exercises/drills & 7.574 & .002 & .016 & .001 & (NS) \\
\hline $\begin{array}{l}Q 25 \\
Q 26\end{array}$ & $\begin{array}{l}\text { Group games } \\
\text { watch assembly events }\end{array}$ & $\begin{array}{l}6.417 \\
3.435\end{array}$ & $\begin{array}{l}.004 \\
.044\end{array}$ & $\begin{array}{l}.045 \\
.048\end{array}$ & $\begin{array}{l}.001 \\
.021\end{array}$ & $\begin{array}{l}\text { (HS) } \\
\text { (NS) } \\
\text { (TD) }\end{array}$ \\
\hline Q27 & Perform in school & (ID) & (ID) & (ID) & (ID) & (1D) \\
\hline
\end{tabular}

prograns
ID=Insufficient data; NS=Not significant; Ih:Not analyzec due to sis 
TASTE 4

COMPAZTSOM OE ORIGINAT SSRS THD REVISED SSZS

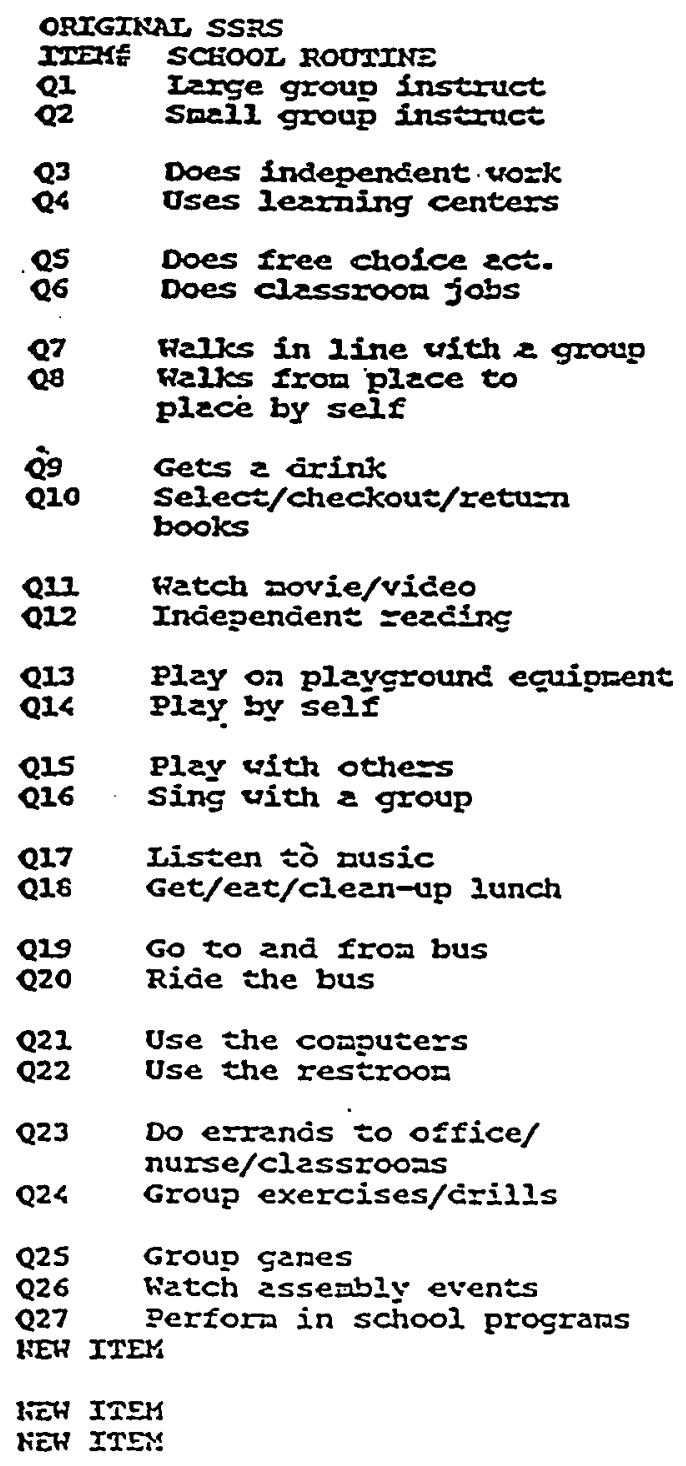

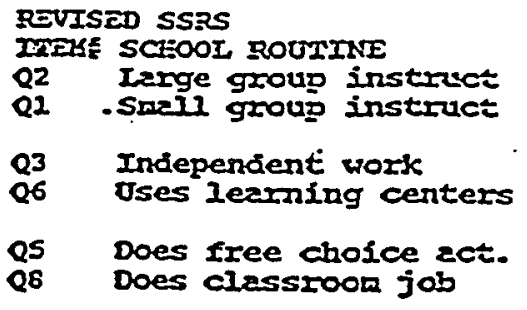


TERCHERS OVERATI JUDGEHEAT OF SUCCESS

IESS SUCCESSTUL

HODERATELY SUCCESSFUL

VERY SOCCESSFUL

TABLE 3

DISCRUTHNANT ANALYSIS

\begin{tabular}{|c|c|c|c|}
\hline IESS & KODERATELY & VERY & TOTALA (H) \\
\hline 758 & $8.337(1)$ & $26.672(2)$ & $100 ₹(12)$ \\
\hline$\neq(3)+1$ & $46.25 \%(6)$ & $30.77 \div$ (4) & $100 \div(13)$ \\
\hline & 9.097 (1) & $90.91 \div(10$ & $100(11)$ \\
\hline
\end{tabular}

-overali ₹ of subjects correctly classified = $70 *$ 
SCHOOL SUCCESS RATING SCALE

(SSRS)

\section{INSTRUCTIONS FOR ADMIIISTRATION OF THE SSRS:} 1. Record the students name, birthdate, grade and date of test
administrailon. 2. For each routine score the student's performance and quality
of performance.

a. The performance score (Colum A.) is completed by placing an " $\mathrm{X}$ " In the appropriate colum to indicate the relative number of parts the student performs/completes for each routine.

b. The quality of performance scores are completed by circling one appropriate number $(1,2,3$ or 4$)$ in each colum $(B, C, D, E$ and $F)$. Do not leave any item unscored!

c: Study the SSRS definitions before beginning to score any students. SSRS definitions are shown on the next page.

3. Calculate the total scores for each routine, the total column scores and the grand total ssRs score.

a. The total routine score is calculated by adding the scores for each routine across columns $A-F$. Column $A$. (Performance) should be scored as follows: No $=1$, Some $=2$, ManY $=3$ and $A I I=4$. For example the minimura score for small group instruction would be 6 and the maximum score would be 24 .

b. The total column scores are calculated by adding the scores together from the top to the bottom of each column. To calculate the total score for column. A. (Performance) use the following: No $=1$, Some $=2$, Many $=3$ and $A I I=4$. For Colums $B-F$ add together the circled numbers. For example the minimum score for Colum $B$. would be 24 and the maximum score for Column $B$ would be 96.

c. The grand total SSRS score is calculated by adding together the total colum scores. Note: The total routine scores and the total column scores should be equal, thus it is only necessary to add together the total column scores. 
DEFINITIONS FOR SCHOOL SUCCESS RATING SCAIE

PERFORHANCE SCORE:

A. RERFORMS/COMPLETES ROUTINE INDERENDENTLY:

Student performs and completes the routine without unnecessary adult assistance.

QUATITY OF ROUTINE SCORES:

B. FOLLOWS DIRECTIONS/RULES/PARTICIPATES:

Performs as directed by the teacher, complies with the rules appropriate to this routine, is actively involved in the routine and responds as required. Student may or may not perform or complete the routine correctly, but is "ON TASK" while engaged in the routine.

Example routine,

Walking In Iine: student follows directions to line up at the door and follows the rule of walking single file down the hall.

Example routine,

Iarge Group Math Instruction: student responds in unison to group presentation and answers questions when called upon.

C. USES MATERIALS APERORRIATELY: .

Student has needed materials to complete the routine and uses - materials appropriately.

Example routine,

Small Group Instruction: Student has a sharp pencil to complete a group writing project and appropriately uses the pencil to write on the paper not on the desk.

D. INTERACTS WITH OTHERS APPROPRIATELY:

Student appropriately engages or refrains from engaging with sthers (peers/adults) during the routine.

Example routine,

Free Choice Activities: Student requests another student to help him/her build with the blocks.

Example routine,

Independent Reading: student silently reads/looks at book without bothering other students. 
E. SOLVES PROBLEMS \& MAXES CHOTCES:

The student is able to work out difficulties and make decisions about options within routines when something other than the expected occurs or more than one alternative is available.

Example routine.

Get/Eat/Cleanup Iunch Routine: student arrives at the milk counter and there is no more milk. student asks for assistunce.

Example routine,

Independent Fork: The student is able to choose which task to do first.

F. MOVES ON TO THE NEXT ROUTINE:

student puts materials away, goes to the next area, gets out materials, begins next routine.

Example routine,

Small Group Instruction Routine: The student puts his book in the desk, goes to the next area and gets out pencil and paper to begin Independent Work Routine.

Example routine,

Uses Restroom Routine: After using restroom student returns to classroom and begins next routine. 


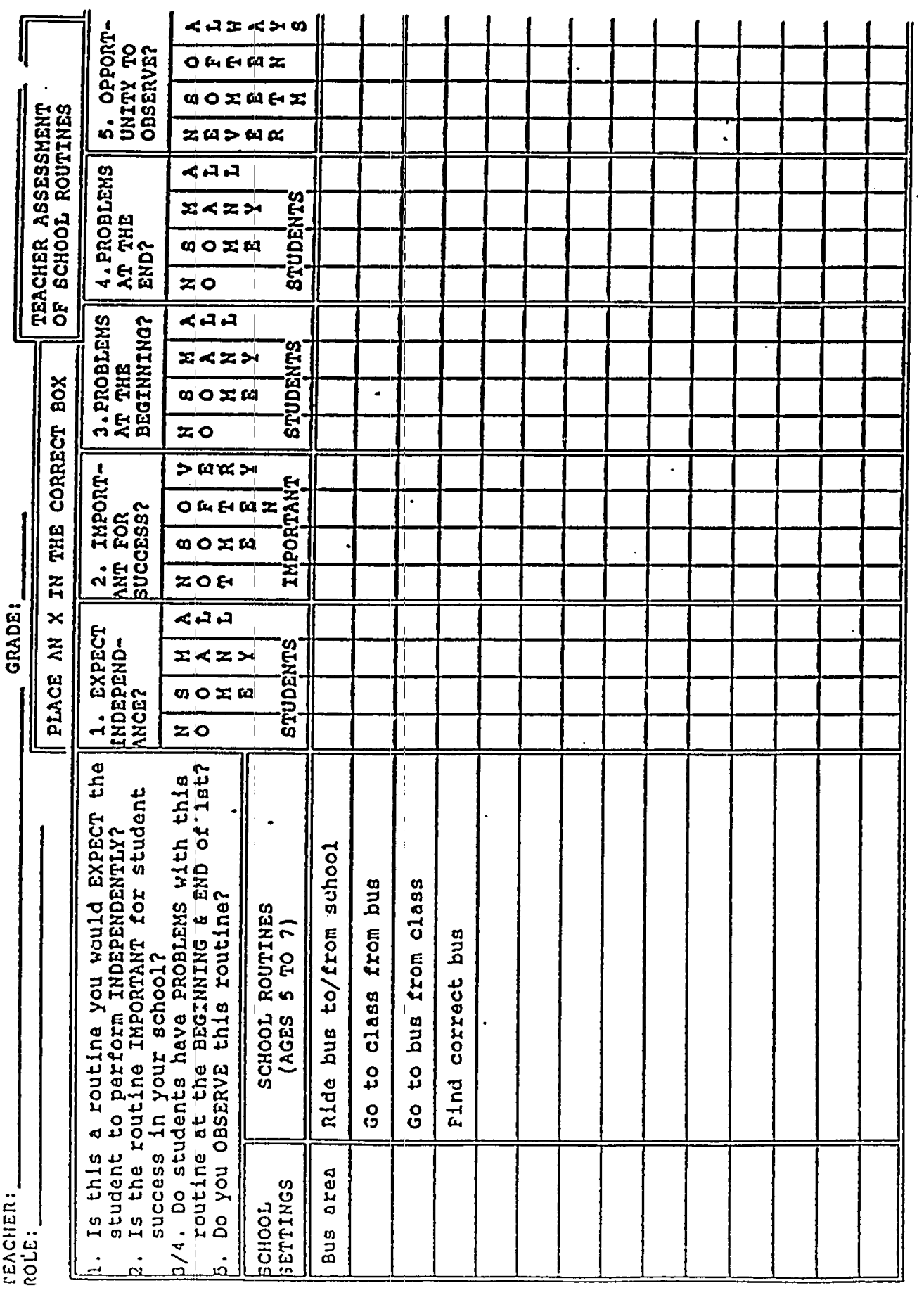

娄

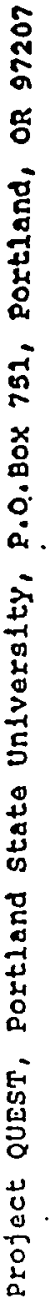




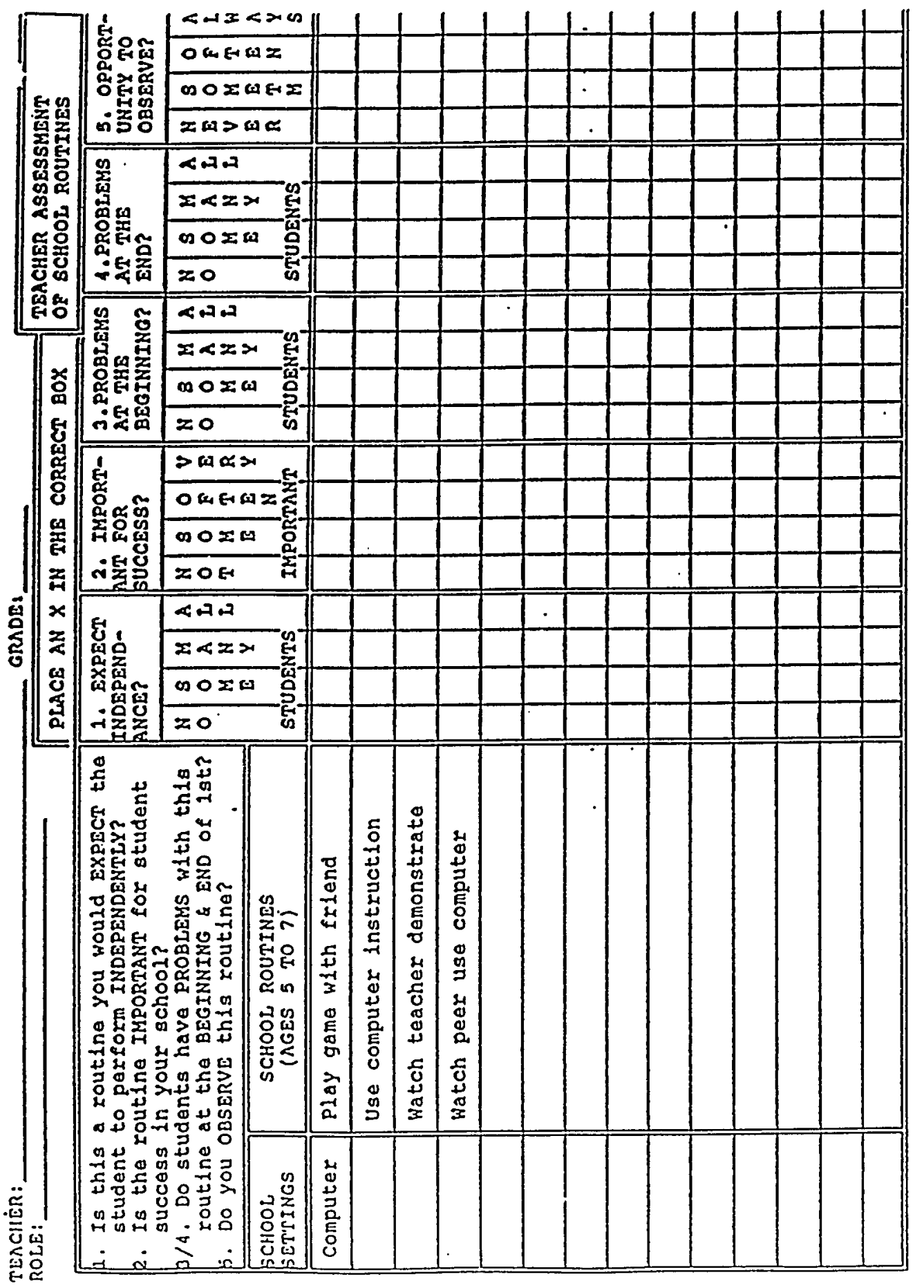

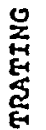

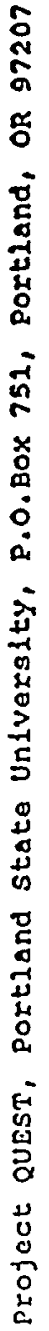




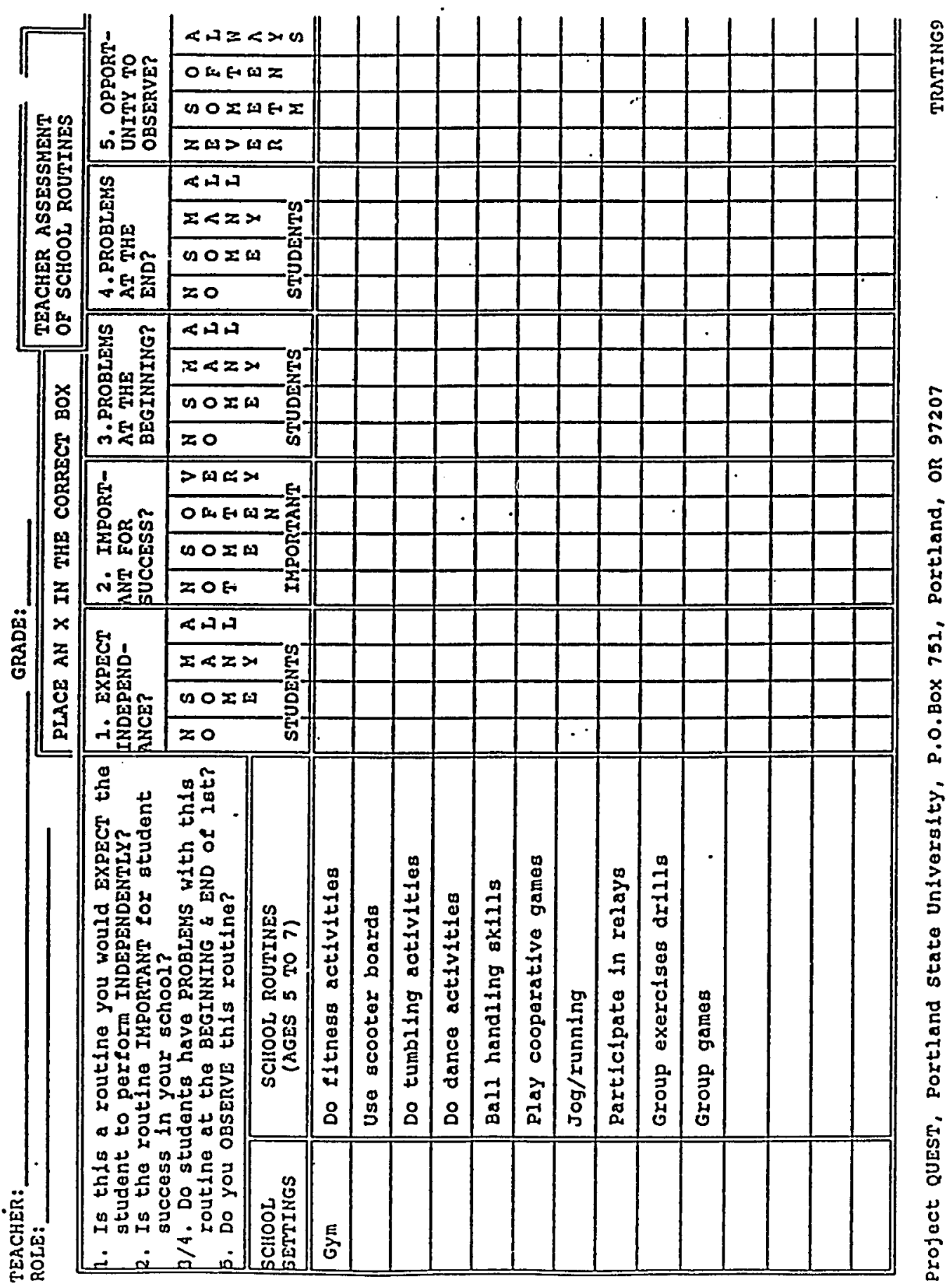




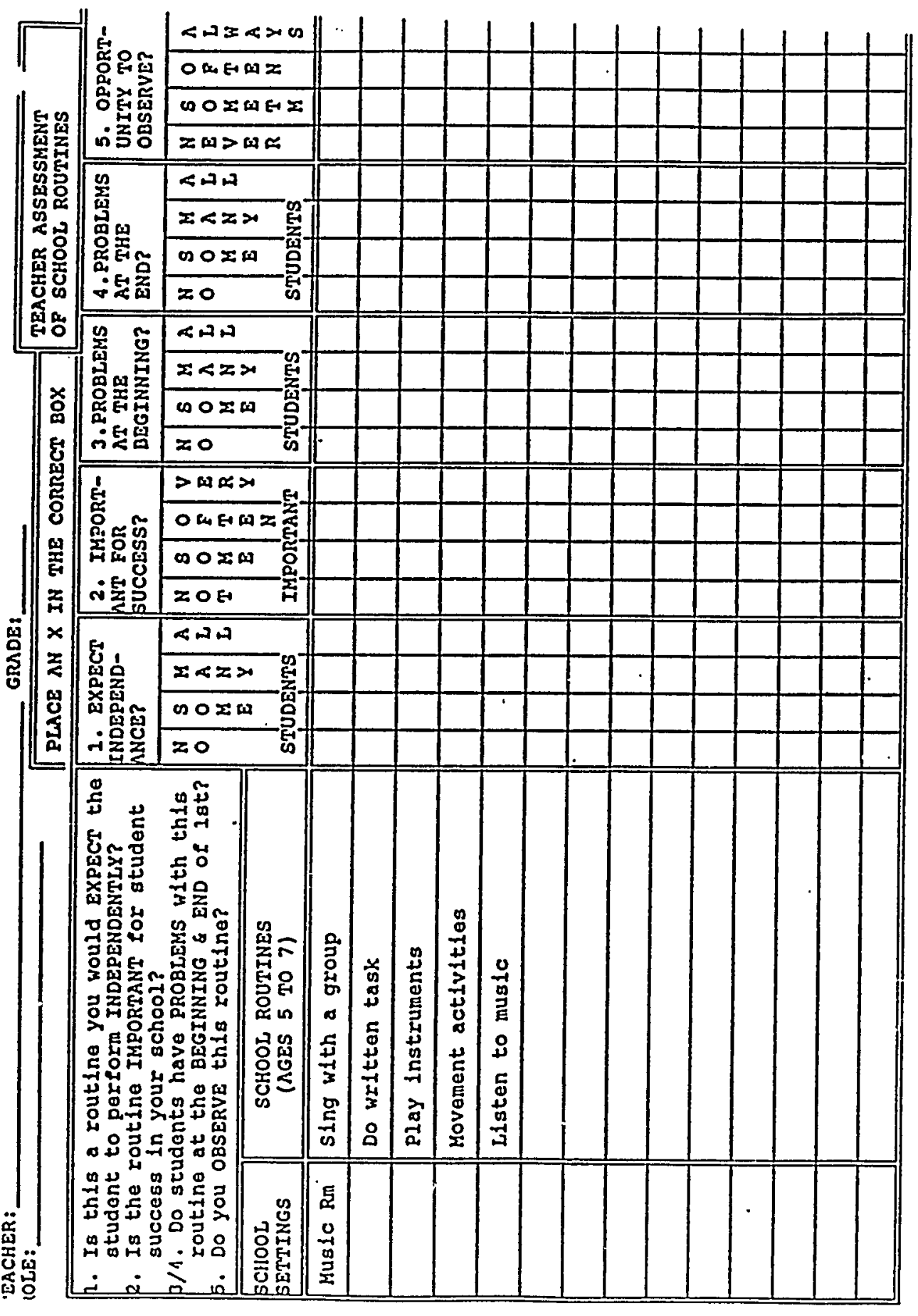

蛋

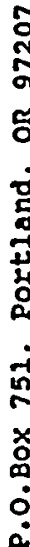

ذे

落

$\stackrel{2}{5}$

ثّ

क

号

मूँ

:

曷

岁

ํㅗㅇ 


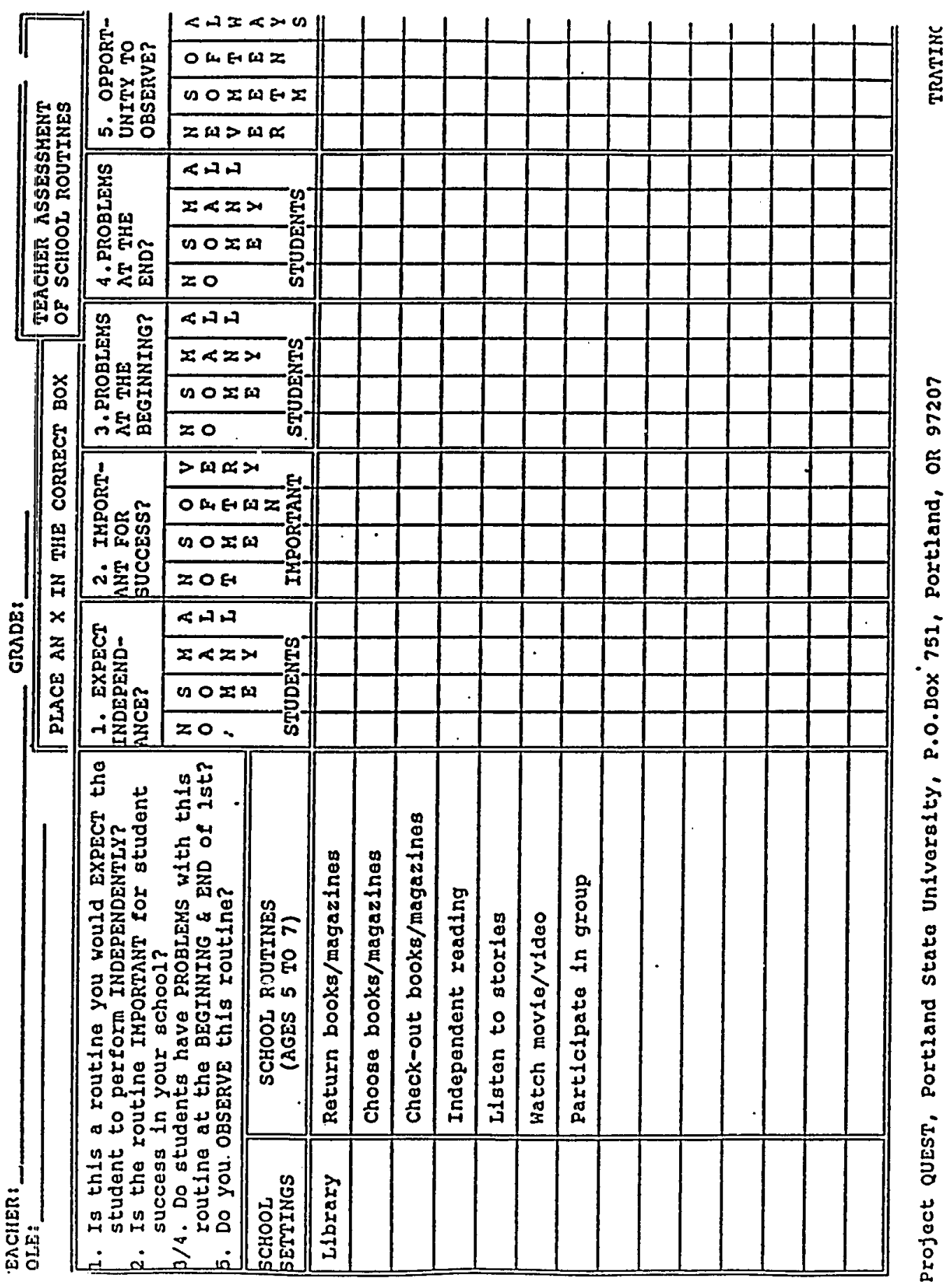




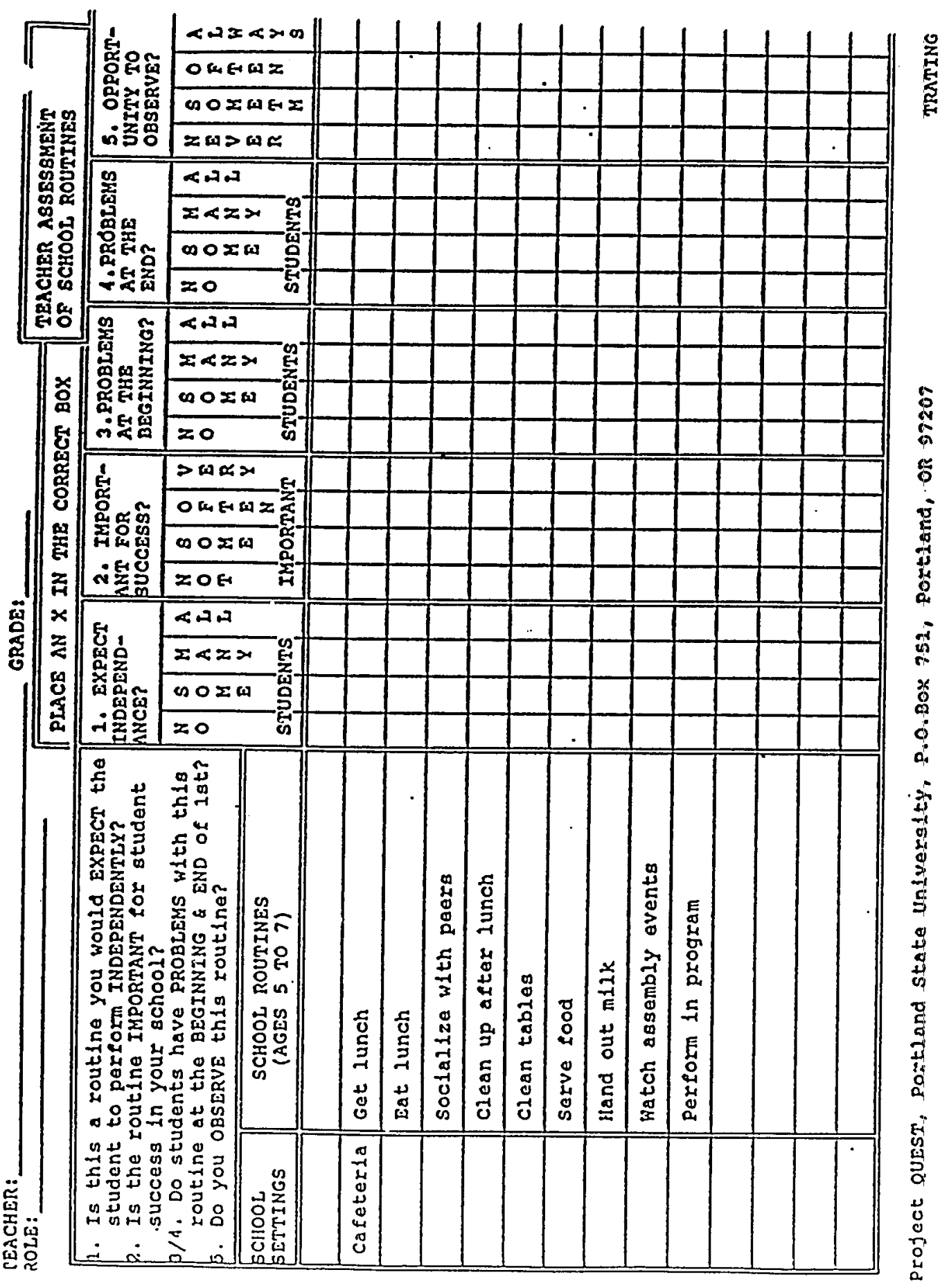




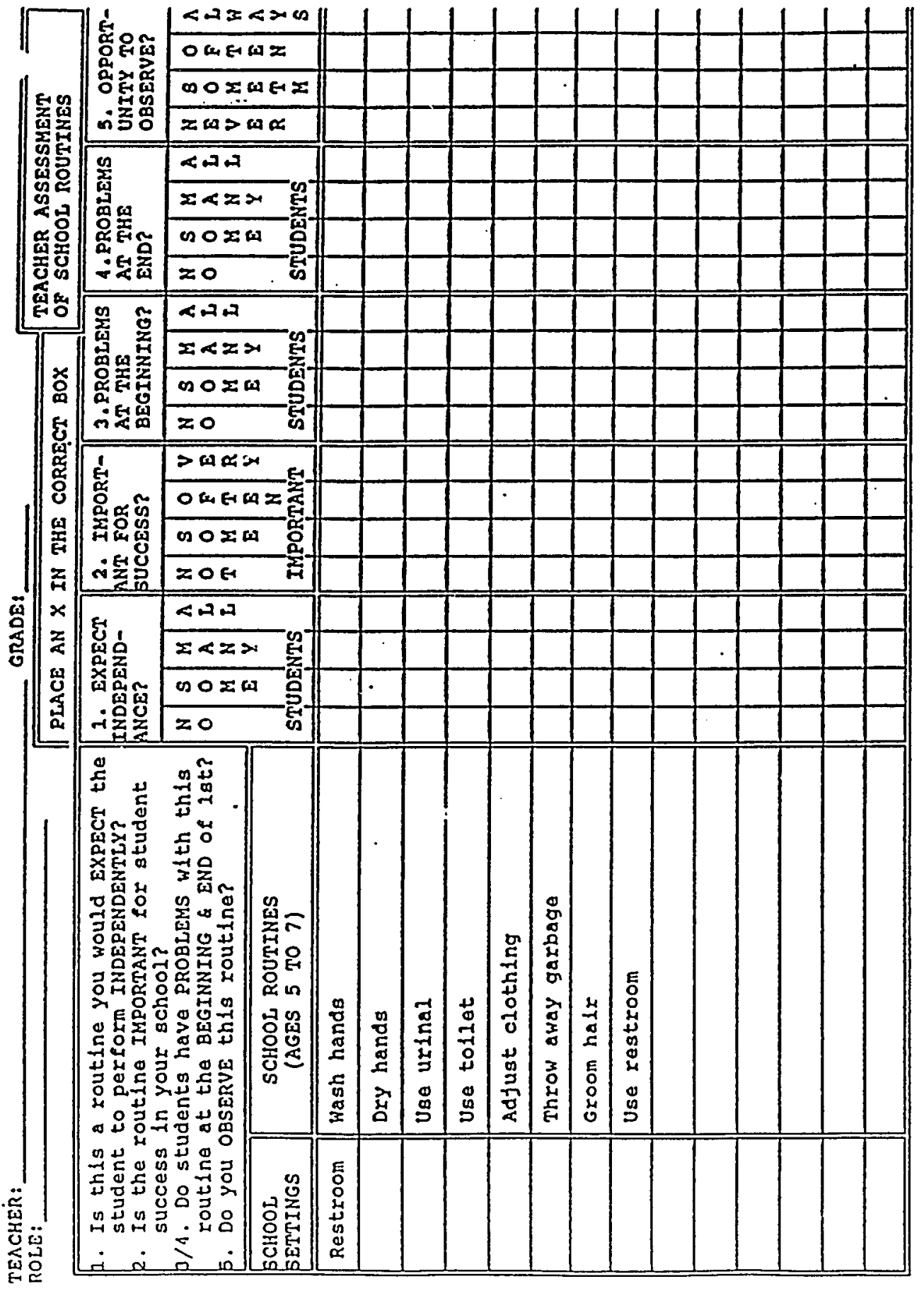

蛋

ริ

ธ

竎

รี่

즘

$\stackrel{\circ}{\circ}$

is

ì

มै

$\frac{2}{5}$

ปั

\&

可

मี

통

$\stackrel{0}{2}$

0
0
0
0 


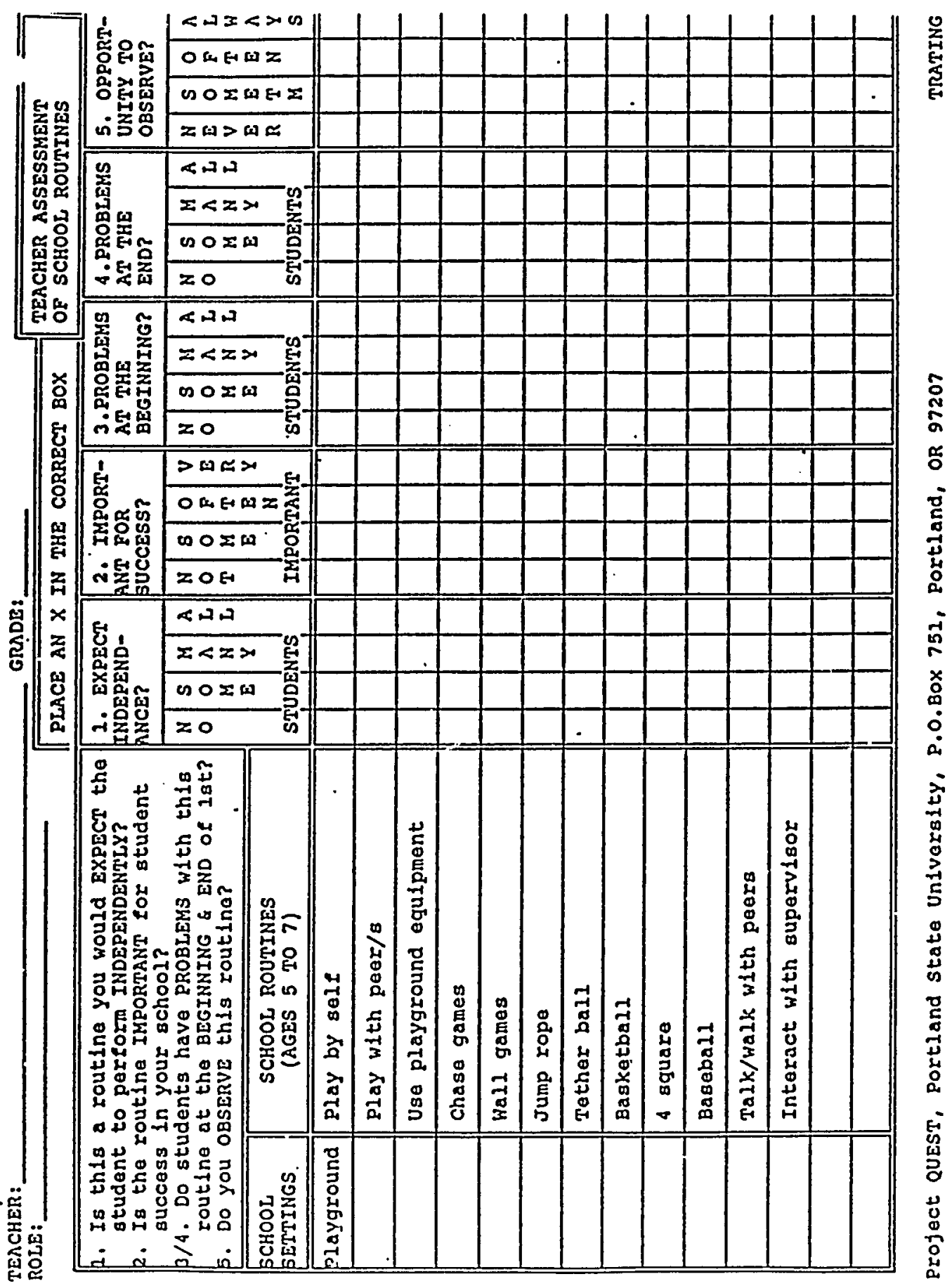




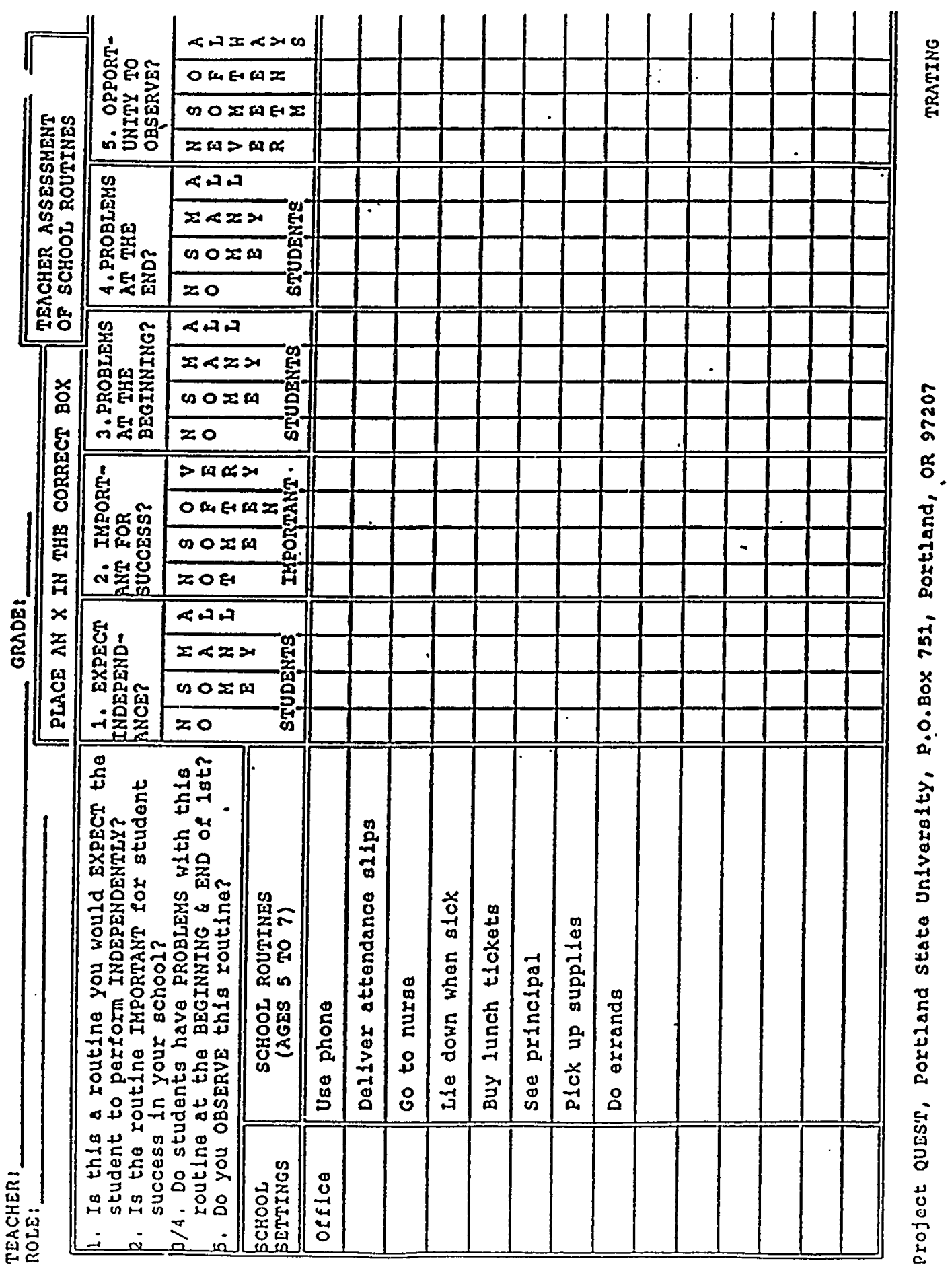




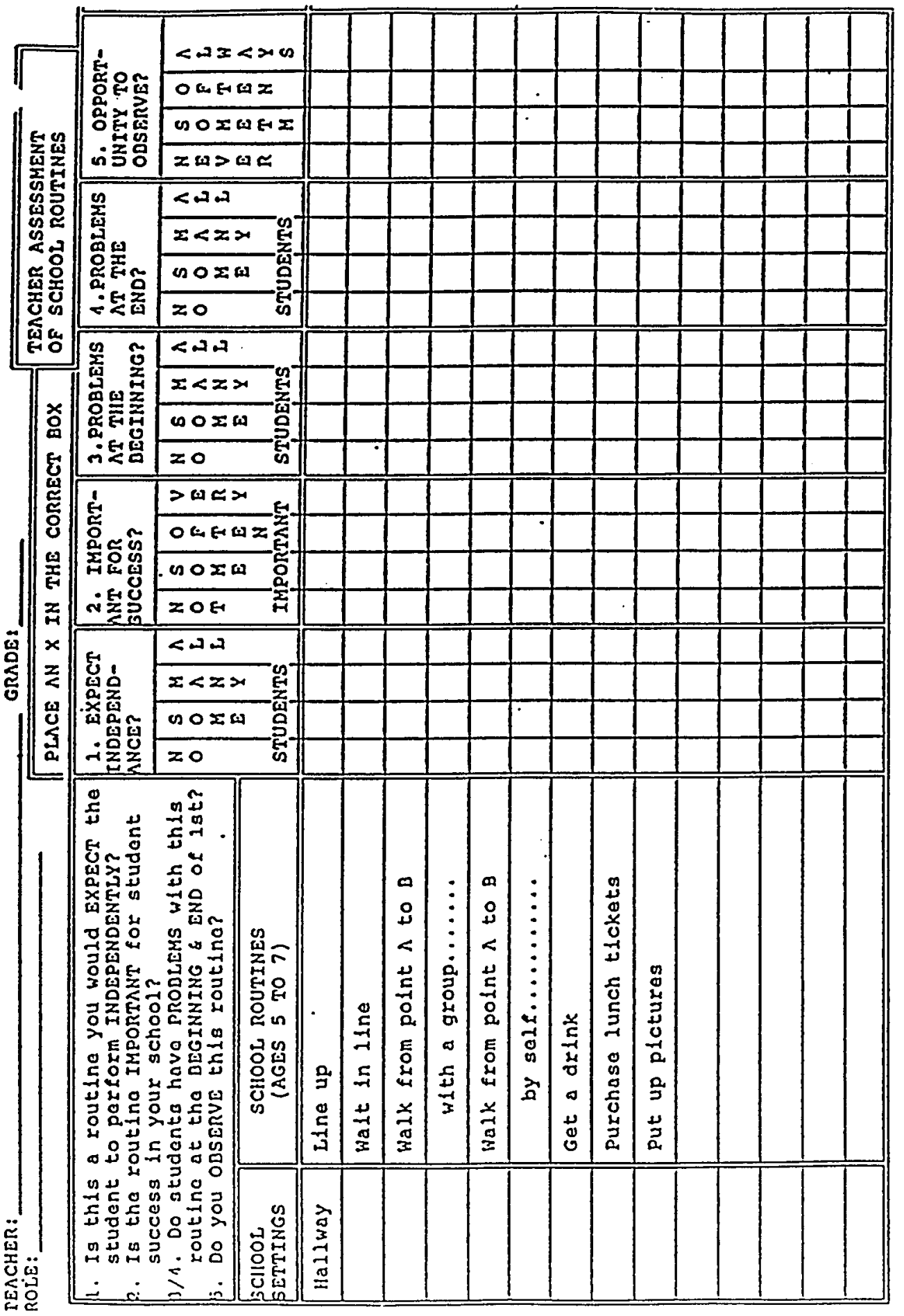

产

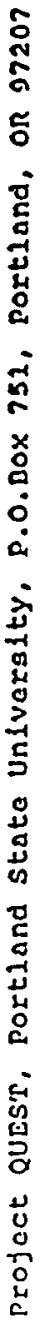




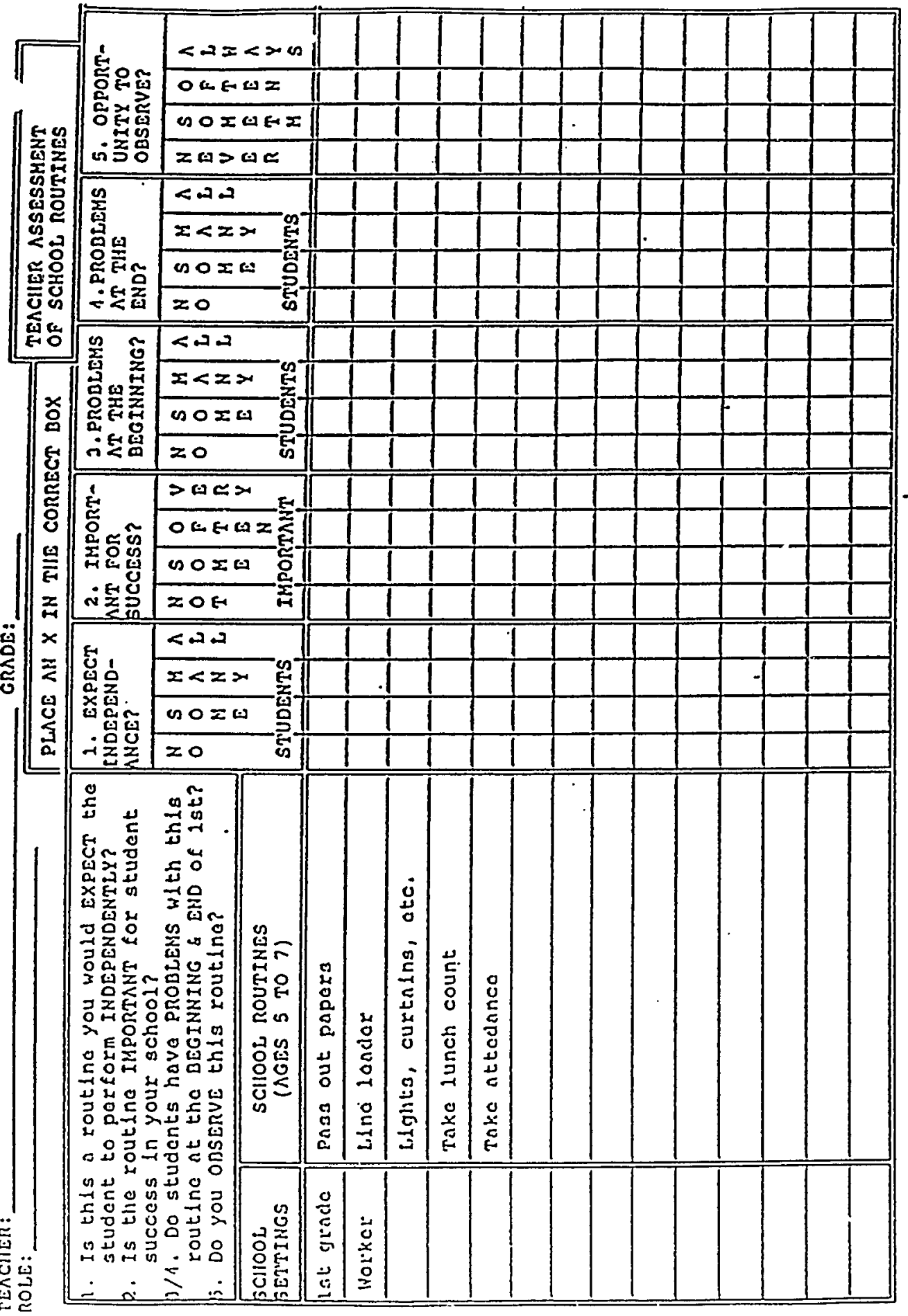

옳

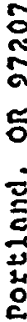

in

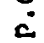

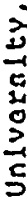

I

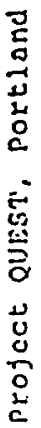




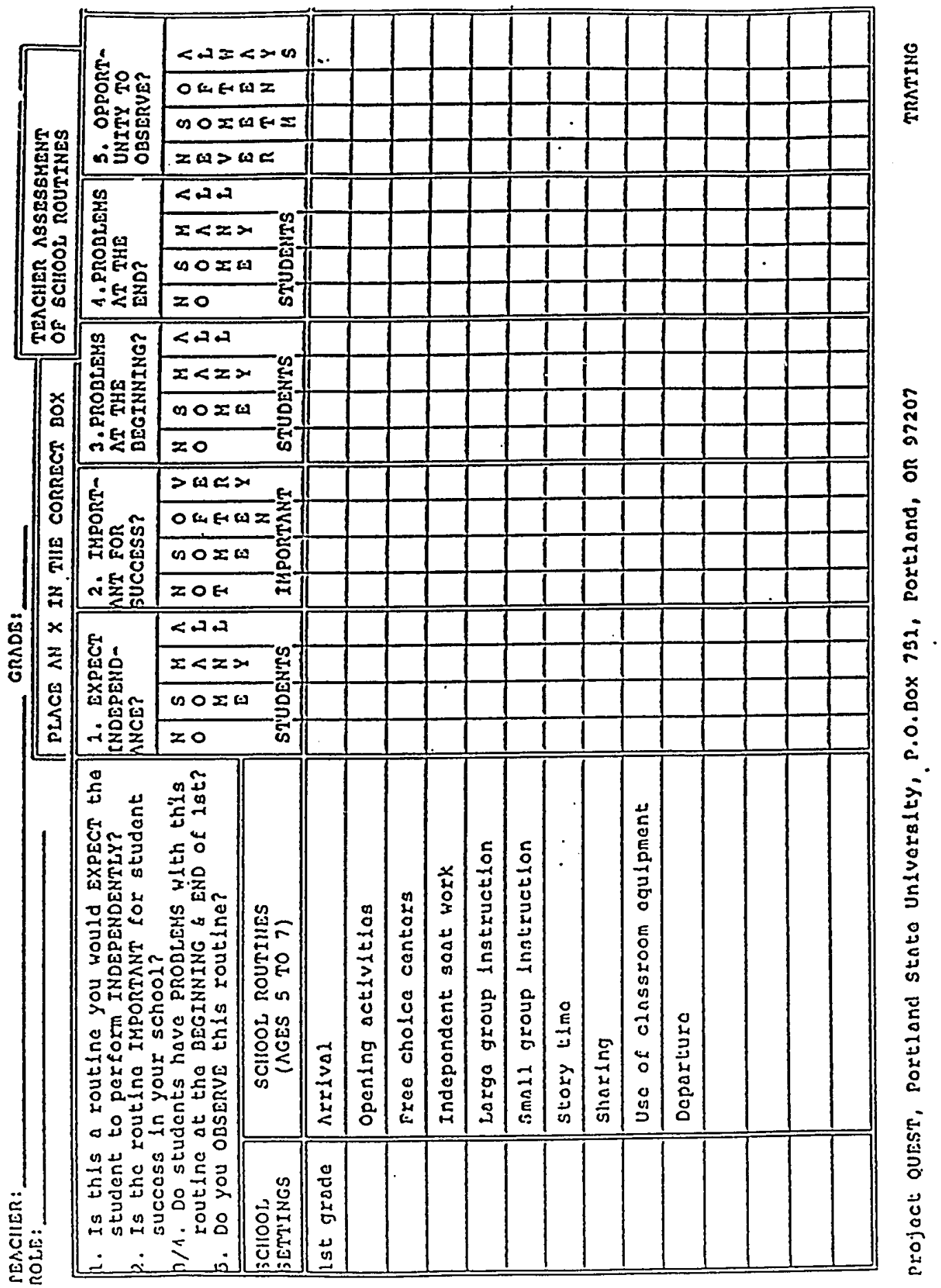




\begin{tabular}{|c|c|c|c|c|c|c|c|c|}
\hline \multirow{2}{*}{ 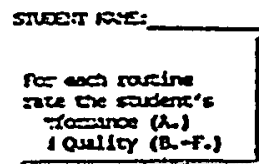 } & \multirow{2}{*}{\multicolumn{2}{|c|}{ 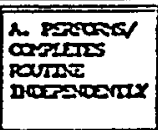 }} & \multicolumn{6}{|c|}{ 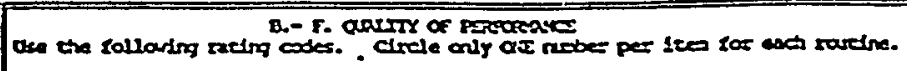 } \\
\hline & & & \multicolumn{3}{|c|}{ 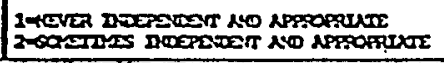 } & \multicolumn{3}{|c|}{ 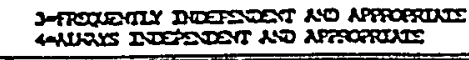 } \\
\hline 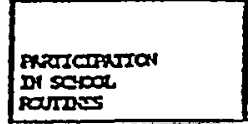 & 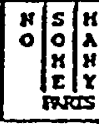 & $\left\{\begin{array}{l}A \\
2 \\
2\end{array}\right.$ & 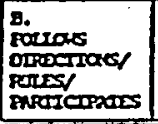 & 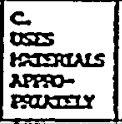 & 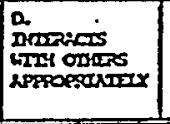 & 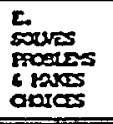 & 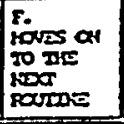 & 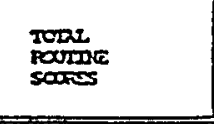 \\
\hline $\begin{array}{l}\text { Soall crop } \\
\text { Iretruxion }\end{array}$ & & & 1234 & 1234 & 2234 & 2234 & 1234 & \\
\hline $\begin{array}{l}\text { Large grap } \\
\text { Instivetion }\end{array}$ & & & 1234 & 1234 & 1234 & 2234 & 2234 & \\
\hline Independent vork & & & 2234 & 1234 & 1234 & 2234 & 2234 & \\
\hline 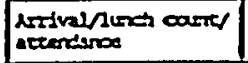 & & & 2234 & 1234 & 1234 & 2234 & 1234 & \\
\hline $\begin{array}{l}\text { Des tros chalor } \\
\text { exivileles }\end{array}$ & & & 2234 & 1234 & 2234 & 2234 & 1234 & \\
\hline $\begin{array}{l}\text { Wes lenting } \\
\text { cerce sueviors }\end{array}$ & & & 2234 & 2234 & 1234 & 1234 & 2234 & \\
\hline $\begin{array}{l}\text { soraring/ shor } \\
\text { exd coll }\end{array}$ & & & 2234 & 2234 & 2234 & 1234 & 2234 & \\
\hline 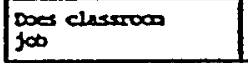 & & & 2234 & 2231 & 1234 & 1234 & 12334 & . \\
\hline $\mid \begin{array}{l}\infty \\
0 \text { secpilies }\end{array}$ & & & 2234 & 1234 & 2234 & 1234 & $123<1$ & \\
\hline 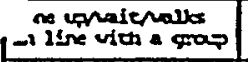 & & & 1234 & & 2234 & 1234 & 1234 & \\
\hline 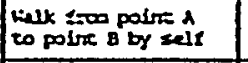 & & & 1234 & & 2224 & $123<$ & 1234 & \\
\hline Uses rerrocos & & & 1234 & 3234 & 1234 & 1234 & $223<$ & $\cdot$ \\
\hline 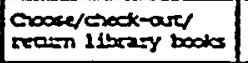 & & & 1232 & 1234 & 2234 & 1234 & 1234 & $\cdot$ \\
\hline Inseperdent randing & & & 1234 & 2234 & 1234 & 1234 & 1234 & \\
\hline Ltsen to stories & & & 1234 & & 2234 & 1224 & 1234 & \\
\hline $\begin{array}{l}\text { playfingart with } \\
\text { poes }\end{array}$ & & & 1234 & 1234 & 1234 & 1234 & $123<$ & \\
\hline Play ty sele & & & 2234 & 2235 & 2234 & 1234 & 2234 & \\
\hline $\begin{array}{l}\text { Uses playtround } \\
\text { oguipher }\end{array}$ & & & 1234 & 1234 & 1234 & 1234 & 1234 & \\
\hline 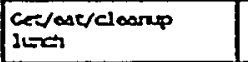 & & & 2234 & 1234 & 1231 & 1234 & 1234 & \\
\hline $\begin{array}{l}\text { Pley copperative } \\
\text { g=0? cotes }\end{array}$ & & & 1234 & 1236 & 1234 & 1234 & 1234 & \\
\hline Caporerises/ & & & 1232 & 1234 & 1234 & 1234 & $123<$ & \\
\hline \begin{tabular}{|l} 
Pesic class \\
ocivities
\end{tabular} & & & 2234 & 1234 & 1234 & 1234 & 1234 & \\
\hline Lisuen wovie/assecoly & & & 1234 & & 2234 & 1234 & $223<$ & \\
\hline $\begin{array}{l}\text { Cos to i tros bus } \\
\text { i lines costect bus }\end{array}$ & & & 1234 & & 1336 & 2234 & & \\
\hline TJEL OL SCDS & & & & & & & & JUEA \\
\hline
\end{tabular}




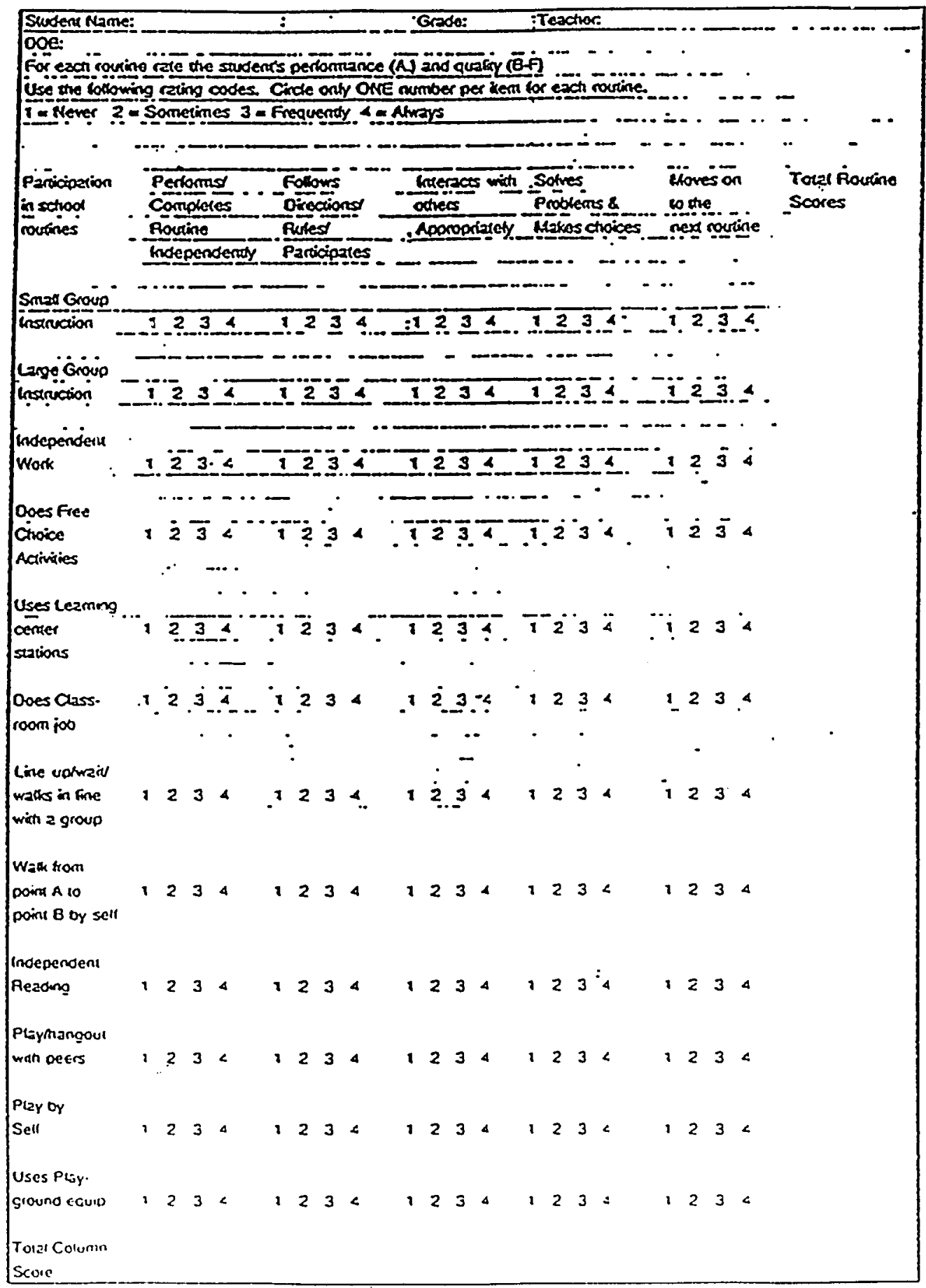


APPENDIX $C$

\section{FIRST GRADE REPORT CARD \\ (a) \\ (n)}

(20)

(n)

(n)

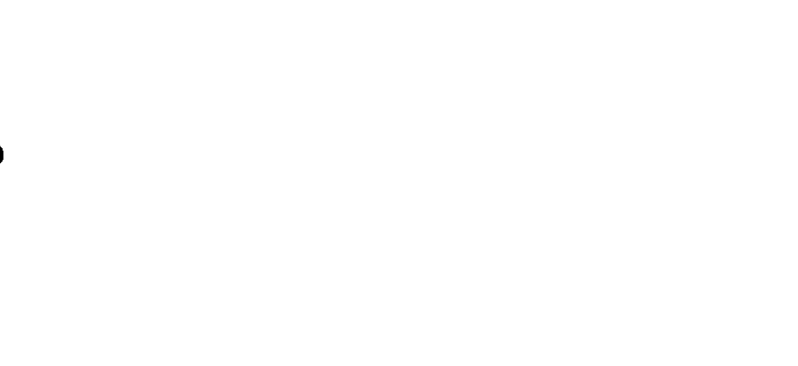

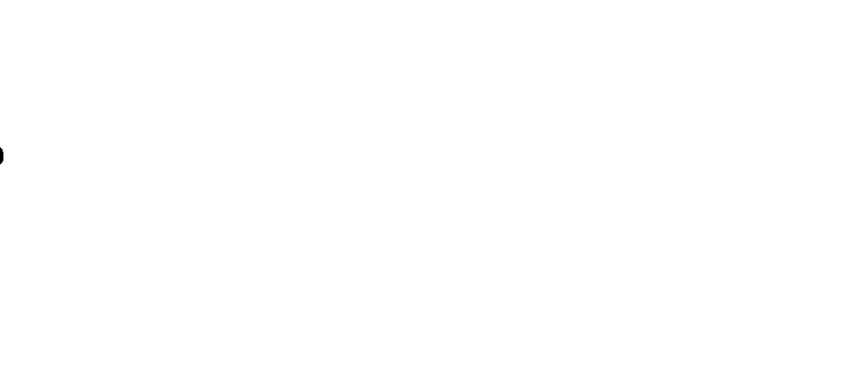




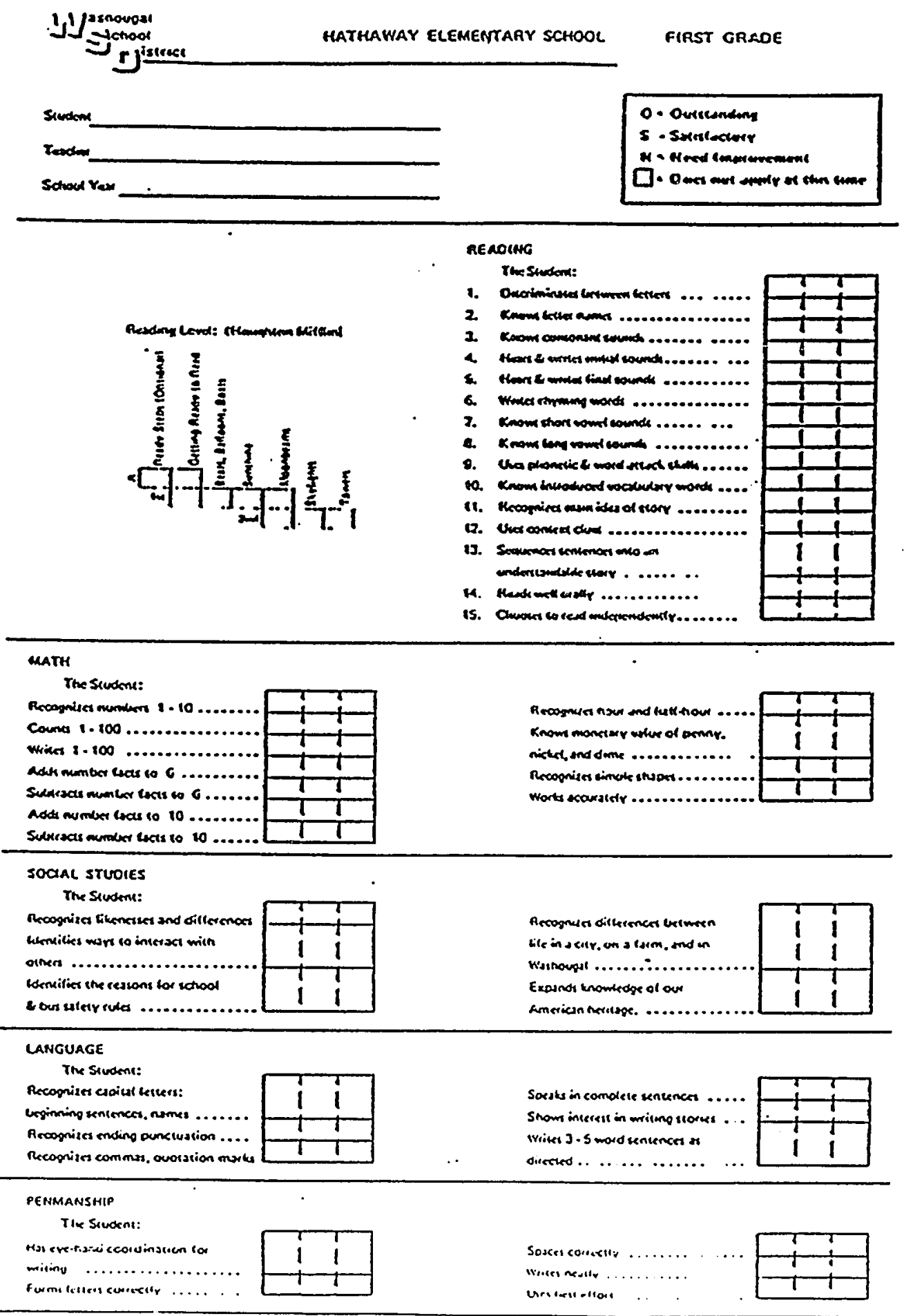




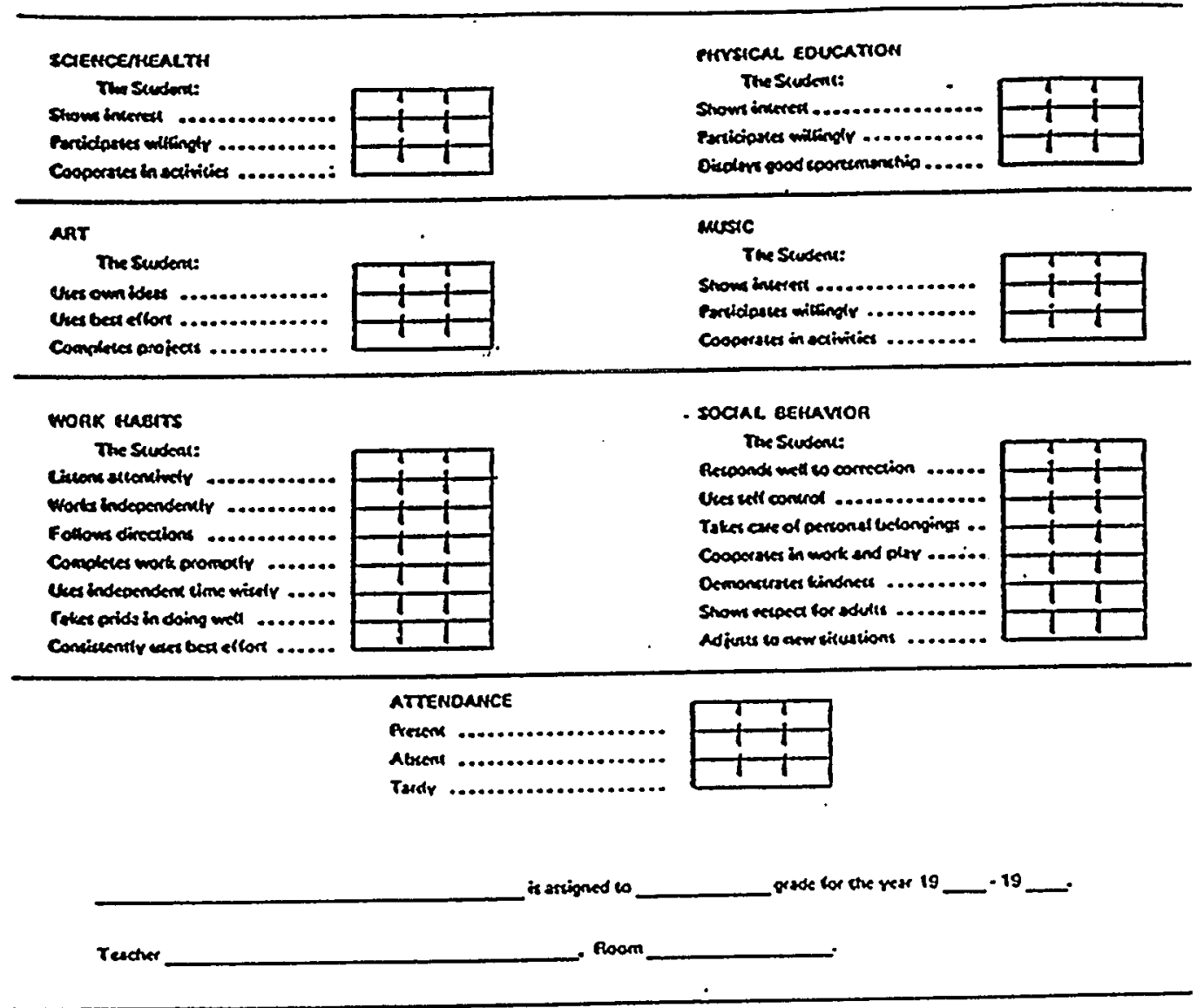

COMMENTS: 
APPENDIX D

DISCRIMINANT ANALYSIS OF VARIANCE

BY PREDICTOR/DEMOGRAPHIC VARIANCE

FOR THE CRITERION VARIABLES 
APPENDIX D (1)

DISCRIMTNANT ANZIYSIS UNTVARIATE F-TEST

BY PREDICTOR/DEMOGRAPHIC VARIABLES FOR PROGRAM PLACEMENT

\begin{tabular}{|c|c|c|c|c|c|c|c|}
\hline Predictor & source & ss & $D P$ & . US & $\boldsymbol{F}$ & $\mathbf{p}$ & $\begin{array}{l}\text { Significant } \\
\text { Predictor }\end{array}$ \\
\hline Screening test & $\begin{array}{c}\text { Betrieen } \\
\text { Fithin }\end{array}$ & $\begin{array}{l}1960.867 \\
19158.926\end{array}$ & $\begin{array}{l}1 \\
143\end{array}$ & $\begin{array}{c}1960.867 \\
133.976\end{array}$ & 14.636 & 0.001 & $\mathbf{x}$ \\
\hline reachr rating(R) & $\begin{array}{l}\text { Betreen } \\
\text { nithin }\end{array}$ & $\begin{array}{r}1.290 \\
17.372\end{array}$ & $\begin{array}{c}1 \\
143\end{array}$ & $\begin{array}{l}1.290 \\
0.121\end{array}$ & 10.622 & 0.001 & $x$ \\
\hline SSES(R) & $\begin{array}{l}\text { Betreen } \\
\text { जithin }\end{array}$ & $\begin{array}{r}26003.580 \\
300183.358\end{array}$ & $\begin{array}{c}1 \\
143\end{array}$ & $\begin{array}{r}26003.580 \\
2099.184\end{array}$ & 12.387 & 0.001 & $x$ \\
\hline Reading readiness & $\begin{array}{l}\text { Betueen } \\
\text { Within }\end{array}$ & $\begin{array}{r}2780.232 \\
18127.078\end{array}$ & $\begin{array}{c}1 \\
143\end{array}$ & $\begin{array}{r}2780.232 \\
130.959\end{array}$ & 21.230 & 0.001 & $x$ \\
\hline ige(3) & $\begin{array}{l}\text { Between } \\
\text { Within }\end{array}$ & $\begin{array}{r}1.168 \\
56.122\end{array}$ & $\begin{array}{c}1 \\
143\end{array}$ & $\begin{array}{l}1.168 \\
0.397\end{array}$ & 2.944 & 0.088 & \\
\hline Sex & $\begin{array}{l}\text { Between } \\
\text { rithin }\end{array}$ & $\begin{array}{r}0.764 \\
35.278\end{array}$ & $\begin{array}{c}1 \\
143\end{array}$ & $\begin{array}{l}0.764 \\
0.274\end{array}$ & 3.096 & 0.081 & \\
\hline Lunch & $\begin{array}{l}\text { Between } \\
\text { Fithin }\end{array}$ & $\begin{array}{r}0.098 \\
33.530\end{array}$ & $\begin{array}{c}1 \\
143\end{array}$ & $\begin{array}{l}0.098 \\
0.234\end{array}$ & 0.416 & 0.520 & \\
\hline Parent(2) & $\begin{array}{l}\text { Between } \\
\text { Fithin }\end{array}$ & $\begin{array}{r}0.031 \\
34.562\end{array}$ & $\begin{array}{c}1 \\
143\end{array}$ & $\begin{array}{l}0.031 \\
0.242\end{array}$ & 0.128 & 0.721 & \\
\hline
\end{tabular}


APPENDIX D (2)

DISCRIMINANT ANALYSIS UNIVARTATE F-TEST

BY PREDICTORSTTUDENT PERFORMANCE

FIRST GRADE

\begin{tabular}{|c|c|c|c|c|c|c|c|}
\hline Predictor & source & $\mathbf{S s}$ & $D P$ & us & $\mathbf{P}$ & $\mathbf{P}$ & significant Predictor \\
\hline screening test & $\begin{array}{l}\text { Betreen } \\
\text { Rithin }\end{array}$ & $\begin{array}{c}3051.208 \\
\mid\end{array}$ & $\begin{array}{c}1 \\
124\end{array}$ & 3051.208 & 27.325 & 0.001 & $x$ \\
\hline Ieacter rating(k) & $\begin{array}{l}\text { Betreen } \\
\text { nithin }\end{array}$ & $\begin{array}{r}0.893 \\
12.321\end{array}$ & $\frac{1}{124}$ & $\begin{array}{l}0.893 \\
0.099\end{array}$ & 8.986 & 0.003 & $\mathbf{x}$ \\
\hline $\operatorname{SSRS}(\mathrm{K})$ & $\begin{array}{l}\text { Betreen } \\
\text { nithin }\end{array}$ & $\begin{array}{r}30151.953 \\
216683.205\end{array}$ & $\begin{array}{c}1 \\
124\end{array}$ & $\begin{array}{r}30151.953 \\
1989.385\end{array}$ & 15.156 & 0.601 & $x$ \\
\hline Reading readiness & $\begin{array}{l}\text { Betreen } \\
\text { nithin }\end{array}$ & $\begin{array}{r}1481.433 \\
16958.036\end{array}$ & $\frac{1}{124}$ & $\begin{array}{r}1481.433 \\
136.959\end{array}$ & 10.832 & 0.001 & $x$ \\
\hline $\operatorname{lgg}(3)$ & $\begin{array}{l}\text { Betreen } \\
\text { nithin }\end{array}$ & $\begin{array}{r}2.191 \\
45.777\end{array}$ & $\frac{1}{124}$ & $\begin{array}{l}2.191 \\
0.369\end{array}$ & 5.936 & 0.016 & $\mathbf{x}$ \\
\hline ser & $\begin{array}{l}\text { Betreen } \\
\text { Rithin }\end{array}$ & $\begin{array}{r}0.180 \\
30.821\end{array}$ & $\frac{1}{124}$ & $\begin{array}{l}0.480 \\
0.249\end{array}$ & 1.932 & 0.167 & \\
\hline Intuch & $\begin{array}{l}\text { Betreen } \\
\text { nithin }\end{array}$ & $\begin{array}{r}0.480 \\
27.179\end{array}$ & $\frac{1}{1.24}$ & $\begin{array}{l}0.480 \\
0.219\end{array}$ & 2.191 & 0.141 & \\
\hline Parent(2) & $\begin{array}{l}\text { Betreen } \\
\text { Rithin }\end{array}$ & $\begin{array}{r}0.000 \\
28.929 \\
\end{array}$ & $\underset{124}{1}$ & $\begin{array}{l}0.000 \\
0.233\end{array}$ & 0.000 & 1.000 & \\
\hline
\end{tabular}


APPENDIX D (3)

DISCRIMINANT ANALYSIS UNIVARIATE F-TEST BY PREDICTOR FOR TEACHER RATINGS FIRST GRADE

\begin{tabular}{|c|c|c|c|c|c|c|c|}
\hline Predictor & source & Ss & DP & HS & $\boldsymbol{P}$ & $p$ & Sigaificant Predictor \\
\hline Screening test & $\begin{array}{l}\text { Betreen } \\
\text { lithin }\end{array}$ & $\begin{array}{r}1128.974 \\
14475.421\end{array}$ & $\begin{array}{c}1 \\
132\end{array}$ & $\begin{array}{r}4126.974 \\
109.662\end{array}$ & 37.633 & 0.001 & $x$ \\
\hline Teacher rating(K) & $\begin{array}{l}\text { Betrieen } \\
\text { nithin }\end{array}$ & $\begin{array}{r}3.285 \\
13.021\end{array}$ & $\frac{1}{132}$ & $\begin{array}{l}3.285 \\
0.099\end{array}$ & 33.307 & 0.001 & $x$ \\
\hline $\operatorname{SSPE}(\mathbf{L})$ & $\begin{array}{l}\text { Betreen } \\
\text { rithin }\end{array}$ & $\begin{array}{r}53070.919 \\
24141.951\end{array}$ & $\frac{1}{132}$ & $\begin{array}{l}53070.919 \\
1851.833\end{array}$ & 28.659 & 0.001 & $x$ \\
\hline Reading readiness & $\begin{array}{l}\text { Betreen } \\
\text { Dithin }\end{array}$ & $\begin{array}{r}2557.621 \\
17043.962\end{array}$ & $\begin{array}{c}1 \\
132\end{array}$ & $\begin{array}{r}2557.621 \\
129.121\end{array}$ & 19.808 & 0.001 & $x$ \\
\hline $\operatorname{lgge}(3)$ & $\begin{array}{l}\text { Betreen } \\
\text { Pithin }\end{array}$ & $\begin{array}{r}2.677 \\
49.203\end{array}$ & $\begin{array}{c}1 \\
132\end{array}$ & $\begin{array}{l}2.677 \\
0.373\end{array}$ & 7.183 & 0.008 & $x$ \\
\hline $\operatorname{sex}$ & $\begin{array}{l}\text { Betreen } \\
\text { Rithin }\end{array}$ & $\begin{array}{r}1.777 \\
31.357\end{array}$ & $\begin{array}{c}1 \\
132\end{array}$ & $\begin{array}{l}1.777 \\
0.238\end{array}$ & 7.482 & 0.007 & 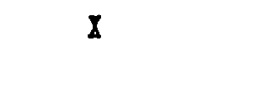 \\
\hline Lunch & $\begin{array}{l}\text { Betreen } \\
\text { yithin }\end{array}$ & $\begin{array}{r}0.949 \\
29.260\end{array}$ & $\begin{array}{c}1 \\
132\end{array}$ & $\begin{array}{l}0.919 \\
0.222\end{array}$ & 4.283 & 0.040 & 1 \\
\hline Parent(2) & $\begin{array}{l}\text { Beireen } \\
\text { Rithin }\end{array}$ & $\begin{array}{r}0.622 \\
30.721\end{array}$ & $\begin{array}{c}1 \\
132\end{array}$ & $\begin{array}{l}0.622 \\
0.233\end{array}$ & 2.673 & 0.104 & \\
\hline
\end{tabular}


APPENDIX D (4)

DISCRIMINANT ANALYSIS UNIVARIATE F TEST

BY PREDICTOR FOR GATES-MACGINITIE READING TESTS (NCE)

\begin{tabular}{|c|c|c|c|c|c|c|c|}
\hline Predictor & source & $\mathfrak{S S}$ & $D ?$ & DS & $\mathbf{P}$ & P & Significant Predictor \\
\hline Screning test & $\begin{array}{l}\text { Betreen } \\
\text { Rithin }\end{array}$ & $\begin{array}{r}2713.0113 \\
13056.035\end{array}$ & $\underset{125}{1}$ & $\begin{array}{r}2713.419 \\
94.945\end{array}$ & 25.979 & 0.001 & $x$ \\
\hline reactier rating $(\mathrm{K})$ & $\begin{array}{l}\text { Betreen } \\
\text { rithin }\end{array}$ & $\begin{array}{r}1.170 \\
12.058\end{array}$ & $\begin{array}{c}1 \\
125\end{array}$ & $\begin{array}{l}1.170 \\
0.096\end{array}$ & 12.132 & 0.001 & $\mathfrak{x}$ \\
\hline $\operatorname{ssph}(x)$ & $\begin{array}{l}\text { Betreen } \\
\text { vithin }\end{array}$ & $\begin{array}{r}30798.759 \\
217229.761\end{array}$ & $\begin{array}{c}1 \\
125\end{array}$ & $\begin{array}{l}30798.759 \\
1977.838\end{array}$ & 15.572 & 0.001 & x \\
\hline Pesding readiness & $\begin{array}{l}\text { Between } \\
\text { vithin }\end{array}$ & $\begin{array}{r}6614.876 \\
11868.136\end{array}$ & $\begin{array}{c}1 \\
125\end{array}$ & $\begin{array}{r}6614.876 \\
94.945\end{array}$ & 69.670 & 0.001 & $x$ \\
\hline loge(3) & $\begin{array}{l}\text { Betreen } \\
\text { Rithin }\end{array}$ & $\begin{array}{r}0.888 \\
49.203\end{array}$ & $\frac{1}{132}$ & $\begin{array}{l}0.688 \\
0.373\end{array}$ & 2.309 & 0.131 & \\
\hline sex & $\begin{array}{l}\text { Between } \\
\text { Dithin }\end{array}$ & $\begin{array}{r}0.355 \\
31.257\end{array}$ & $\begin{array}{c}1 \\
125\end{array}$ & $\begin{array}{l}0.355 \\
0.219\end{array}$ & 1.424 & 0.235 & \\
\hline Lunch & $\begin{array}{l}\text { Betreen } \\
\text { Yithin }\end{array}$ & $\begin{array}{r}0.077 \\
27.687\end{array}$ & $\begin{array}{c}1 \\
125\end{array}$ & $\begin{array}{l}0.077 \\
0.221\end{array}$ & 0.349 & 0.556 & \\
\hline Parent(2) & $\begin{array}{l}\text { Betreen } \\
\text { vithin }\end{array}$ & $\begin{array}{r}0.281 \\
28.774\end{array}$ & $\begin{array}{c}1 \\
125\end{array}$ & $\begin{array}{l}0.281 \\
0.230\end{array}$ & 1.221 & 0.271 & \\
\hline
\end{tabular}




\begin{abstract}
APPENDIX D (5)
DISCRTMINANT ANALYSIS UNIVARIATE F TEST

BY PREDICTOR FOR REPORT CARD
\end{abstract}

\begin{tabular}{|c|c|c|c|c|c|c|c|}
\hline Predictar & sounce & SS & DP & XS & 8 & $\mathbf{P}$ & Significant Predictor \\
\hline Screaning test & $\begin{array}{l}\text { Betreen } \\
\text { nithin }\end{array}$ & $\begin{array}{r}5167.135 \\
13425.782\end{array}$ & $\begin{array}{c}1 \\
131\end{array}$ & $\begin{array}{r}5167.135 \\
102.887\end{array}$ & 50.418 & 0.001 & $x$ \\
\hline lescter rating(R) & $\begin{array}{l}\text { Betreen } \\
\text { Pithin }\end{array}$ & $\begin{array}{r}1.868 \\
14.117\end{array}$ & $\begin{array}{c}1 \\
131\end{array}$ & $\begin{array}{l}1.868 \\
0.110\end{array}$ & 16.977 & 0.001 & $x$ \\
\hline $\operatorname{sstes}(\mathrm{R})$ & $\begin{array}{l}\text { Betreen } \\
\text { Rithin }\end{array}$ & $\begin{array}{r}39034.500 \\
.257154 .703\end{array}$ & $\begin{array}{c}1 \\
131\end{array}$ & $\begin{array}{l}39034.500 \\
1963.013\end{array}$ & 19.885 & 0.001 & $\mathbb{x}$ \\
\hline Resding readiness & $\begin{array}{l}\text { Betreen } \\
\text { Rithin }\end{array}$ & $\begin{array}{r}1783.688 \\
17779.982\end{array}$ & $\begin{array}{c}1 \\
191\end{array}$ & $\begin{array}{r}1783.688 \\
135.725\end{array}$ & 13.142 & 0.001 & $x$ \\
\hline $\operatorname{lge}(3)$ & $\begin{array}{l}\text { Betreen } \\
\text { Rithin }\end{array}$ & $\begin{array}{r}0.666 \\
50.267\end{array}$ & $\begin{array}{c}1 \\
131\end{array}$ & $\begin{array}{l}0.666 \\
0.384\end{array}$ & 1.735 & 0.190 & \\
\hline sex & $\begin{array}{l}\text { Betreen } \\
\text { Rithin }\end{array}$ & $\begin{array}{r}0.839 \\
32.093\end{array}$ & $\begin{array}{c}1 \\
131\end{array}$ & $\begin{array}{l}0.839 \\
0.215\end{array}$ & 3.425 & 0.066 & \\
\hline Innch & $\begin{array}{l}\text { Betreen } \\
\text { nitbin }\end{array}$ & $\begin{array}{r}0.626 \\
29.464\end{array}$ & .1 & $\begin{array}{l}0.626 \\
0.225\end{array}$ & 2.784 & 0.098 & \\
\hline Parent(2) & $\begin{array}{l}\text { Betreen } \\
\text { Xithin }\end{array}$ & $\begin{array}{r}0.029 \\
31.174\end{array}$ & $\begin{array}{c}1 \\
131\end{array}$ & $\begin{array}{l}0.029 \\
0.238\end{array}$ & 0.122 & 0.728 & \\
\hline
\end{tabular}


APPENDIX D (6)

DISCRIMINANT ANAIYSIS UNIVARIATE F TEST

BY PREDICIOR FOR STUDENT SUCCESS

RATING SCAIE (IST)

\begin{tabular}{|c|c|c|c|c|c|c|c|}
\hline Predictor & source & 5 & $D R$ & as & $F$ & $\mathbf{p}$ & Significant Predictor \\
\hline screening test & $\begin{array}{l}\text { Betreen } \\
\text { Bithin }\end{array}$ & $\begin{array}{r}1180.201 \\
17422.195\end{array}$ & $\frac{1}{132}$ & $\begin{array}{r}1180.201 \mathrm{~L} \\
131.986\end{array}$ & 8.912 & 0.003 & $x$ \\
\hline Sescher rating(X) & $\begin{array}{l}\text { Betreen } \\
\text { Vithin }\end{array}$ & $\begin{array}{r}2.139 \\
13.867\end{array}$ & $\begin{array}{c}1 \\
132\end{array}$ & $\begin{array}{l}2.319 \\
0.105\end{array}$ & 23.213 & 0.001 & $x$ \\
\hline $\operatorname{SSPS}(\mathrm{A})$ & $\begin{array}{l}\text { Betureen } \\
\text { Rithin }\end{array}$ & $\begin{array}{r}52850.562 \\
244662.311\end{array}$ & $\frac{1}{132}$ & $\begin{array}{r}52850.562 \\
1853.502\end{array}$ & 28.514 & 0.001 & $\boldsymbol{I}$ \\
\hline $\begin{array}{c}\text { beading readiness } \\
\text {. }\end{array}$ & $\begin{array}{l}\text { Betreen } \\
\text { Rithin }\end{array}$ & $\begin{array}{r}595.643 \\
19009.939\end{array}$ & $\begin{array}{c}1 \\
132\end{array}$ & $\begin{array}{l}595.643 \\
143.984\end{array}$ & 4.137 & 0.044 & $x$ \\
\hline $2 g \in(3)$ & $\begin{array}{l}\text { Betureen } \\
\text { Dithin }\end{array}$ & $\begin{array}{r}4.501 \\
47.379\end{array}$ & $\frac{1}{132}$ & $\begin{array}{l}1.501 \\
0.359\end{array}$ & 12.510 & 0.001 & $x$ \\
\hline Sex & $\begin{array}{l}\text { Betreen } \\
\text { Vithin }\end{array}$ & $\begin{array}{r}0.139 \\
32.995\end{array}$ & $\frac{1}{132}$ & $\begin{array}{l}0.139 \\
0.250\end{array}$ & 0.558 & 0.457 & \\
\hline Inench & $\begin{array}{l}\text { Betraen } \\
\text { nithin }\end{array}$ & $\begin{array}{r}2.573 \\
27.636\end{array}$ & $\begin{array}{c}1 \\
132\end{array}$ & $\begin{array}{l}2.573 \\
0.209\end{array}$ & 12.291 & 0.001 & $x$ \\
\hline Parent(2) & $\begin{array}{l}\text { Betueen } \\
\text { githin }\end{array}$ & $\begin{array}{r}0.938 \\
30.105\end{array}$ & $\begin{array}{c}1 \\
132\end{array}$ & $\begin{array}{l}0.938 \\
0.230\end{array}$ & 4.071 & 0.046 & $x$ \\
\hline
\end{tabular}

